\title{
DETERMINAÇÃO DE PARÂMETROS PRODUTIVOS E QUALITATIVOS DE Cynodon spp. EM FUNÇÃO DE VARIÁVEIS CLIMÁTICAS
}

\author{
FELIPE TONATO
}

Dissertação apresentada à Escola Superior de Agricultura "Luiz de Queiroz", Universidade de São Paulo, para obtenção do título de Mestre em Agronomia, Área de Concentração: Ciência Animal e Pastagens.

\section{PIRACICABA}

Estado de São Paulo - Brasil

Julho - 2003 


\title{
DETERMINAÇÃO DE PARÂMETROS PRODUTIVOS E QUALITATIVOS DE Cynodon spp. EM FUNÇÃO DE VARIÁVEIS CLIMÁTICAS
}

\author{
FELIPE TONATO
}

Zootecnista

Orientador: Prof. Dr. CARLOS GUILHERME SILVEIRA PEDREIRA

Dissertação apresentada à Escola Superior de Agricultura "Luiz de Queiroz", Universidade de São Paulo, para obtenção do título de Mestre em Agronomia, Área de Concentração: Ciência Animal e Pastagens.

PIRACICABA

Estado de São Paulo - Brasil

Julho - 2003 
Dados Internacionais de Catalogação na Publicação (CIP) DIVISÃO DE BIBLIOTECA E DOCUMENTAÇÃO - ESALQ/ USP

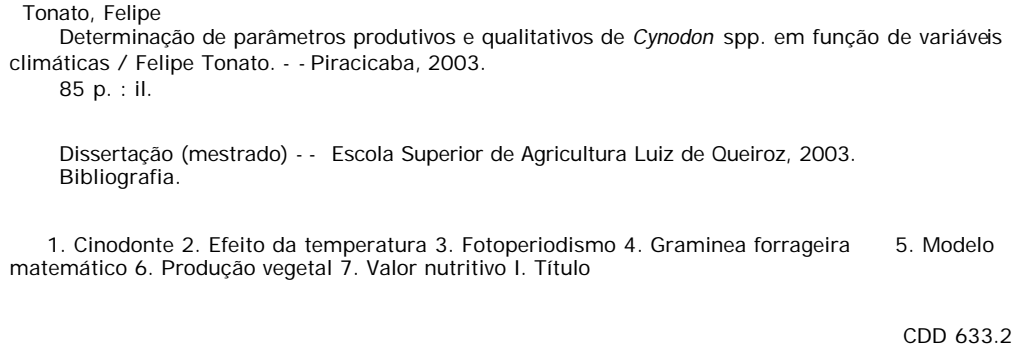

5. Modelo

CDD 633.2

"Permitida a cópia total ou parcial deste documento, desde que citada a fonte - $\mathrm{O}$ autor" 


\section{DEDICO}

Aos meus pais LIGIA e ROBERTO,

e a minha irmã CAROLINA,

pelo amor, carinho, apoio e incentivo.

MINHA GRATIDÃO

A toda a minha família pelo apoio e segurança e em especial ao meu tio Lian Tock pelo carinho e confiança.

\section{OFEREÇO}




\section{AGRADECIMENTOS}

A Escola Superior de Agricultura "Luiz de Queiroz" (ESALQ/USP) pela oportunidade de realização do curso.

A Faculdade de Zootecnia e Engenharia de Alimentos (FZEA/USP) e seus professores pela minha formação profissional.

Ao Prof. Dr. Carlos Guilherme Silveira Pedreira pela orientação, constantes ensinamentos, receptividade e fundamentalmente pela amizade desenvolvida.

Ao Coordenador Prof. Dr. Sila Carneiro Da Silva e a todos os professores do Curso de Ciência Animal e Pastagens, pela dedicação e conhecimentos transmitidos.

Ao amigo e colega Leonardo Simões de Barros Moreno pela disposição e inestimável ajuda na realização desse trabalho.

Ao amigo e colega Luís Gustavo Barioni, pela disponibilidade e auxilio fundamentais ao término desse trabalho.

Aos colegas Lyssa Otani, Alexandre Mello, Henrique Rocha, João Menezes, Daniel Castro e Gustavo Braga, pela valiosa colaboração e disposição na realização dos trabalhos a campo.

Ao Prof. Dr. Nilson Augusto Villa Nova pelos ensinamentos e sugestões necessários ao desenvolvimento do trabalho.

Ao Prof. Dr. Cláudio Haddad pela concessão da área experimental.

A todos os colegas do Curso de Ciência Animal e Pastagens, pela convivência alegre e constante trocas de experiências e conhecimentos.

A todos os amigos conquistados nos anos de "Piracicaba", pela amizade incentivo e companheirismo que fizeram a vida aqui mais alegre. 
Em especial a toda a minha família pelo carinho, apoio, incentivo e compreensão fundamentais durante os anos aqui transcorridos.

À Fundação de Amparo a Pesquisa do Estado de São Paulo - FAPESP, pela concessão de bolsa de estudos e suporte financeiro à execução do trabalho. 


\section{SUMÁRIO}

Página

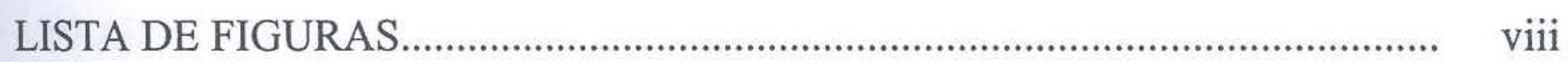

LISTA DE TABELAS................................................................................... ix

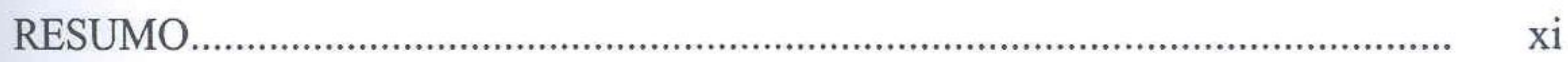

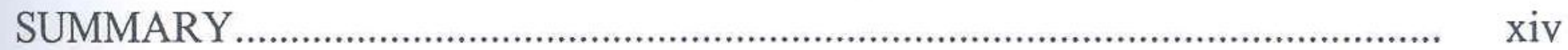

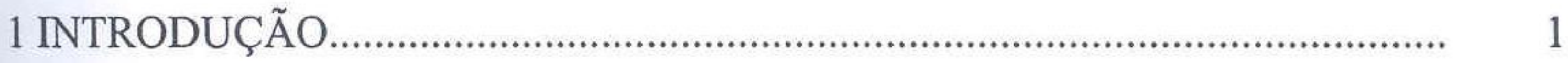

2 REVISÃO DE LITERATURA......................................................................

2.10 Gênero Cynodon........................................................................................

2.2 Determinantes climáticos para a produção de plantas forrageiras.................... 5

2.3 Estacionalidade de produção de forragem em pastagens tropicais.................... $\quad 7$

2.4 Efeito da temperatura na produção de forragem................................................. 9

2.5 Efeito da intensidade e qualidade da luz sobre a produção de forragem.......... 14

2.6 Fotoperíodo e seus efeitos sobre as plantas forrageiras................................... 16

2.7 Modelagem matemática: racionalizando o processo produtivo em função do

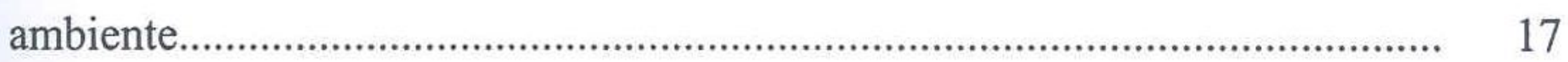

3 MATERIAL E MÉTODOS....................................................................... 21

3.1 Massa de Forragem....................................................................................... 25

3.2 Parâmetros qualitativos.............................................................................. 28

3.3 Modelagem das respostas produtivas............................................................... 29

3.4 Modelagem das respostas qualitativas............................................................. $\quad 30$

4 RESULTADOS E DISCUSSÃO....................................................................... 33

4.1 Acúmulo de Forragem (AF)....................................................................... 
4.2 Taxa média diária de acúmulo de forragem (TMDAF)..................................... 37

4.3 Distribuição estacional........................................................................................ 39

4.4 Temperatura base inferior (TBi) ..................................................................

4.5 Graus-dia (GD) e unidade fototérmica (UF).................................................. 46

4.6 Ajuste dos modelos de estimativa de acúmulo de matéria seca........................ 48

4.7 Proteína Bruta (PB) ................................................................................... 53

4.8 Fibra em Detergente Neutro (FDN),............................................................. 55

4.9 Digestibilidade in vitro da matéria orgânica (DIVMO)................................... 57

4.10 Ajuste dos modelos de estimativa de PB, FDN e DIVMO.............................. 59

5 CONCLUSÕES.......................................................................................... 70

REFERÊNCIAS BIBLIOGRÁFICAS................................................................. 72 


\section{LISTA DE FIGURAS}

Página

1 Vista da área experimental.

2 Temperaturas médias mensais do ar (máxima média, mínima média e média), durante todo o período experimental (dezembro de 2000 a março de 2002) e comparação com os dados de 1919 a 2002

3 Precipitação pluviométrica, durante todo o período experimental (dezembro de 2000 a março de 2002) e comparação com os dados de 1919 a 2002 ................

4 Balanço hídrico descendial (Thornthwaite \& Mather, 1955) no decorrer do período experimental, dezembro de 2000 a março de 2002 (dados referentes à irrigação não inclusos)

5 Aspecto das faixas centrais de amostragem após o corte.

6 Distribuição estacional de Cynodon spp. sob um intervalo de cortes de (a) 4 semanas e (b) 6 semanas.

7 Variação estacional no acúmulo de forragem, temperatura e fotoperíodo no decorrer do período experimental para plantas do gênero Cynodon spp. sob um intervalo de cortes de (a) 4 semanas e (b) 6 semanas.

8 Temperatura base inferior, e a correlação entre TMADF a temperatura média do ar em cada uma das rebrotas para os cinco cultivares de Cynodon spp. 


\section{LISTA DE TABELAS}

Página

1 Análise da terra da área experimental............................................................... 21

2 Datas das coletas e alocação nas diferentes estações agrostológicas.................... 27

3 Homogeneidade de regressões entre tratamentos para um delineamento

completamente casualizado............................................................................... 32

4 Acúmulo de forragem de gramíneas Cynodon spp. sob corte.................................. 33

5 Taxas médias de acúmulo de forragem de gramíneas Cynodon spp................... 37

6 Graus-dia para os cinco cultivares de Cynodon spp a cada período de rebrota.. $\quad 46$

7 Unidades fototérmicas (UF) para os cinco cultivares de Cynodon spp. a cada período de rebrota................................................................................................ 47

8 Modelos de GD e UF para a média de todos os cultivares e intervalos............. 48

9 Modelos de GD e UF para a média de todos os cultivares em cada um dos intervalos.

10 Modelos de GD e UF para cada um dos cultivares na média do intervalos......

11 Modelos de GD e UF para cada um dos cultivares em cada um dos

intervalos

12 Modelos de GD e UF para grupo de cultivares

13 Teores médios de proteína bruta de forragem de Cynodon spp. em três estações.

14 Teores médios de FDN em Cynodon spp. em três estações............................... 56

15Valores médios de DIVMO em Cynodon spp. em três estações.......................... 57 
16 Modelos de PB com base em GD e UF para média de todos os cultivares e intervalos

17 Modelos de FDN com base em GD e UF para média de todos os cultivares e intervalos.

18 Modelos de DVMO com base em GD e UF para média de todos os cultivares e intervalos

19 Modelos de PB com base em GD e UF para a média de todos os cultivares em cada um dos intervalos.

20 Modelos de FDN com base em GD e UF para a média de todos os cultivares em cada um dos intervalos.

21 Modelos de DIVMO com base em GD e UF para a média de todos os

cultivares em cada um dos intervalos.

22 Modelos de PB com base em GD e UF para cada um dos cultivares na média do intervalos.

23 Modelos de FDN com base em GD e UF para cada um dos cultivares na média do intervalos.

24 Modelos de DIVMO com base em GD e UF para cada um dos cultivares na média do intervalos.

25 Modelos de PB com base em GD e UF para cada um dos cultivares em cada um dos intervalos.

26 Modelos de FDN com base em GD e UF para cada um dos cultivares em cada um dos intervalos.

27 Modelos de DIVMO com base em GD e UF para cada um dos cultivares em cada um dos intervalos. 


\section{DETERMINAÇÃO DE PARÂMETROS PRODUTIVOS E QUALITATIVOS DE Cynodon spp. EM FUNÇÃO DE VARIÁVEIS CLIMÁTICAS}

Autor: FELIPE TONATO

Orientador: Prof. Dr. CARLOS GUILHERME SILVEIRA PEDREIRA

\section{RESUMO}

As pastagens são o principal recurso alimentar para pecuária brasileira, sendo fundamentais na viabilização dos sistemas produtivos. Fatores climáticos como temperatura e fotoperíodo têm grande importância no crescimento das plantas forrageiras, influenciando o acúmulo de forragem a distribuição estacional da produção e do valor nutritivo, fatores de grande impacto no sistema produtivo como um todo. Dessa forma, o desenvolvimento de ferramentas que racionalizem o processo produtivo das plantas possibilitando a sua predição em função dos parâmetros ambientais que o condicionam são importantes para o planejamento desses sistemas. O presente estudo foi desenvolvido no Departamento de Zootecnia da ESALQ/USP em Piracicaba, SP, de Dezembro de 2000 a Março de 2002, com o objetivo de gerar um banco de dados sobre as características produtivas e qualitativas de gramíneas forrageiras do gênero Cynodon e, a partir desse banco de dados, avaliar modelos matemáticos propostos na literatura para estimar o acúmulo de massa seca e as alterações no valor nutritivo [teores de proteína bruta $(\mathrm{PB})$, fibra em detergente neutro $(\mathrm{FDN})$, e a digestibilidade in vitro da matéria orgânica (DIVMO)] dessas forragens. Foram estudadas duas variáveis 
climáticas, uma gerada em função da soma térmica diária (graus-dia, GD), e outra incorporando os efeitos das alterações no fotoperíodo à soma térmica (a unidade fototérmica, UF). Os tratamentos constituiram de todas as combinações possíveis entre dois intervalos entre cortes (4 e 6 semanas) e cinco cultivares de Cynodon spp. (Tifton 85, Coastcross, Florico, Florona e Estrela) mecanicamente colhidos a $7 \mathrm{~cm}$. As parcelas eram irrigadas para garantir ausência de déficit hídrico e adubadas com o equivalente a $400 \mathrm{~kg} \mathrm{~N} \mathrm{ha}{ }^{-1}$ ano $^{-1}$. O delineamento experimental utilizado foi o de blocos completos casualizados com quatro repetições. Nas três estações de crescimento determinadas, "estação completa", "verão" e "inverno" foram avaliados o acúmulo de forragem (AF), a taxa média diária de acúmulo de forragem (TMDAF), a distribuição estacional da produção e os teores de PB e de FDN, além da DIVMO. O intervalo de seis semanas proporcionou maior AF, maior TMDAF, menor teor de $\mathrm{PB}$, menor DIVMO e maior teor de FDN do que o intervalo de quatro semanas nas três "estações" consideradas. A distribuição estacional da produção foi igual para os dois intervalos, com $73 \%$ da produção no "verão" e $27 \%$ no "inverno". O AF e a TMDAF para a "estação completa" não foram diferentes entre os cultivares, mas no "verão" Tifton 85 foi superior a Coastcross e Florona. No "inverno", os cultivares não se diferenciaram nessas características, o que resultou em maior estacionalidade de produção de Tifton 85 do que de Coastcross, Florico e Florona. Coastcross apresentou os menores teores de PB e juntamente com Tifton 85 os maiores teores de FDN nas três"estações". A digestibilidade só foi diferente entre os cultivares na "estação completa", onde Florona superou Coastcross. Os modelos gerados para a resposta quantitativa (AF) foram altamente significativos, apresentando melhores resultados nos menores níveis de agregação. As duas variáveis climáticas foram eficientes, mas os modelos de UF apresentaram capacidade preditória superior. Os modelos para as respostas qualitativas também apresentaram alta significância, com melhores resultados nos maiores níveis de agregação. No entanto, em função da alta variabilidade tiveram sua capacidade preditória comprometida. Os cultivares estudados demonstraram significativas diferenças produtivas e qualitativas, que devem ser consideradas quando de sua adoção em sistemas produtivos. Nos intervalos entre cortes a produção e o valor nutritivo 
estiveram inversamente associados. A utilização de variáveis climáticas para a predição de parâmetros produtivos se mostrou efetiva em condições de ausência de déficit hídrico. Para a modelagem qualitativa o conceito se mostrou válido, mas novos modelos incluindo maior amplitude de maturidades da forragem devem ser gerados e avaliados. 


\title{
PREDICTING YIELD AND QUALITATIVE CHARACTERISTICS OF Cynodon spp. IN RESPONSE TO CLIMATIC VARIABLES
}

\author{
Author: FELIPE TONATO
}

Adviser: Prof. Dr. CARLOS GUILHERME SILVEIRA PEDREIRA

\section{SUMMARY}

Pastures are the main feed resource in the Brazilian livestock industry and they are key in making forage-livestock systems feasible. Climatic variables such as temperature and daylength are important to forage growth as they affect herbage accumulation as well as the seasonal distribution of both yield and nutritive value, two major characteristics that impact the systems as a whole. Thus, the development of manegerial tools that allow for the rationalization of the production process and for the prediction of forage responses to environmental variables may be valuable for planning and managing whole systems. The present study was carried out at the Departamento de Zootecnia of ESALQ-USP in Piracicaba, SP, from December 2000 through March 2002. The objective was to generate a comprehensive dataset on the productive and qualitative characteristics of Cynodon grasses and to use this dataset to evaluate prediction models reported in the literature, using them to estimate forage accumulation and changes in forage nutritive value [measured as concentrations of crude protein (CP) and neutral detergent fiber (NDF), as well as the in vitro organic matter digestibility (IVOMD)]. Two climatic variables were studied, one generated as a function of daily caloric sum 
(degree-days, DD) and the other combining the effect of daylength with DD and known as the photothermal unit (PU). Treatments included all possible combinations between two intervals between clippings (every four or six weeks) and five Cynodon spp. cultivars (Tifton 85, Coastcross, Florico, Florona e Stargrass) harvested mechanically at a 7-cm height. Plots were irrigated to ensure that soil moisture was not limiting at any point during the experiment and fertilized at the rate of $400 \mathrm{~kg} \mathrm{~N} \mathrm{ha}^{-1} \mathrm{yr}^{-1}$. The experimental design was a randomized complete block with four replications. For the three "seasons" established ("whole season", "summer", and "winter"), total herbage accumulation (HA), the mean daily HA rate (MDHAR), the seasonal yield distribution and the concentrations of $\mathrm{CP}$ and $\mathrm{NDF}$ plus the IVOMD of the forage produced were characterized. The 6 wk harvest interval resulted in higher HA and MDHAR, lower CP and IVOMD, and higher NDF than the $4 \mathrm{wk}$ interval, for all three "seasons". Seasonal yield distribution was similar between intervals, with $73 \%$ of the total forage accumulating during the "summer" and 27\% in the "winter". HA and MDHAR for the "whole season" was the same across cultivars but during the "summer", these responses were higher in Tifton 85 than on Coastcross and Stargrass. In the "winter", no differences were found across cultivars for these quantitative responses and this resulted in more pronounced seasonality for Tifton 85 than for Coastcross, Florico and Florona. Coastcross forage had the lowest CP concentration and, together with Tifton 85 forage, the highest NDF concentrations in all three "seasons". Forage IVOMD was the same across treatments except among cultivars in the "whole season", where Florona showed higher IVOMD than Coastcross. The prediction models generated for the quantitative response HA were highly significant and seem to be better predictors at lower aggregation levels. Both climatic variables were efficient, although the PU models had a better prediction ability than the DD models. For the qualitative characteristics were also significant, but with better results for the higher aggregation levels. Because of the high variability involved, however, their predictive ability may have been somewhat compromised. The grass cultivars used in this study have contrasting productive and qualitative characteristics, which must be taken into account when one considers their inclusion into the system. Within harvest intervals yield and nutritive value were 
inversely related. The use of climatic variables to predict forage quantitative responses appears to be promising in the absence of water deficit. For qualitative characteristics, the concept seems to hold although more modeling is needed using a wider range of forage maturities. 


\section{INTRODUÇÃO}

A agropecuária representa um dos setores produtivos mais importantes para a economia brasileira, com grande participação na geração de divisas para o país (Zimmer et al., 2002). Nos últimos anos, essa atividade econômica tem experimentado um processo de evolução, abandonando o perfil amador de caráter extrativista com ganhos puramente especulativos, e adotando um perfil profissional, de enfoque empresarial.

Esse novo conceito de atividade agropecuária, transformou fazendas em empresas, e criou novas demandas por mecanismos de geração e gerenciamento da informação, com ferramentas que possibilitem o planejamento das atividades no campo, minimizando suas incertezas e seus riscos. Nesse contexto, a modelagem matemática de sistemas e de processos produtivos vêm tomando espaço no ambiente rural, tendo seu uso difundido como forma de embasamento à tomada de decisão.

Nos sistemas de produção animal, o planejamento e as decisões ligadas à alimentação assumem papel fundamental, pois os alimentos se configuram no insumo de maior demanda, perfazendo grande parte dos custos, o que traz implicações diretas no sucesso da atividade. Para a pecuária brasileira as pastagens são o principal suprimento alimentar, compondo a maior parte da dieta dos animais do nosso rebanho (Bürgi \& Pagoto, 2002). Fatores como baixo custo, grande aptidão produtiva e fácil cultivo, tornam os pastos a base de nossa exploração pecuária, e fazem com que boa parte de nossas áreas agriculturáveis sejam cultivadas por plantas forrageiras (Da Silva \& Sbrissia, 2000), as quais em função dessa grande extensão territorial que ocupam estão sujeitas a diversas condições de clima e ambiente (Pinheiro et al. 2002).

Os fatores climáticos são um dos principais determinantes da produtividade das forragens, e por conseqüência condicionantes do sistema produtivo. Aspectos como 
temperatura, precipitação pluviométrica e luminosidade (fotoperíodo e qualidade da luz) afetam diretamente características de grande importância como acúmulo de massa, estacionalidade de produção e valor nutricional dessas plantas, representando um ponto chave para o entendimento de seu processo produtivo.

Dessa forma, o sucesso dos empreendimentos agropecuários esta cada vez mais ligado ao conhecimento dos diversos aspectos ligados às plantas que os compõem, e ao desenvolvimento de ferramentas que racionalizem seus processos produtivos, possibilitando a sua predição em função dos parâmetros ambientais que o condicionam. Tal capacidade, minimiza as incertezas e os riscos inerentes a atividade agrícola, facilitando o seu planejamento e aumentando a sua competitividade.

O trabalho aqui desenvolvido objetivou conhecer alguns parâmetros produtivos e nutricionais de plantas do gênero Cynodon spp. e com base nessas características gerar modelos de predição da produtividade, estacionalidade e valor nutricional em função de variáveis do clima. 


\section{REVISÃO DE LITERATURA}

\subsection{Gênero Cynodon}

O gênero Cynodon é composto de gramíneas tropicais e sub-tropicais em sua maioria originárias dos continentes africano e asiático, com centros de origem na porção leste da África Tropical (Quênia, Uganda e Tanzânia), África Ocidental (Angola) e sul da Ásia e ilhas do Pacífico Sul (Harlan, 1970). São plantas pertencentes à tribo Cynodonteae (Santos \& Boechat, 1994) sendo, de acordo com Harlan et al. (1970), subdivididas em oito espécies. Existe ainda outra subdivisão de grupos dentro do gênero, denominados de gramas bermuda (C. dactylon L. Pers. ) para as plantas que apresentam rizomas, e de gramas estrela (C. nlemfuënsis Vanderyst, C. plectostachyus K. Schum. e C. aethiopicus Clayton \& Harlan) para as plantas mais robustas e não rizomatosas (Harlan et al. 1970). Este gênero apresenta uma grande capacidade de adaptação a diferentes ambientes, vegetando principalmente entre os paralelos $35^{\circ} \mathrm{N}$ a $35^{\circ} \mathrm{S}$ (Pedreira et al., 1998), sendo descrita como "uma invasora onipresente e cosmopolita" por Harlan \& De Wet (1969).

Até o lançamento de Coastal, o primeiro cultivar melhorado, em 1943 pelo Dr. Glenn Burton do Departamento de Agricultura dos Estados Unidos (USDA-ARS) as gramíneas do gênero Cynodon eram consideradas invasoras, configurando-se em um grande problema à agricultura americana (Pedreira et al., 1998). O lançamento do cultivar Coastal representou uma revolução na pecuária do Sul dos EUA, pois evidenciou a viabilidade das gramíneas Cynodon como espécies forrageiras, sendo a partir de então seguida pelo lançamento de diversos outros cultivares advindos dos 
programas de melhoramento da Universidade da Geórgia e da Universidade da Flórida. Dentre os cultivares lançados pelos programas de melhoramento e que são hoje mais largamente utilizados no Brasil está o Coastcross-1 (Cynodon spp), um híbrido oriundo do cruzamento de Coastal com PI 255445 (um grama bermuda originária do Quênia), liberado como cultivar comercial em 1972 (Burton, 1972), e que se caracteriza por apresentar boas produções de massa, boa digestibilidade, relação folha/haste favorável, mas um lento estabelecimento e baixa tolerância ao frio (Burton \& Hanna, 1995), sendo o cultivar mais largamente disseminado em nosso país.

O Tifton 85 (Cynodon spp.) é uma introdução recente no Brasil, sendo um híbrido $F_{1}$ de Tifton 68 com PI 290884 (uma introdução sul-africana), lançado pela Universidade da Geórgia em 1993 (Burton et al., 1993). É tido como o melhor híbrido desenvolvido até o momento, caracterizando-se por ser bastante produtivo, de elevado valor nutricional, boa digestibilidade, e grande resistência ao frio (Hill et al., 1993; Sollenberger et al., 1995). Configura-se em uma planta alta, com hastes grandes, folhas finas e de cor verde bastante escuro. (Burton et al.,1993).

Florico (Cynodon nlemfuënsis Vanderyst var nlemfuënsis cv. Florico), é uma grama-estrela lançada conjuntamente em 1989 pela Florida Agricultural Experimental Station, Puerto Rico Agicultural Experiment Station e pelo USDA-ARS (Mislevy et al., 1989a). Apresenta alta produção de matéria seca, e boa resposta a altos níveis de adubação, e é descrita como uma planta com hastes e folhas em um tom verde bastante escuro, e inflorescência de cor roxa acentuada (Mislevy et al., 1993a).

A grama-estrela Florona (Cynodon nlemfuënsis Vanderyst var. nlemfuënsis cv. Florona) foi observada pela primeira vez misturada a outra gramínea em uma área pastagem de uma das estações experimentais da Universidade da Flórida em 1974, sendo então coletada, multiplicada e selecionada em ensaios, para ser liberada em 1988 (Mislevy et al., 1989b). Seu registro de cultivar foi obtido em 1993, juntamente com Florico (Mislevy et al., 1993a; 1993b), onde é apresentada como um cultivar com hastes e folhas de cor verde clara, e inflorescência roxa, bem adaptada a uma grande variedade de solos, sendo selecionada por sua persistência e alta produção (Mislevy et al., 1993b). 
No Brasil, não existem registros precisos da introdução das plantas do gênero, sendo as espécies inicialmente trazidas para as Américas provavelmente por conquistadores espanhóis como fenos para alimentar os animais (Maraschin,1988) mas não possuindo grande potencial forrageiro (Santos \& Boechat, 1994). Nos últimos anos tem havido uma "reintrodução" dessas plantas em nosso meio, com a chegada de diversos novos cultivares recentemente lançados pelos programas de melhoramento americanos, fato que vem renovando o interesse pelo gênero (Pedreira \& Mello, 2000).

As plantas do gênero Cynodon, principalmente as bermudas são consideradas a base da exploração pecuária no sudeste dos EUA, onde na primavera/verão são o principal recurso forrageiro, e nos meses de restrição alimentar os fenos com elas confeccionados são a principal fonte de alimento (Hill et al., 1998). Nas condições brasileiras estas espécies tem sido empregadas principalmente em explorações leiteiras e para a produção de forragem conservada e em menor escala em explorações de gado de corte (Vilela \& Alvim, 1998).

Capins do gênero Cynodon apresentam em nossas condições um elevado potencial de produção por animal e por área (Corsi \& Martha Jr., 1998) e grande flexibilidade de manejo (Nussio et al., 1998), com elevada produção de matéria seca (superando as $20 \mathrm{Mg} \mathrm{MS} \cdot \mathrm{ha}^{-1} \cdot \mathrm{ano}^{-1}$ ), e uma das melhores distribuições estacionais de crescimento quando comparada por Pedreira \& Mattos (1981) a outras 25 espécies de gramíneas forrageiras, e possibilitando a conservação sob as mais diversas formas (Corsi \& Martha Jr., 1998).

\subsection{Determinantes climáticos para a produção de plantas forrageiras}

O processo básico a desencadear o crescimento das plantas é a obtenção e transformação da energia solar em compostos orgânicos através do processo fotossintético (Nabinger \& Pontes, 2001), onde a temperatura do ar, radiação solar global incidente (luz), fotoperíodo e umidade do solo podem ser considerados os maiores condicionantes, e consequentemente os principais determinantes ambientais das 
variações estacionais da produção primária (Eagles \& Wilson, 1982b; Korte et al., 1987).

A magnitude das respostas das plantas a um determinado fator ambiental está associada à intensidade dos demais fatores (Laude, 1972; citado por Pedreira et al., 2001), onde o efeito cumulativo do ambiente sobre as plantas é refletido nas taxas de crescimento, desenvolvimento, na produção e na qualidade da forragem através de processos fisiológicos (Buxton \& Fales, 1994). De acordo com Pedreira (1972), é bastante conciso e claro o conceito dado por Cooper \& Tainton (1968) de que a distribuição estacional da energia solar é o fator climático básico e limitante da produção das plantas e que a utilização dessa energia poderia ser restringida por outros fatores climáticos, tais como as baixas temperaturas, deficiências de água, além de carências de nutrientes no solo.

O clima pode ser definido como a resultante das trocas de energia e umidade que ocorrem entre as superfícies sólidas e de águas na Terra (Rocha, 1991). Algumas variáveis climáticas como a temperatura do ar, comprimento do dia ou radiação solar estão, normalmente, correlacionadas e por isso a interpretação das diferenças estacionais e regionais na produção e valor nutritivo da forragem utilizando uma única variável climática torna-se difícil (Wilson, 1982a). De acordo com Nabinger (1997) a disponibilidade de radiação solar, a temperatura e o tipo de plantas presentes determinam o potencial de produtividade primária de um ecossistema de pastagem, mas este potencial, no entanto, é limitado pela disponibilidade dos demais fatores, notadamente água e minerais. Dentre estes fatores, tanto a radiação solar incidente como a temperatura são impossíveis de serem modificados pelo homem, enquanto que todos os demais podem, em certa medida, ser alterados ou manejados. De maneira geral, no Brasil Central, a radiação solar recebida nos meses de maio, junho, julho e agosto equivale a aproximadamente $66 \%$ daquela dos meses mais produtivos (novembro, dezembro, janeiro e fevereiro), sendo que esta redução, aliada à entrada de massas de ar frio provenientes da região Antártica e a diminuição do fotoperíodo, determinam uma acentuada variação estacional da produção das plantas forrageiras (Soto, 1981). 
Outros processos metabólicos são afetados pelas condições ambientais, como evidenciado no trabalho de PEDREIRA et al. (1966), que compararam produções de diferentes gramíneas para capineira, e reportaram pequeno ou nenhum acréscimo na produção forrageira, em função da adubação nitrogenada durante a seca. Entretanto, Pedreira (1972) não encontrou variação no número médio de perfilhos por unidade de área nas pastagens durante o inverno em relação ao verão, embora a redução no peso dos perfilhos tenha sido significativa, sugerindo que essa seja a causa da redução da produção durante o inverno. Isso possivelmente ocorreu em função das flutuações estacionais na quantidade de energia luminosa provocarem variações estacionais na área foliar e na densidade populacional de perfilhos (Matthew et al., 1999).

\subsection{Estacionalidade de produção de forragem em pastagens tropicais}

A estacionalidade de produção de forragem das pastagens é, portanto, a distribuição desuniforme da produção total de uma espécie ou cultivar durante as diferentes épocas do ano, em função de oscilações nas variáveis ambientais que caracterizam cada estação. A interação entre genótipo e as condições ambientais faz com que cada espécie ou cultivar apresente potencial único de acúmulo de forragem, e conseqüentemente de produção e distribuição da massa total no decorrer do ano (Fontes et al., 1993). As diferenças estacionais na produção e na qualidade da forragem são pontos chave nos sistemas de produção, pois o estabelecimento das taxas médias de lotação, épocas de compra e venda de animais, práticas de conservação e armazenamento de alimento e fornecimento da suplementação, entre outros, dependem do conhecimento e da quantificação da estacionalidade de produção de forragem (Barioni et al., 2002).

As condições climáticas no Brasil permitem a exploração pecuária em pastagens o ano todo (Rolim, 1980), apesar de na grande maioria das áreas destinadas à pecuária (Brasil Central) as espécies forrageiras apresentarem acentuada estacionalidade de produção, com a produção no "inverno" decrescendo bastante em relação a produção de 
"verão" (Leme, 1985). Essa variação estacional de distribuição da produção é constantemente citada como um dos principais fatores responsáveis pela baixa produtividade animal no Brasil (Rolim, 1980), e é considerada uma das características mais indesejadas pelos produtores em relação à planta forrageira (Corsi \& Martha Jr., 1998). Países de clima temperado, entretanto, apresentam estacionalidade ainda mais marcante e inverno mais severo, e mesmo assim, produtividade bastante alta, indicando que na verdade a baixa produtividade não é decorrente das características da planta ou do clima, e sim da mentalidade do produtor em função de fatores como a tradição, preconceito etc. (Rolim, 1980), e que se refletem na estruturação e organização dos sistemas produtivos em nosso país.

Diversos trabalhos realizados no Brasil Central como os conduzidos por Werner (1970), Pedreira (1972), Ghelfi Filho (1972), Corsi (1972), Pedreira \& Mattos (1981); Rolim (1980) e Müller (2000) demonstraram que as produções das pastagens tropicais concentram-se (cerca de 75 a $85 \%$ da produção total) no período quente e chuvoso, geralmente de outubro a março, e apenas 15 a $25 \%$ da produção total é obtida no período de "inverno" (de abril a setembro). Esta tendência também registrada em países do hemisfério Norte, conforme relatado por Mislevy \& Everett (1981) que obtiveram produções de 14 a 27\% da anual no período de "inverno" (outubro a março) na Flórida (EUA).

Monteiro (1996) citou o trabalho de Diez \& Perez (1983) onde o capim Coastcross-1 (Cynodon spp.), grama estrela (C. nlemfuënsis Vanderyst) cultivares jamaicana e panamenha, recebendo doses de $0,100,200$ e $300 \mathrm{~kg} \mathrm{~N} \mathrm{ha}^{-1}$.época do noo $^{-1}$ (seca e chuvas) apresentaram uma eficiência de uso deste nutriente quatro a cinco vezes maior no período das águas do que no período seco. Monteiro (1996) também mencionou o trabalho de Brunet et al. (1988b) que encontraram maiores teores de nitrogênio na forragem colhida na época seca que aquela colhida na época chuvosa. Em grande parte dos trabalhos em que se objetivou avaliar a distribuição estacional da produção, no entanto, o manejo de reposição dos nutrientes configurou-se em uma fonte de confundimento, pois as adubações eram realizadas apenas nas "águas" e raramente nas "secas", exacerbando as diferenças produtivas entre as duas épocas. 


\subsection{Efeito da temperatura na produção de forragem}

As vias metabólicas das plantas, tais como fotossíntese e respiração, são catalisadas por enzimas, sendo a temperatura um dos principais fatores que controlam as taxas com que esses e outros processos, ocorrem na planta. A respiração, que fornece a energia necessária ao crescimento e a outros processos metabólicos, também é fortemente influenciada pela temperatura (Volenec et al., 1984).

A temperatura expressa a energia contida no meio (Ortolani \& Camargo, 1987), constituindo-se em importante fator abiótico determinante da distribuição, adaptabilidade e produtividade das plantas (Larcher, 1975). Ela pode ser considerada, juntamente com a precipitação pluviométrica, um dos fatores mais importantes na caracterização do clima (Trewartha, 1968; citado por Rocha, 1991). Isto se deve ao fato de as variações que ocorrem na temperatura ambiente afetarem a fotossíntese líquida, a taxa de expansão da área foliar e a produção de matéria seca das plantas (Rodrigues \& Rodrigues, 1987). Estas variações ocorrem em função da estação do ano, altitude, face de exposição do terreno e declividade, e desta forma regem o crescimento das plantas e a distribuição da sua produção, de maneira direta ou indireta, já que interferem na fisiologia e nos processos de absorção e translocação de nutrientes na planta (Da Silva, 1995).

Em condições de saturação luminosa e concentração de $\mathrm{CO}_{2}$ normal $(0,035 \%$ ou $350 \mathrm{ppm}$ ), a fotossíntese e o crescimento são afetados pela temperatura porque os processos bioquímicos são limitados por ela (Cooper \& Tainton, 1968). A temperatura também influencia a distribuição de assimilados entre a raiz e a parte aérea, sendo que o crescimento da raiz aumenta relativamente sob baixas temperaturas ao passo que o crescimento da parte aérea aumenta sob temperaturas elevadas, causando aumento na relação parte aérea/raiz com o aumento da temperatura (Cooper \& Tainton, 1968).

Para Nabinger \& Medeiros (1995), a temperatura é o principal elemento meteorológico a afetar o crescimento das forragens tropicais, pois afeta a eficiência da fotossíntese, refletindo na taxa do alongamento foliar e no perfilhamento. Segundo esses mesmos autores, o perfilhamento de uma gramínea forrageira está relacionado aos 
fatores que regulam o funcionamento do colmo que lhes deu origem. Na ausência de limitações hídricas e nutricionais, a haste primária surgida a partir da semente, produz folhas em um ritmo determinado geneticamente e que é modificado pela ação da temperatura ambiente sobre o meristema apical. De acordo com Nabinger \& Pontes (2001) quando não existem condições limitantes ao crescimento como déficits ou excedentes de água, nutrientes, temperatura e radiação solar, e as plantas não estão sendo pastejadas, a velocidade com que o acúmulo de biomassa ocorre é função do "tempo térmico" decorrido (acúmulo de graus-dia), pois a temperatura é o fator regulador da atividade meristemática.

Três componentes da dinâmica do desenvolvimento vegetal são diretamente afetados pela temperatura. O primeiro é a taxa de aparecimento foliar (TAF) ou ainda o filocrono (intervalo de tempo decorrente entre o aparecimento de duas folhas consecutivas) que responde imediatamente a qualquer mudança de temperatura percebida pelo meristema apical, apresentando relação linear com o acúmulo de grausdia (Nabinger \& Pontes, 2001). O segundo é a taxa de expansão foliar (TEF) que, de acordo com Nabinger \& Pontes (2001) também apresenta variações em função da temperatura ambiente, pois em grande parte das gramíneas temperadas a TEF responde à temperatura média diária de forma exponencial quando esta se situa entre 0 e $12^{\circ} \mathrm{C} \mathrm{e}$ de forma linear acima destes valores, pelo menos até valores entre 20 e $25^{\circ} \mathrm{C}$, conforme a espécie. O terceiro componente é a duração de vida das folhas (DVF) e, conseqüentemente a senecência foliar, que são influenciadas pela temperatura da mesma forma que a TAF. Assim, quando um perfilho atinge um número máximo de folhas vivas, passa a haver um equilíbrio entre a taxa de surgimento de folhas e a senecência das folhas que ultrapassaram o seu período de duração de vida (Nabinger \& Pontes, 2001).

O perfilhamento também é afetado pela temperatura pois o surgimento de cada folha determina o surgimento de um fitômero (unidade estrutural básica do perfilho) e portanto, pode-se esperar que o surgimento de novos perfilhos também acompanhe o acúmulo de graus-dia (Nabinger \& Pontes, 2001). No entanto, temperaturas elevadas aumentam a velocidade de surgimento de folhas e aumentam, em igual proporção, a 
velocidade de surgimento de perfilhos, e ao aumentar simultaneamente a quantidade de folhas e, conseqüentemente, o índice de área foliar (IAF), a elevação da temperatura acaba levando à redução do perfilhamento por auto-sombreamento (Nabinger \& Medeiros, 1995).

Normalmente, a temperatura é o fator ambiental que exerce a maior influência sobre o valor nutritivo das plantas forrageiras (Wilson, 1982a; Buxton \& Fales, 1994), sendo que de acordo com Wilson (1982a), o menor valor nutritivo das espécies forrageiras tropicais é um indicativo da influência negativa da temperatura em latitudes mais baixas. Isto se deve à importância da temperatura nos processos bioquímicos, pois ela determina a energia cinética das moléculas e, em última análise, a velocidade das reações químicas e se as reações irão ou não ocorrer. As reações catalisadas por enzimas geralmente são aceleradas com o aumento da temperatura, dentro da amplitude de temperatura para a qual a enzima seja estável e mantenha sua atividade (Buxton \& Fales, 1994). A temperatura também determina a taxa de crescimento e desenvolvimento da planta, e influencia a proporção relativa de folhas e caules, ocorrendo maior alongamento de hastes quando as temperaturas são mais altas (Wilson,1982a; Silva et al., 1987). Como consequiência, aumenta a participação relativa das hastes na massa total da planta, particularmente em gramíneas tropicais, o que causa redução na digestibilidade. A diminuição na digestibilidade sob altas temperaturas também parece estar relacionada com maior lignificação da parede celular (Wilson, 1982a).

Temperaturas desfavoráveis ao desenvolvimento de uma planta alteram o plastocrono (tempo decorrente entre a iniciação de dois primórdios foliares consecutivos) e promovem mudanças na morfologia da folha que estão relacionadas às alterações no tamanho e número de células. Baixas temperaturas em períodos prolongados afetam a pressão de turgescência, o alongamento e a divisão celular (Pollock, 1990). Silbury (1970) afirmou que a temperatura provavelmente apresenta maior efeito sobre o peso da folha, sendo a luz o fator preponderante para na determinação da área foliar. 
Um efeito secundário da elevação da temperatura resulta em diferenças no tipo de tecido das folhas ou caules gerando aumento na proporção de parede celular e menor digestibilidade tanto da folha como da haste (Buxton \& Fales, 1994), além de aumento na lignificação da parede celular (Van Soest, 1994). Este efeito é mais pronunciado em tecidos velhos que em tecidos jovens (Buxton \& Fales, 1994). Quando a água não é um fator limitante, a taxa de declínio na digestibilidade da MS da forragem com a idade é mais lenta durante os meses frios que durante os meses quentes (Wilson, 1982b).

Outro processo influenciado pela temperatura é a relação fonte:dreno. Variações na temperatura podem alterar o metabolismo do dreno, acelerando ou retardando reações individuais e alterando as taxas de transporte ativo pela membrana plasmática, através de seus efeitos sobre a atividade e concentração enzimática. Há evidencias na literatura que indicam que, sob altas temperaturas, ocorre uma grande conversão de fotoassimilados em componentes estruturais (Buxton \& Fales, 1994).

Segundo Rocha (1991), o crescimento das plantas é interrompido quando a temperatura cai abaixo de um certo valor mínimo ou excede um certo valor máximo, independente das condições de luminosidade e, entre estes limites, existe a temperatura ótima, sob a qual a planta cresce com maior rapidez. Desta forma, as espécies tropicais e sub-tropicais apresentam a máxima taxa de acúmulo de forragem entre 25 e $35^{\circ} \mathrm{C}$ e seu crescimento é reduzido até taxas de acúmulo de forragem muito baixas ou nulas sob temperaturas abaixo de $10{ }^{\circ} \mathrm{C}$ e $15{ }^{\circ} \mathrm{C}$ (Cooper \& Tainton, 1968). Temperaturas extremas podem ser letais às plantas, mas o mais comum é que determinados limiares de temperatura restrinjam o seu crescimento. A temperatura mínima e máxima que limitam o crescimento das plantas recebem a denominação de temperatura base inferior e temperatura base superior, respectivamente, sendo que a temperatura base ( $\mathrm{Tb}$ ) é definida por McWilliam (1978) como a temperatura que limita o acúmulo de massa de uma espécie de forma que este se torne nulo ou "desprezível". O conhecimento destas temperaturas é importante para estimar o potencial produtivo de uma cultura em uma dada região, sendo variável em função de espécie e cultivar (Alcântara et al., 1989). Segundo Jacques (1994), o capim-elefante (Pennisetum purpureum Schum), por 
exemplo, cessa seu crescimento quando a temperatura é superior a $30-35{ }^{\circ} \mathrm{C}$ ou inferior a $10{ }^{\circ} \mathrm{C}$, havendo diferenças entre cultivares quanto à tolerância ao frio.

Pedro Jr. et al. (1990) correlacionaram a temperatura mínima média mensal com os dados de produção de forragem de 32 espécies forrageiras reportados por vários autores no Estado de São Paulo e concluíram que na média a produção de forragem de espécies tropicais foi quase nula a $10{ }^{\circ} \mathrm{C}$. Segundo Jones (1982), o estresse causado por temperaturas baixas é em geral mais freqüente do que o causado por temperaturas altas, quando se trata de espécies tropicais. Por serem de fisiologia $\mathrm{C}_{4}$, essas espécies apresentam drástica redução da atividade fotossintética, sob temperaturas inferiores a 15 ${ }^{\circ} \mathrm{C}$, fator que é tido como um dos principais agentes causadores da estacionalidade de produção (Da Silva, 1995). As baixas temperaturas noturnas em algumas regiões dos trópicos e subtrópicos são apontadas como um dos principais agentes causadores da estacionalidade de produção de plantas forrageiras tropicais (Corsi, 1976; Bryan \& Sharpe, 1970 e Cooper,1970, citados por Rolim, 1980).

Corsi (1976) e Nabinger \& Pontes (2001) afirmaram que a temperatura é o principal fator ambiental a afetar o crescimento das plantas, mas Wang (1960) salientou que existe influência do fotoperíodo e de fatores hídricos nas respostas das plantas às variações na temperatura. Corsi (1994), ao sumarizar resultados obtidos com diversas gramíneas, apontou que o efeito da temperatura para um mesmo fotoperíodo, é mais pronunciado do que o efeito de diferentes fotoperíodos para uma mesma temperatura. Moore \& Russel (1976; citados por Rolim, 1980) apontaram que um dos principais problemas para a interpretação de resultados experimentais em ambientes sob condições controladas pode ser a dificuldade de se separar os efeitos de luz (fotoperíodo e intensidade de luz) e temperatura no processo. 


\subsection{Efeito da intensidade e qualidade da luz sobre a produção de forragem}

Toda a energia necessária à vida se origina da radiação eletromagnética liberada pelo sol (Reichardt, 1985), e a assimilação de carbono via fotossíntese é responsável por mais de $90 \%$ do peso seco das plantas. A recepção de grande quantidade de luz é importante para a maximização da produção devido à relação muito próxima entre irradiância e o acúmulo líquido de matéria seca por unidade de área foliar (Dovrat, 1993).

A distribuição estacional da radiação solar sobre a superfície terrestre é fundamental para que ocorram os fenômenos físicos e biológicos nas diferentes regiões do globo (Ortolani \& Camargo, 1987), e a intensidade estacional dessa radiação é o principal determinante de todos os fenômenos meteorológicos. A quantidade potencial de radiação solar recebida pela superfície da Terra, entretanto, é fortemente influenciada pela latitude e época do ano (Rosenberg et al., 1983; citados por Buxton \& Fales, 1994), e Rocha (1991) ponderou que a quantidade de energia disponível para produção de forragem varia com a latitude, hora do dia, estação do ano e limpidez atmosférica.

A energia solar que atinge a Terra compõe-se de radiação em comprimentos de onda que variam de 200 a $4000 \mathrm{~nm}$ (Bernardes, 1987). Do total incidente, todavia, 53\% são refletidos de volta ao espaço ou absorvidos por nuvens, e apenas os $47 \%$ restantes alcançam a superfície terrestre na forma de radiação incidente (24\%), radiação difusa (17\%) e direta do céu (6\%) de acordo com Rocha (1991). Esse mesmo autor afirmou que apenas $45 \%$ da energia incidente estão no comprimento de onda entre 380 e 720 $\mathrm{nm}$, sendo que a radiação fotossintéticamente ativa, a que pode ser efetivamente utilizada pelas plantas esta compreendida no espectro de 400 a $700 \mathrm{~nm}$ (Bernardes, 1987). A eficiência dos capins tropicais no aproveitamento da energia luminosa, no entanto, é da ordem de 5 a $6 \%$ e dos temperados de 2 a 3\%, sendo que estes apresentam saturação luminosa entre 996,5 e 1494,7 micro fótons $/ \mathrm{m}^{2} / \mathrm{s}$, ao passo que nos capins tropicais o aumento fotossintético ocorre até os 2990,4 micro fótons $/ \mathrm{m}^{2} / \mathrm{s}$ (Rocha, 1991). Um fator que é regulado pela luminosidade é o controle de abertura dos estômatos que permite às plantas controlarem a captura de $\mathrm{CO}_{2}$ e a perda de água em 
função das mudanças nas condições ambientais. Desta forma, a energia luminosa controla diretamente a reação estomatal por sua influência nos sistemas receptores existentes nas células guarda. Existe uma resposta rítmica na abertura e fechamento dos estômatos e sua amplitude de oscilação varia em função da alternância luz/escuro (Kaiser \& Kappen, 1997).

Os aspectos qualitativos do comprimento de onda da radiação incidente, assim como os fatores quantitativos ligados ao total de radiação captada pela planta e à duração dos períodos de luz e escuro no dia (fotoperíodo) influenciam a quantidade e a qualidade da forragem produzida, pois determinam a taxa de crescimento da planta e por conseqüência sua constituição morfológica e seu valor nutritivo (Deregibus et al., 1983). Pedreira et al. (1998) apontaram que diferentes respostas em relação à razão entre radiação infra-vermelha $(700 \mathrm{~nm})$ e ultra-violeta $(<400 \mathrm{~nm})$ nas diversas épocas do ano poderiam explicar as diferenças na produção total e a distribuição estacional da produção de cultivares de uma mesma espécie. A diminuição da razão entre vermelho e infra-vermelho pode causar atraso no desenvolvimento das gemas em perfilhos (Deregibus et al., 1983) ou pode, quando alta, estimular a brotação das gemas e a produção de novos perfilhos (Zimmer, 1988; Lemaire \& Chapman, 1996), alterando assim o ritmo de acúmulo de massa das plantas.

Apesar de na maioria dos casos a luz poder ser considerada como o menor fator limitante da produção (Rocha,1991), sua intensidade é provavelmente o fator ambiental mais importante na dinâmica de perfilhamento em gramíneas (Pedreira et al., 2001), uma vez que na maior parte das espécies, maiores intensidades luminosas estimulam o perfilhamento (Langer, 1979) enquanto que baixos níveis inibem o desenvolvimento e crescimento das gemas axilares e basais (Robson et al., 1988). O perfilhamento também é afetado pela qualidade da luz e pelos efeito morfogênicos a ela ligados, atuando sobre a taxa de aparecimento de folhas e sobre as taxas de alongamento e longevidade das folhas (Lemaire \& Chapman, 1996). 


\subsection{Fotoperíodo e seus efeitos sobre as plantas forrageiras}

O fotoperíodo consiste na duração ou comprimento do período de presença de radiação solar nas $24 \mathrm{~h}$ do dia, sendo uma característica estacional (variando com a latitude e estação do ano). Constitui-se num dos principais fatores ambientais a influenciar o crescimento e desenvolvimento das plantas (Hay, 1990; Sinclair et al., 2003), sendo grande o número de espécies forrageiras sensíveis às suas alterações (Nelson \& Volenec, 1995). Segundo Hay (1990) os mecanismos pelos quais o fotoperíodo afeta o crescimento e desenvolvimento das plantas são três, (1) servindo de estímulo para o início da fase reprodutiva, (2) alternado a taxa com que os perfilhos reprodutivos se desenvolvem e (3) alterando a taxa de expansão da área foliar e de acúmulo de massa não necessariamente relacionados à fase reprodutiva. Em um experimento de dois anos conduzido na Flórida (EUA), onde as limitações de fotoperíodo foram artificialmente retiradas em condições de campo, Sinclair et al. (2003) obtiveram para quatro gramíneas sub-tropicais incrementos de produção total da ordem de 2 a 4 vezes a obtida pelas testemunhas em condições de fotoperíodo curto. Hay (1990), no entanto, enfatizou o fato de as respostas das plantas às variações no fotoperíodo poderem ser modificadas por outros fatores climáticos (principalmente temperatura e disponibilidade hídrica) que estão fortemente associados com o fotoperíodo em condições de campo e que também apresentam distribuição estacional (Pedreira et al., 1998).

A sensibilidade de muitas espécies a mudanças no comprimento do dia, em função da latitude ou estação do ano, tem efeito pronunciado no desenvolvimento e na produção (Costa, 1984), bem como sobre a morfologia (Nelson \& Volenec, 1995). De acordo com Nelson \& Volenec (1995), as folhas e caules apresentam crescimento ereto em condições de fotoperíodos longos, e prostrado em condições de fotoperíodo curtos. Ainda em relação à morfologia, nos dias longos, ocorre um acréscimo na relação parte área/raiz e decréscimo na relação folha/caule com o aumento do comprimento do dia (Buxton \& Fales, 1994). 
O valor nutritivo é outro fator influenciado pelo comprimento do dia, e geralmente, fotoperíodos longos resultam em aumento do valor nutritivo da forragem devido à maior atividade fotossintética, que aumenta os teores de açúcares solúveis e geram um efeito de diluição da parede celular (Denium, 1984; citado por Buxton \& Fales, 1994). Esse crescimento nos dias longos, no entanto, também causa diluição do N na forragem, diminuindo a sua concentração total (Wilson, 1982a). Sinclair et al. (2003), em um estudo de dois anos em que quatro espécies subtropicais foram submetidas a diferentes fotoperíodos, um curto (naturalmente variável), e outro longo (15h), apontaram que o valor nutritivo da forragem em ambos os tratamentos foi semelhante, ou ligeiramente maior nos fotoperíodos curtos.

O florescimento também é influenciado pelo comprimento do dia, principalmente em gramíneas temperadas (Nelson e Volenec, 1995). As gramíneas tropicais são em muitos casos consideradas neutras (não respondem ao fotoperíodo), estando seu florescimento relacionado à fenologia e a maturação fisiológica (Pedreira et al., 1998). As espécies forrageiras tropicais que apresentam fotoperiodismo (tais como Panicum maximum e Pennisetum purpureum) florescem em dias curtos, ou seja, entram em floração quando as noites são mais longas que um determinado número de horas.

\subsection{Modelagem matemática: racionalizando o processo produtivo em função do ambiente}

A modelagem pode ser definida como a descrição simplificada de sistemas reais, por meio da integração de conhecimentos de diferentes áreas, no intuito de sintetizar e analisar diversos aspectos da produção agropecuária, possibilitando a previsão e o monitoramento do comportamento do sistema (Dourado Neto, 1998), e constituindo-se em uma ferramenta de apoio à tomada de decisões (Caixeta Filho, 2000). Desta forma, a idealização de modelos preditores de produção e taxa de acúmulo de forragem consiste na tentativa de identificar uma ferramenta adequada para a definição de estratégias de manejo da produção das pastagens e qualidade da forragem produzida (Fick, 1994). 
Em função dos determinantes ambientais das respostas quantitativas e qualitativas das plantas forrageiras, têm sido propostas abordagens e estudos envolvendo técnicas de modelagem matemática baseadas em variáveis climáticas, para a racionalização dos processos biológicos. O calendário humano (cronológico) não é o método mais adequado para explicar o crescimento das plantas (Nabinger 1997), não podendo também ser utilizado para nortear as práticas de manejo, a menos que as condições de temperatura e radiação sejam rigorosamente constantes ao longo do tempo e também não ocorram limitações hídricas e nutricionais, o que, no campo é praticamente impossível. Em função disso, modelos baseados em parâmetros ambientais e não no calendário (tempo cronológico) têm sido desenvolvidos, já que possibilitam estimar a produção de forragem em regiões e sob condições climáticas diferentes daquelas onde foram desenvolvidos (Medeiros et al., 2002).

Um dos primeiros modelos baseados em variáveis climáticas proposto foi o de graus-dia (GD), que segundo Ometto (1981), é uma avaliação simplificada da energia (soma calórica) que está à disposição da planta a cada dia, e representa um acúmulo diário de energia acima de uma condição mínima exigida e abaixo da máxima suportada pela planta (temperaturas base inferior e superior, respectivamente). $\mathrm{O}$ conceito de GD permite integrar ao calendário cronológico uma unidade de tempo à qual as plantas são sensíveis qual sejam as temperaturas a que estão expostas a cada dia Nabinger (1997), sendo biologicamente mais significativo (Johnson \& Thornley, 1985).

Villa Nova et al. (1999) citaram que em estudos de estacionalidade de produção de gramíneas tropicais a máxima produção de matéria seca não ocorre nos meses de temperatura do ar mais elevadas mas sim no início do verão, mesmo quando irrigadas, e que as magnitudes das variações estacionais de energia demonstradas pelo conceito de GD e de produção de MS, não correspondem às das variações na produção. Para esses autores, isso indica que deve existir outro fator ambiental influenciando a resposta produtiva, provavelmente o fotoperíodo, sugerindo que modelos baseados unicamente em soma térmica provavelmente não são os mais eficientes para a previsão da produção. Sanderson \& Moore (1999), estudaram o desenvolvimento morfológico de Panicum virgatum L. nos EUA, utilizando o modelo de GD além de um modelo baseado em dias 
Julianos (contagem contínua dos dias a partir de $1^{\circ}$ de Janeiro, não considerando os meses), e concluíram que o modelo GD não foi adequado para as variáveis estudadas provavelmente devido a interações envolvendo fotoperíodo.

Em função disso, um modelo baseado em uma unidade de grandeza denominada unidade fototérmica (UF), que possibilita prever a produtividade das culturas em resposta às oscilações estacionais do ambiente, combinando o efeito da temperatura do ar e do fotoperíodo sobre a resposta da planta foi proposto por Villa Nova et al. (1983). Villa Nova et al. (1999) estudaram a eficiência da UF como preditor de produção de forragem em capim elefante (Pennisetum purpureum Schum. cv. Napier), e constataram que o modelo foi capaz de explicar grande parte da variação estacional nas taxas de acúmulo de forragem, além de demonstrar boa capacidade para estimar a produção anual.

Apesar de se constituir em uma importante ferramenta para pesquisadores e produtores, a modelagem tem tido as sua utilização limitada principalmente pela carência de informações e dados referentes aos sistemas de produção animal brasileiros, dificultando o desenvolvimento e avaliação dos modelos matemáticos (Tatizana, 1995). Isso é lamentável, pois a utilização de modelos matemáticos é uma das técnicas que mais poderiam contribuir para o aumento de eficiência e competitividade dos sistemas de produção brasileiros, pois permitem a simulação de vários cenários, e a realização de estimativas da repercussão dos diferentes cursos de ação sobre os sistemas de produção, facilitando a comparação entre diferentes situações, e a identificação de possíveis pontos de estrangulamento dos sistemas. Por exemplo, o planejamento e controle do forrageamento a partir de previsões na quantidade e qualidade da forragem produzida pode contribuir para aumentar a produtividade dos sistemas pecuários, (Parker et al., 1993), proporcionando uma base mais segura para analisar a viabilidade, retornos econômicos e riscos das alternativas (Barioni et al. 1998).

Embora, seja impossível a obtenção de informações completas sobre o futuro, tornando a tomada de qualquer decisão uma atividade com algum risco (Barioni, 2002), um maior acesso às informações minimiza estes risco, e aumenta a eficiência na tomada de decisões (Turban, 1988). 
No entanto, apesar da importância cada vez maior da utilização de ferramentas capazes de estimar a produção, e/ou identificar limitações de uma forrageira a um determinado ambiente para as atividades produtivas ou de pesquisa, apesar do relativo consenso existente de quais as variáveis ambientais mais estreitamente ligadas à determinação ou limitação desta produção, e da existência de modelos conceituais baseados nessa variáveis, até o momento, poucos ou nenhum trabalho de campo foram delineados e conduzidos com o único intuito de gerar um banco de dados específico para a parametrização destes modelos. O que tem se constituído em um entrave a sua aplicação prática e ao desenvolvimento de modelos mais elaborados.

Em função disso, objetivou-se gerar um banco de dados que possibilitasse testar dois modelos matemáticos já existentes e previamente usados (baseados em variáveis climáticas), em relação à sua capacidade em estimar a produção de matéria seca de gramíneas forrageiras em diferentes períodos do ano, e com base nos parâmetros climáticos acompanhados, estudar as influências que estes fatores possam ter sobre características quantitativas e qualitativas da forragem produzida, fornecendo subsídios para a realização mais precisa de previsões de produção de forragem. 


\section{MATERIAL E MÉTODOS}

O experimento foi conduzido em área experimental do Departamento de Zootecnia da Escola Superior de Agricultura "Luiz de Queiroz", Universidade de São

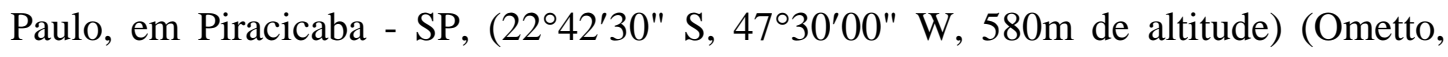
1989). O período experimental foi de 21 de dezembro de 2000 a 7 de março de 2002.

O solo da área experimental é classificado como Nitossolo Vermelho eutroférrico, com horizonte A moderado e textura argilosa/muito argilosa (EMBRAPA, 1999). A análise de amostras de terra colhidas em junho de 2000 , revelou não ser necessária correção da fertilidade do solo (Tabela 1).

Tabela 1. Análise do solo da área experimental

\begin{tabular}{|c|c|c|c|c|c|c|c|c|c|}
\hline $\mathrm{pH}$ & MO & $\mathrm{P}$ & $\mathrm{K}$ & $\mathrm{Ca}$ & $\mathrm{Mg}$ & $\mathrm{H}+\mathrm{Al}$ & SB & $\mathrm{T}$ & $\mathrm{V}$ \\
\hline & $\mathrm{g} / \mathrm{dm}^{3}$ & $\mathrm{mg} / \mathrm{dm}^{3}$ & \multicolumn{6}{|c|}{-------------------- $\mathrm{mmol}_{\mathrm{c}} / \mathrm{dm}^{3}$------------------- } & $\%$ \\
\hline 5,5 & 29 & 32 & 3,9 & 57 & 25 & 26 & 86,6 & 112,9 & 77 \\
\hline & capaci & le de troca & á & & & ura & de base & & \\
\hline
\end{tabular}

Foram estudadas cinco gramíneas do gênero Cynodon sp., cultivares Florico e Florona e Estrela (Cynodon nlemfuënsis Vanderyst var nlemfuënsis), e Tifton 85 e Coastcross (Cynodon spp.), submetidas a intervalos entre cortes de quatro e seis semanas. As parcelas foram estabelecidas vegetativamente no verão de 1998 e mediam $4 \times 4 \mathrm{~m}$ com corredores de aproximadamente $1 \mathrm{~m}$ de largura entre elas (Figura 1). 


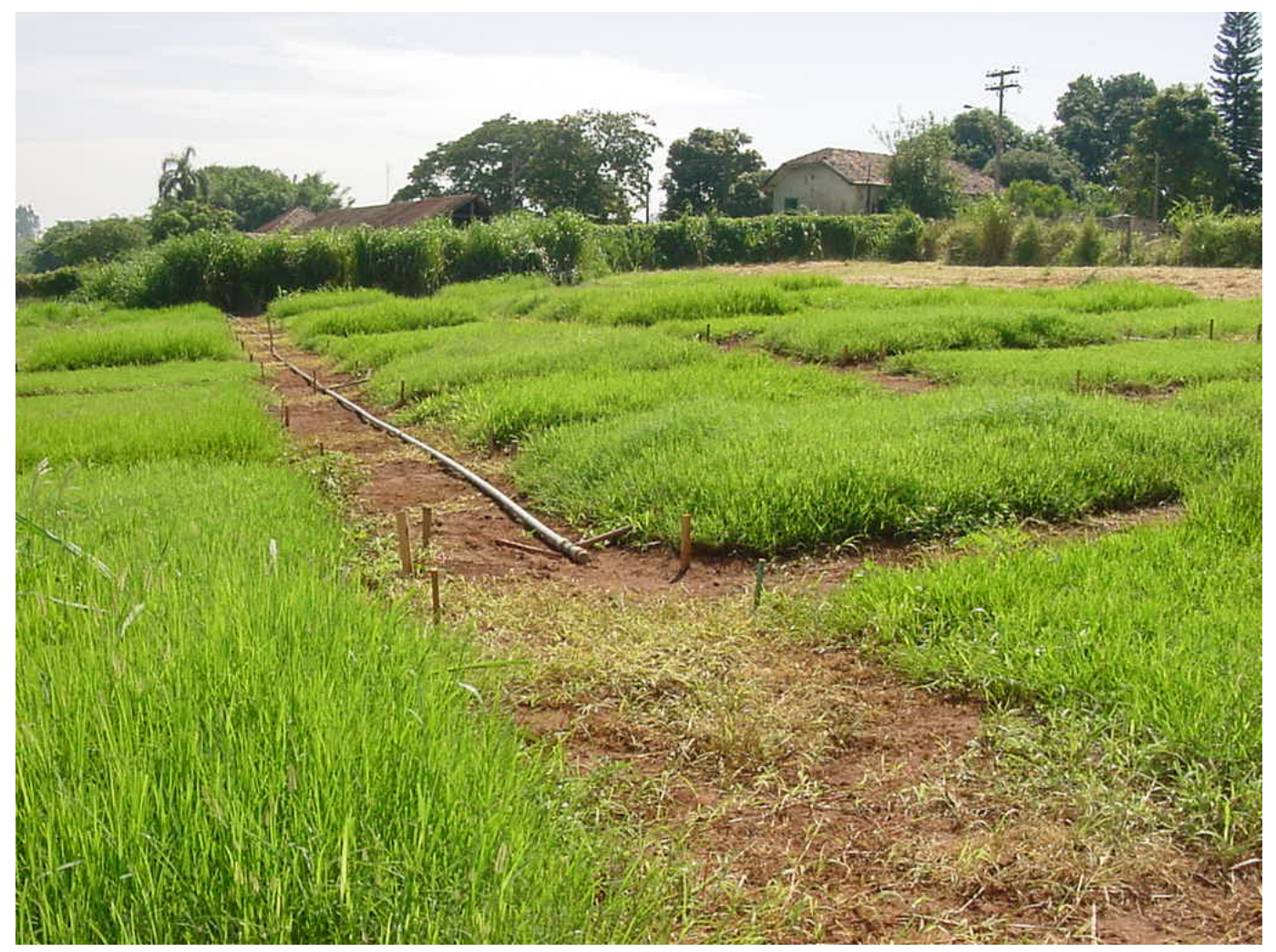

Figura 1 - Vista da área experimental

Os dados climáticos referentes ao período experimental (Figuras 2, 3 e 4) foram obtidos no posto meteorológico do Departamento de Ciências Exatas da ESALQ, distante cerca de $1 \mathrm{~km}$ da área experimental.

Em função da ausência déficit hídrico ser uma das premissas fundamentais para os objetivos do experimento, a área foi equipada com um sistema de irrigação por aspersão, com capacidade para gerar uma lâmina de irrigação de $16 \mathrm{~mm}$ por hora. $\mathrm{O}$ manejo da irrigação era realizado com base na leitura semanal de três tênsiometros instalados aleatoriamente na bordadura de três das parcelas experimentais, e toda a vez que um dos tênsiometros apresentava leitura inferior a $-30 \mathrm{~mm} \mathrm{Hg}$, aplicava-se uma lâmina de $8 \mathrm{~mm}$. 


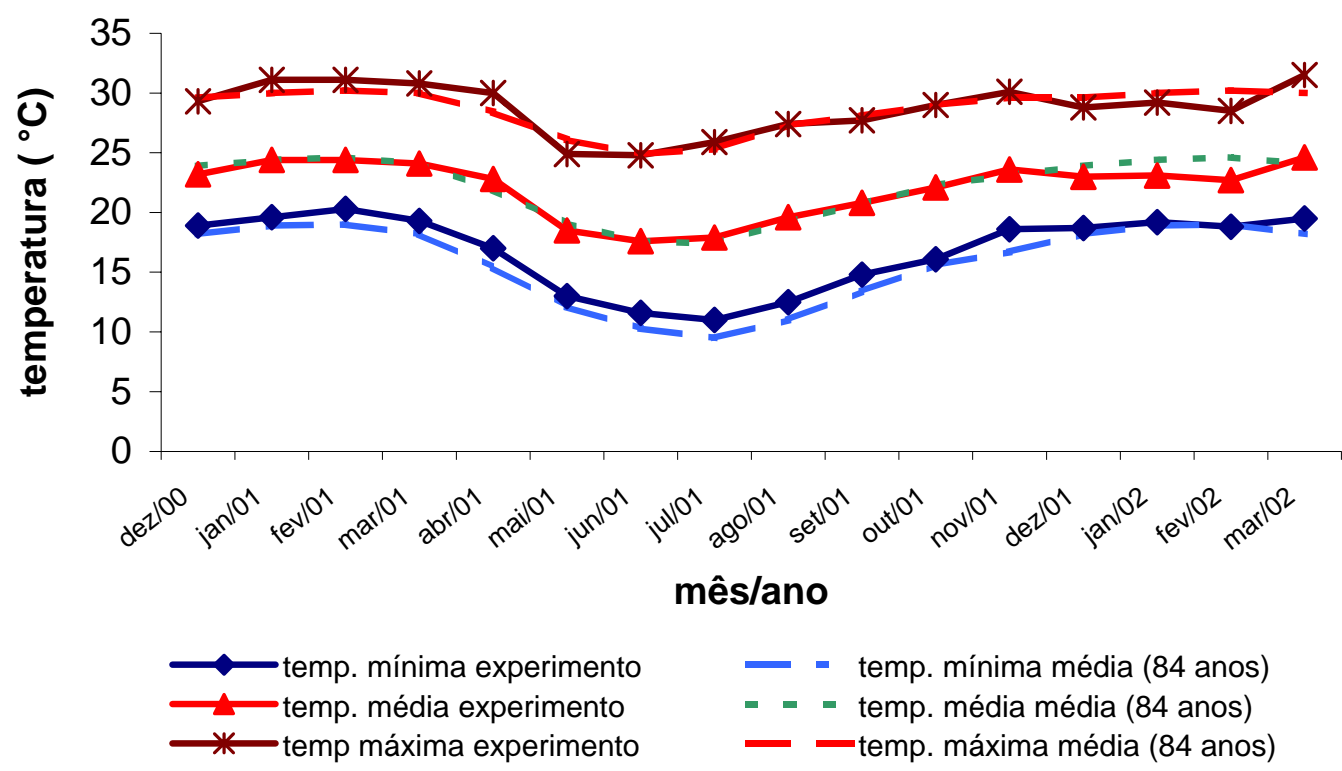

Figura 2 - Temperaturas médias mensais do ar (máxima média, mínima média e média), durante todo o período experimental (dezembro de 2000 a março de 2002) e comparação com os dados de 1919 a 2002

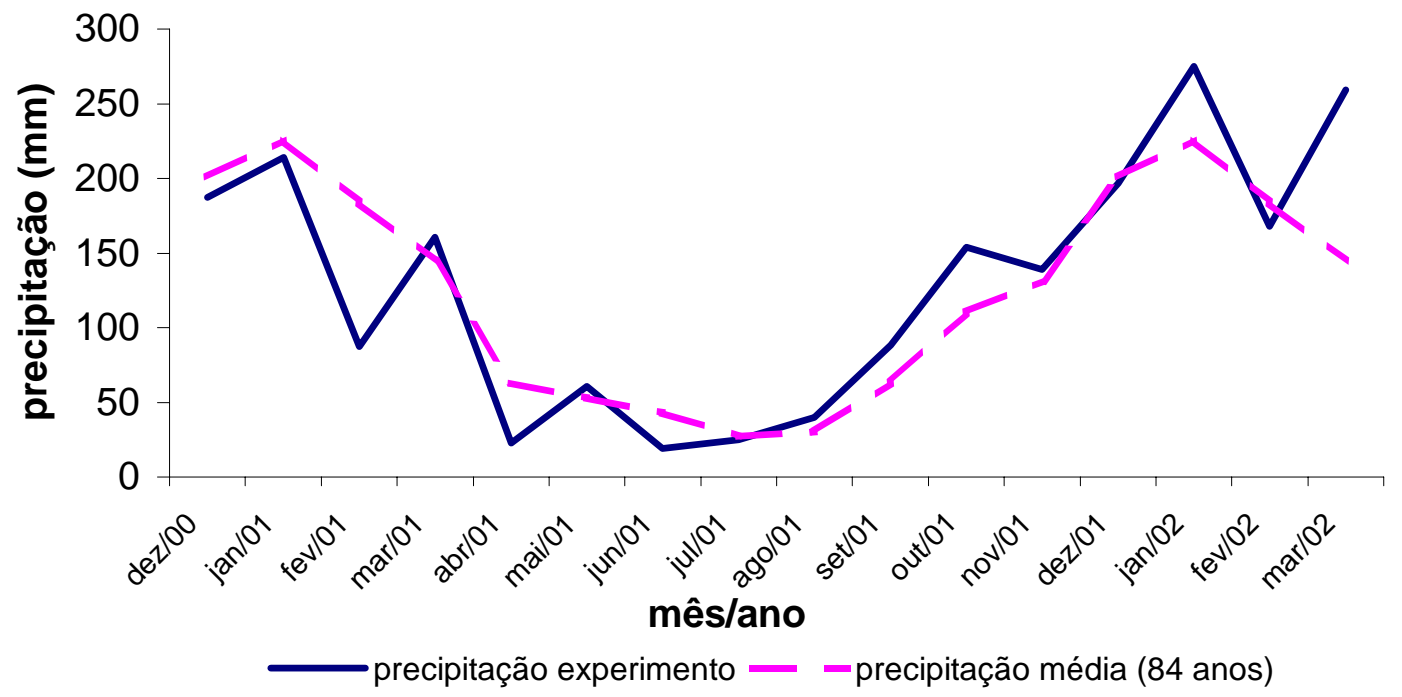

Figura 3 - Precipitação pluviométrica, durante todo o período experimental (dezembro de 2000 a março de 2002) e comparação com os dados de 1919 a 2002 


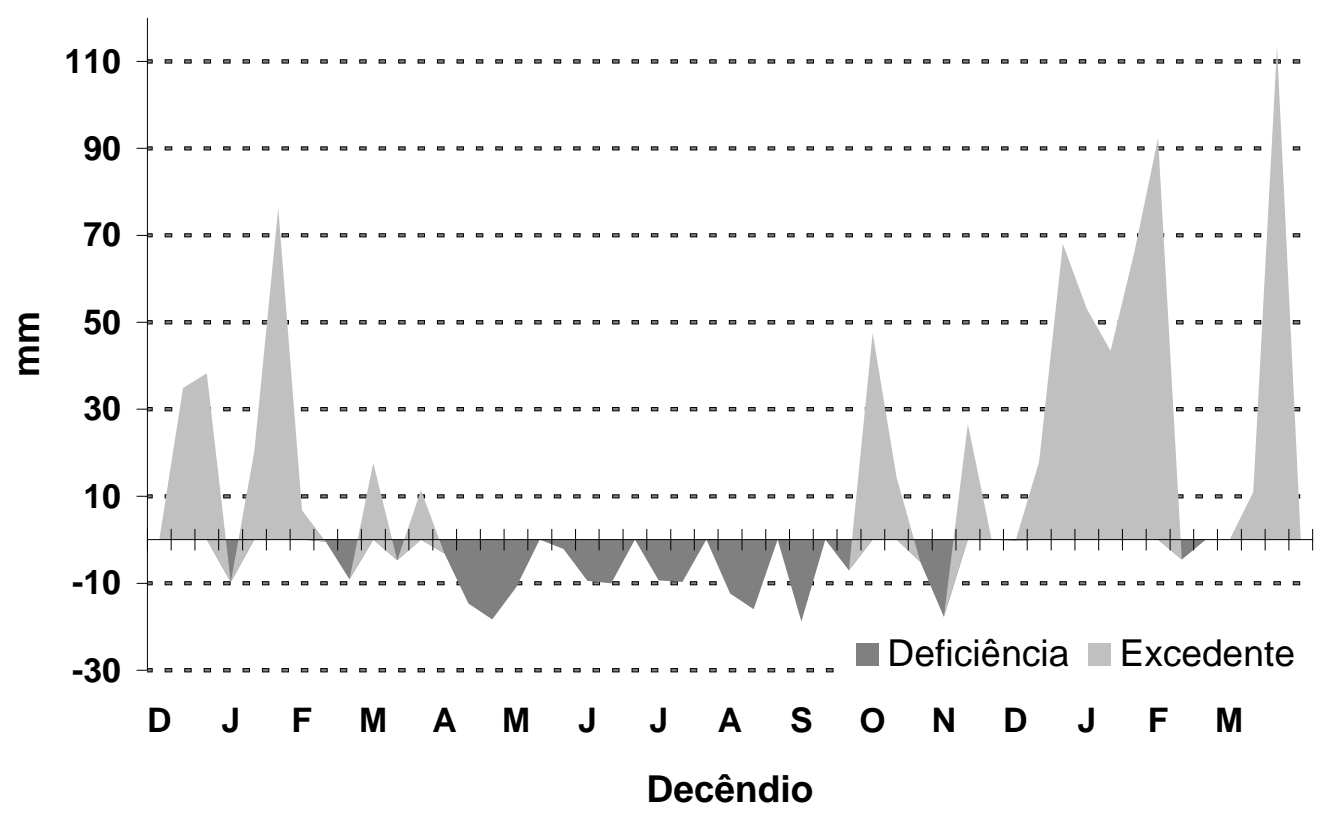

Figura 4 - Balanço hídrico descendial (Thornthwaite \& Mather, 1955) no decorrer do período experimental, dezembro de 2000 a março de 2002 (dados referentes à irrigação não inclusos)

O delineamento experimental foi o de blocos completos casualizados com dez tratamentos, que correspondiam aos cinco cultivares de Cynodon combinados com os dois intervalos entre cortes, 4 e 6 semanas, num arranjo fatorial, com quatro repetições.

O experimento teve início em 21 de dezembro de 2000 com a realização de um corte de igualação de todas as parcelas a aproximadamente $7 \mathrm{~cm}$ do solo. Após esse corte iniciou-se a adubação de todas as parcelas com as doses parceladas de nutrientes com equivalente a $400 \mathrm{~kg}$ de $\mathrm{N}$ e de $\mathrm{K}_{2} \mathrm{O}$ por hectare por ano. A adubação foi dimensionada em função de uma produção média estimada dos cinco cultivares da ordem de $25 \mathrm{Mg} \mathrm{MS}^{-1}$ ano $^{-1}$ e uma extração ao redor de $16 \mathrm{~kg}$ de $\mathrm{N}$ e K por tonelada de 
MS produzida (Raij et al. 1997). Como prática de manejo da fertilidade de solo adotouse parcelar as aplicações de adubo em função dos cortes amostrais, o que levou a realização de 13 adubações com $50 \mathrm{~g}$ de $\mathrm{N}$ e $50 \mathrm{~g}$ de $\mathrm{K}_{2} \mathrm{O}$ nas parcelas cortadas a cada 4 semanas, e 9 adubações com $72 \mathrm{~g}$ de $\mathrm{N}$ e $72 \mathrm{~g}$ de $\mathrm{K}_{2} \mathrm{O}$ nas parcelas cortadas a cada 6 semanas.

\subsection{Massa de Forragem}

Nas datas de corte do que se convencionou chamar de amostragens "de produção" (Tabela 2), as amostras eram geradas colhendo-se uma faixa da parcela medindo 3 x $1 \mathrm{~m}$ a uma altura média de $7 \mathrm{~cm}$ da superfície, empregando-se uma motosegadora com barra de corte de $1 \mathrm{~m}$. A amostragem de massa de forragem levou em consideração uma bordadura de cerca de $0,5 \mathrm{~m}$ de largura que foi descartada. Aleatoriamente determinou-se, em cada parcela, uma metade que seria usada para as amostragens "de produção" (Figura 5).

A forragem proveniente desses $3 \mathrm{~m}^{2}$ era pesada verde no campo em balança tipo dinamômetro e uma sub-amostra de aproximadamente $1 \mathrm{~kg}$ era retirada e também pesada verde. Essa sub-amostra era então seca em estufa de ar forçado a $65^{\circ} \mathrm{C}$ até peso constante, pesada novamente para determinação do teor de MS. Os teores eram então usados na determinação da massa de forragem (MF) relativa a cada amostragem (período de rebrota), sendo esta considerada igual ao acúmulo de forragem (AF) colhida nos $3 \mathrm{~m}^{2}$, uma vez que os cortes sucessivos eram sempre feitos à mesma altura. Após cada corte, toda a parcela era cortada a $7 \mathrm{~cm}$ (mesma altura da amostragem) e a forragem descartada. Para cada período de rebrota, além da MF (AF) foram calculadas as taxas médias diárias de acúmulo de forragem (TMDAF), dividindo-se o AF pelo número de dias correspondentes do período de rebrota. Ao final do experimento, os AFs referentes a cada rebrota foram somados para a geração do acúmulo total de forragem (AFT) referente a cada parcela. 


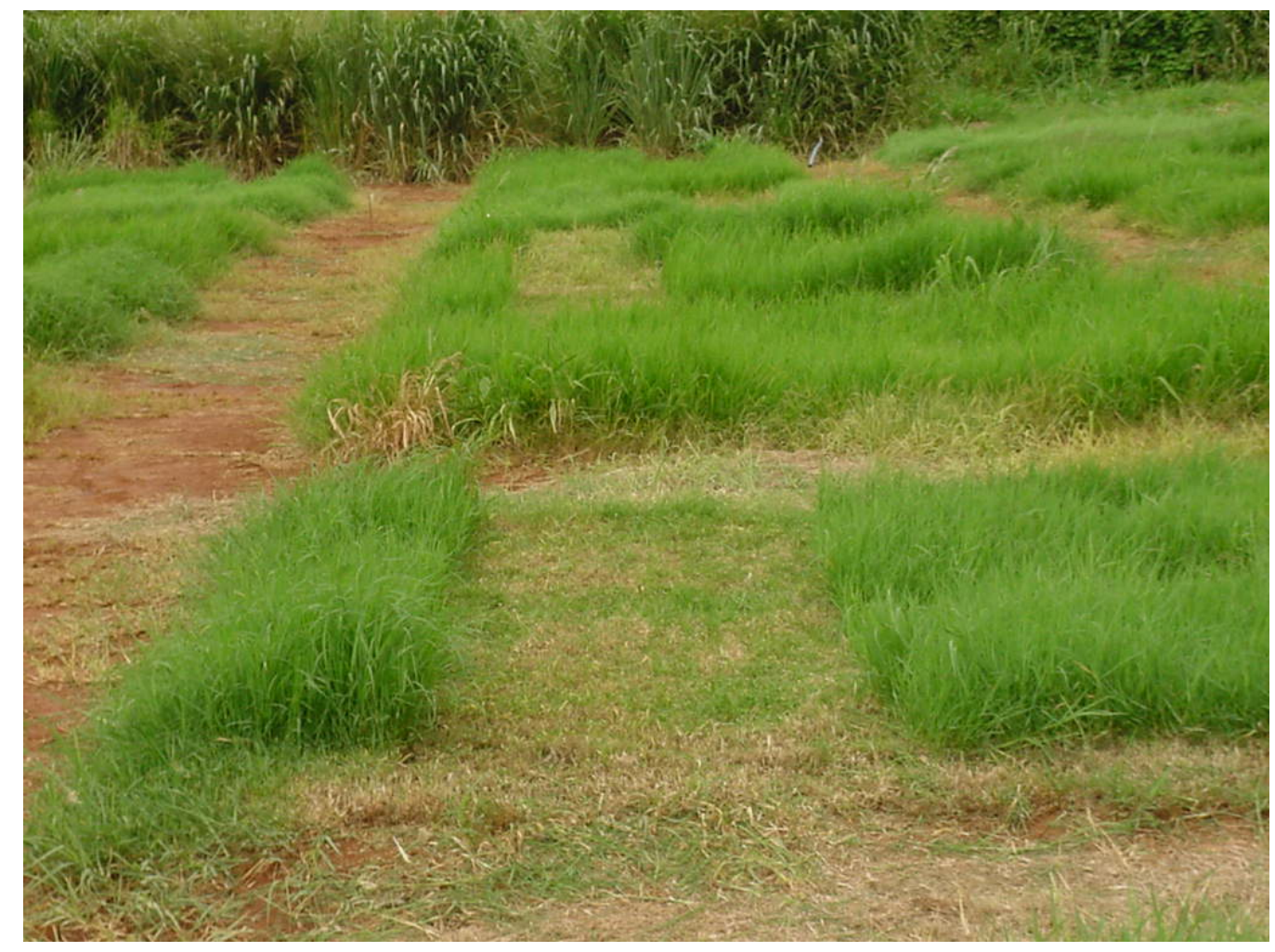

Figura 5 - Aspecto das faixas centrais de amostragem após o corte

Também foram calculados os AFs estacionais, de "verão" (AFV) e "inverno" (AFI). Para o cálculo destas respostas convencionou-se que as estações climáticas de primavera e verão configurariam o "verão agrostológico", e o outono e inverno o "inverno agrostológico", sendo os valores de AFV a somatória de todos os cortes compreendidos entre 21 de dezembro de 2000 e 14 de março de 2001 (corte mais próximo ao dia 20 de março, fim do "verão") e o AFI com a somatória dos cortes entre 15 de março de 2001 e 29 de setembro do mesmo ano (também, respectivamente as datas de coleta mais próximas a 21 de março e 20 de setembro, dias inicial e final do “inverno") (Tabela 2). As taxas médias diárias de acúmulo de forragem para o "verão" (TMADFV) e para o "inverno" (TMADFI) foram calculadas fazendo-se as médias das TMADF dos cortes utilizados para a obtenção dos AFV e AFI. Ainda, em função dos AFs de cada uma das estações foram gerados os valores de distribuição estacional de 
"verão" (DISTV) e de "inverno" (DISTI) como proporções da produção total anual, dividindo-se os respectivos AF das estações pelo AFT.

Tabela 2. Datas das coletas e alocação nas diferentes estações agrostológicas

\begin{tabular}{cccc}
\hline \multicolumn{2}{c}{ 4 semanas } & \multicolumn{2}{c}{ 6 semanas } \\
“verão” & “inverno” & “verão” & “inverno” \\
\hline $18 / 01 / 01$ & - & $01 / 02 / 01$ & - \\
$15 / 02 / 01$ & - & $14 / 03 / 01$ & - \\
$14 / 03 / 01$ & - & - & $26 / 04 / 01$ \\
- & $12 / 04 / 01$ & - & $07 / 06 / 01$ \\
- & $10 / 05 / 01$ & - & $19 / 07 / 01$ \\
- & $07 / 06 / 01$ & - & $30 / 08 / 01$ \\
- & $06 / 07 / 01$ & $11 / 10 / 01$ & - \\
- & $02 / 08 / 01$ & $21 / 11 / 01$ & - \\
- & $30 / 08 / 01$ & $03 / 01 / 02$ & - \\
$29 / 09 / 01$ & - & & \\
$25 / 10 / 01$ & - & & \\
$21 / 11 / 01$ & - & & \\
$21 / 12 / 01$ & - & & \\
\hline
\end{tabular}

Os dados foram analisados utilizando-se o procedimento GLM (General Linear Models) do programa estatístico SAS (Statistical Analysis Sistem; SAS Institute, 1988), com comparações de médias pelo teste de Tukey ao nível de significância de 5\%. 


\subsection{Parâmetros qualitativos}

A caracterização qualitativa (valor nutritivo) da forragem foi feita através da determinação dos teores de de proteína (PB), fibra em detergente neutro (FDN) e digestibilidade in vitro da matéria orgânica (DIVMO) nas sub-amostras retiradas dos corte "de produção". Após secas e pesadas elas foram moídas em moinho tipo Wiley com peneira de abertura de $1 \mathrm{~mm}$ e submetidas a leituras de infravermelho proximal em um aparelho NIRS (Near Infrared Reflectance Spectometer) para a geração de suas curvas espectrais. O aparelho utilizado, foi um monocromato NIRS 5000 (NIRSystems, Silver Spring, MD, USA) que trabalha lendo comprimentos de onda entre 700 e 2100 $\mathrm{nm}$, que são convertidos em curvas de $\log (1 / \mathrm{R})$ em intervalos de $2 \mathrm{~nm}$ e armazenadas em seu banco de dados. Após a leitura de todas as amostras, o software integrante do sistema NIRS foi empregado para realizar as estimativas dos parâmetros bromatológicos de interesse, utilizando a "biblioteca" de dados do Laboratório de Bromatologia da ESALQ - USP. Para a comparação entre os tratamentos, trabalhou-se com os valores médios de PB, FDN e DIVMO. Também foram gerados valores médios estacionais de "verão" (PBV, FDNV e DIVMOV) e de "inverno" (PBI, FDNI e DIVMOI) para os parâmetros qualitativos, adotando-se a mesma convenção e calendário empregados na determinação do acúmulos de forragem estacionais (Tabela 2).

Para a análise estatísticas destes dados, também foi utilizado o procedimento GLM (General Linear Models) do programa estatístico SAS (Statistical Analysis Sistem; SAS Institute, 1988), realizando-se a comparações de médias pelo teste de Tukey ao nível de significância de 5\%. 


\subsection{Modelagem das respostas produtivas}

Foram realizadas regressões lineares múltiplas (PROC REG; SAS, 1988) entre as MF obtidas para cada cultivar sob cada regime de corte, e duas variáveis climáticas, buscando estabelecer uma relação funcional entre estas variáveis.

Através de regressão linear simples (PROC REG; SAS, 1988) correlacionando a taxa média diária de acúmulo de forragem (obtida dividindo-se os valores de AF em cada rebrota pelo número de dias de crescimento correspondente à respectiva rebrota) e a temperatura média do ar em cada uma das rebrotas obteve-se as temperaturas base inferior $(\mathrm{TBi})$, resolvendo $\mathrm{y}=\mathrm{a}+\mathrm{bx}$ para $\mathrm{y}=0$, sendo esta uma característica fisiológica intrínseca (i.e., determinada geneticamente) de cada cultivar.

Em função das TBi, calculou-se para cada unidade experimental em cada período de rebrota os totais de graus-dia (GD) e unidades fototérmicas (UF) através das seguintes fórmulas:

$$
\begin{aligned}
& G D=N(\bar{T}-T B i) \quad, \text { quando } \mathrm{TBi}<\bar{T} \min \\
& G D=N\left(\frac{(\bar{T} \max -T B i)^{2}}{2(\bar{T} \max -\bar{T} \min )}\right), \text { quando TBi }>\bar{T} \min \\
& U F=\frac{\left(\frac{N}{2} G D\right)^{\frac{N f}{N i}+1}}{\frac{N f}{N i}+1}
\end{aligned}
$$

onde:

GD = número de graus-dia acumulados no período;

$\mathrm{N}$ = número de dias no período;

$\bar{T}$ = média das temperaturas médias do período;

$\mathrm{TBi}=$ temperatura base inferior para o determinado cultivar;

$\bar{T} \max =$ média das temperaturas máximas do período; 
$\bar{T} \min =$ média das temperaturas mínimas do período;

$\mathrm{UF}$ = número de unidades fototérmicas acumuladas no período;

$N f$ = valor do fotoperíodo (horas e décimos) no final do período de crescimento;

$\mathrm{Ni}=$ valor do fotoperíodo (horas e décimos) no inicio do período de crescimento.

Os valores de GD e UF foram usados para gerar regressões com os AF medidos em cada corte. Antes disso, todo o conjunto de dados foi testado para verificar obediência às prerrogativas básicas para a análise de variância (independência dos erros, normalidade dos dados, aditividade do modelo e homogeneidade das variâncias). Em função do não cumprimento da premissa de homogeneidade das variâncias, realizou-se a transformação dos dados através da aplicação da raiz quadrada à variável AF. Os dados foram então analisados pelo PROC GLM do SAS (utilizando-se um modelo em que o parâmetro analisado, GD ou UF, foi tratado como co-variável) visando identificar a existência de efeitos lineares ou não lineares. Em função das tendências de efeito apresentadas pelos dados, utilizou-se o procedimento PROC REG do SAS para gerar os modelos para GD e UF.

Os modelos gerados foram então comparados independentemente (não havendo comparações entre os modelos de GD e UF) através da metodologia de testes de coincidência (Seber, 1977) (Tabela 3).

\subsection{Modelagem das respostas qualitativas}

O procedimento utilizado para a geração dos modelos para as variáveis qualitativas foi o mesmo adotado para a variável produtiva (AF), sendo por tanto, os valores da variável independente (GD e UF) empregados em ambas as regressões idênticos. A única diferença, foi a substituição do parâmetro AF utilizado na 
modelagem quantitativa pelos parâmetros PB, FDN e DIVMO. O conjunto de dados referentes a esse parâmetros foi testado para verificar obediência às prerrogativas básicas para a análise de variância, mostrando ser necessário que as variáveis PB e DIVMO fossem transformadas para a obtenção da homogeneidade da variância. Para a variável PB aplicou-se a transformação por $\log _{10}$, e para a variável DIVMO aplicou-se a raiz quadrada. A comparação entre os modelos também foi independente (modelos de GD e UF não foram comparados entre si) utilizando-se da metodologia de testes de coincidência (Seber, 1977) (Tabela 3). 
Tabela 3. Homogeneidade de regressões entre tratamentos para um delineamento completamente casualizado

\begin{tabular}{|c|c|c|c|c|c|c|}
\hline Tratamento & df & $\sum(x-\bar{x})^{2}$ & $\sum(x-\bar{x})(y-\bar{y})$ & $\sum(y-\bar{y})^{2}$ & df & SQ Residual \\
\hline 1 & $n_{1}-1$ & $E_{x x}(1)$ & $E_{x y}(1)$ & $E_{y y}(1)$ & $n_{1}-2$ & $S Q_{1}($ residual $)$ \\
\hline 2 & $n_{2}-1$ & $E_{x x}(2)$ & $E_{x y}(2)$ & $E_{y y}(2)$ & $n_{2}-2$ & $S Q_{2}($ residual $)$ \\
\hline$\vdots$ & $\vdots$ & $\vdots$ & $\vdots$ & $\vdots$ & $\vdots$ & $\vdots$ \\
\hline$t$ & $n_{t}-1$ & $E_{x x}(t)$ & $E_{x y}(t)$ & $E_{y y}(t)$ & $n_{t}-2$ & $S Q_{\mathrm{t}}($ residual $)$ \\
\hline $\begin{array}{l}\text { Resíduo da } \\
\text { regressão } \\
\text { individual }\end{array}$ & & & & & $\sum n_{t}-2 t$ & $\begin{array}{c}\sum S Q_{t}(\text { residual })=\text { erro } \\
\text { pooled }=\mathrm{A}\end{array}$ \\
\hline $\begin{array}{c}\text { Totais para } \\
\text { regressão } \\
\text { simples }\end{array}$ & $\sum n_{t}-t$ & $\sum_{t} E_{x x}(i)$ & $\sum_{t} E_{x y}(i)$ & $\sum_{t} E_{y y}(i)$ & $\sum n_{t}-t-1$ & $\sum E_{y y}(i)-\frac{\left[\sum E_{x y}(i)\right]^{2}}{\sum E_{x x}(i)}=B$ \\
\hline \multicolumn{7}{|l|}{ Diferença para } \\
\hline $\begin{array}{l}\text { homogeneidade } \\
\text { das regressões }\end{array}$ & & & & & $t-1$ & $\mathbf{B}-\mathbf{A}$ \\
\hline
\end{tabular}

Para testar a homogeneidade da regressão, $F=[(B-A) /(t-1)] /\left[A /\left(\sum n_{t}-2\right)\right]$, com $\mathrm{t}-1$ e $\sum n_{t}-2 t$ df

Adaptado de Seber (1977) 


\section{RESULTADOS E DISCUSSÃO}

\subsection{Acúmulo de Forragem (AF)}

Houve efeito do intervalo entre cortes $(\mathrm{P}=0,0001)$ para as três "estações" de crescimento ("estação completa"; "verão" e "inverno"), sempre com o maior intervalo apresentando valores de AF superiores ao menor intervalo. Entre os cultivares, só se detectou diferença no "verão" $(\mathrm{P}=0,0056)$ (Tabela 4).

Tabela 4. Acúmulo de forragem de gramíneas Cynodon spp. sob corte

\begin{tabular}{|c|c|c|c|c|c|c|}
\hline \multirow{2}{*}{ Cultivar } & \multicolumn{2}{|c|}{ “estação completa” } & \multicolumn{2}{|c|}{ “verão” } & \multicolumn{2}{|c|}{ "inverno" } \\
\hline & $4 \mathrm{sem}$. & $6 \mathrm{sem}$. & 4 sem. & 6 sem. & 4 sem. & 6 sem. \\
\hline & \multicolumn{6}{|c|}{----1- } \\
\hline Coas & $21,8^{\mathrm{a}} \pm 1,3$ & $29,2^{\mathrm{a}} \pm 1,2$ & $15,5^{\mathrm{b}} \pm 1,3$ & $21,2^{\mathrm{b}} \pm 0,6$ & $6,3^{a} \pm 0,6$ & $8,0^{\mathrm{a}} \pm 0,6$ \\
\hline Estrela & $22,9^{\mathrm{a}} \pm 1,8$ & $28,0^{\mathrm{a}} \pm 2,7$ & $17,1^{\mathrm{ab}} \pm 1,9$ & $20,6^{\mathrm{ab}} \pm 2,3$ & $5,9^{\mathrm{a}} \pm 0,1$ & $7,4^{\mathrm{a}} \pm 0,6$ \\
\hline Florico & $23,2^{\mathrm{a}} \pm 3,0$ & $29,4^{\mathrm{a}} \pm 1,6$ & $16,8^{\mathrm{ab}} \pm 2,3$ & $20,8^{\mathrm{ab}} \pm 1,5$ & $6,4^{\mathrm{a}} \pm 1,6$ & $8,6^{\mathrm{a}} \pm 0,2$ \\
\hline Florona & $21,3^{\mathrm{a}} \pm 1,3$ & $29,3^{\mathrm{a}} \pm 3,7$ & $15,2^{\mathrm{b}} \pm 1,1$ & $20,7^{\mathrm{b}} \pm 2,9$ & $6,1^{\mathrm{a}} \pm 0,3$ & $8,5^{\mathrm{a}} \pm 1,3$ \\
\hline Tifton 85 & $24,7^{\mathrm{a}} \pm 3,7$ & $30,4^{\mathrm{a}} \pm 0,7$ & $18,6^{\mathrm{a}} \pm 2,4$ & $23,2^{\mathrm{a}} \pm 1,1$ & $6,1^{\mathrm{a}} \pm 1,4$ & $7,2^{\mathrm{a}} \pm 0,3$ \\
\hline Média & $22,8^{\mathrm{B}}$ & $29,3^{A}$ & $16,6^{\mathrm{B}}$ & $21,3^{A}$ & $6,2^{B}$ & $7,9^{\mathrm{A}}$ \\
\hline
\end{tabular}

Médias nas colunas seguidas de mesma letra minúscula, e na última linha dentro de estação, seguidas de mesma letra maiúscula não diferem entre si $(\mathrm{P}>0,05)$. 
As diferenças de AF para os intervalos entre corte mantiveram uma certa proporcionalidade nas diferentes "estações" de crescimento, apresentando valores $28 \%$ superiores para o intervalo de seis semanas em relação ao de quatro na "estação completa" e no "verão", e $27 \%$ maiores no "inverno". Este maior AF no maior intervalo entre cortes possivelmente decorra maior eficiência na utilização de $\mathrm{N}$, como a reportada por Vicente-Chandler et al. (1959) que trabalhando com três forrageiras tropicais (Pennisetum purpureum Schum., Panicum maximum Jacq. e Panicum purpurascens L.) obtiveram para a média das três forrageiras e doses de até $448 \mathrm{~kg} \mathrm{~N}$ $\mathrm{ha}^{-1}$ ano $^{-1}$, uma eficiência de conversão ( $\mathrm{kg} \mathrm{MS} \mathrm{kg} \mathrm{N}^{-1}$ ) de 30,4; 48,0 e 62,4 kg MS para as freqüências de desfolha de 40, 60 e 90 dias respectivamente.

Outro fator que explicaria os maiores AF do intervalo de 6 semanas estaria ligado à provável maior participação das hastes na massa acumulada, pois este é um componente morfológico responsável por grande parte do acúmulo de matéria seca em plantas tropicais (Lemaire \& Chapman, 1996), tendo sua participação aumentada com o avançar da idade de rebrota (Acunha \& Coelho, 1997). Um experimento com capimelefante-anão (Pennisetum purpurem Schum. cv. Mott) realizado por Acunha \& Coelho (1997) apresentou valores de 12, 21, 28, 37 e 41\% de hastes na massa colhida a intervalos de corte de 28,56, 84, 112 e 140 dias de crescimento respectivamente, evidenciando esse acréscimo.

Para as plantas do gênero Cynodon, o componente haste é um componente particularmente importante, com grande participação na massa total, o que é evidenciado pelos estudos conduzidos por Pinto (2000) que trabalhando com três diferentes cultivares de Cynodon obteve valores de 58\% (verão) e 77\% (inverno) de participação de hastes no crescimento das plantas, e Carnevalli \& Da Silva (1999) relataram que $54 \%$ da massa de forragem pré-pastejo de Coastcross foram proveniente de hastes.

O trabalho realizado por Gomide (1996) com cinco diferentes cultivares de Cynodon em que a relação folha/colmo média para os cultivares sofreu alterações de 0,9 (28 dias de crescimento) para 0,75 (42 dia de crescimento) é um indicativo do incremento de haste com o avançar da idade para os cynodons. Herrera \& Ramos (1981; 
citados por Gomide, 1996) verificaram que com o aumento da idade de rebrota as plantas de Cynodon aumentaram não apenas comprimento, mas também o diâmetro do colmo, fator que também poderia estar contribuindo para os maiores AF no maior intervalos entre corte.

Apesar desses fatores, as diferenças em produção (AF) constatadas, indicam que caso o valor nutritivo, não sofra alterações muito significativas entre os intervalos de corte, ou em situações onde estes parâmetros sejam de menor importância (caso atual de explorações comerciais de feno, por exemplo), a adoção de um intervalo de corte de seis semanas em qualquer épocas do ano seria vantajosa. Brown \& Mislevy (1989), estudando o efeito de cortes a intervalos de 2, 4, 6 e 8 semanas em plantas do gênero Cynodon, concluíram que no verão, o intervalo de 4 semanas proporcionou maior produção do que os demais, recomendando a sua adoção. Embora os intervalos para realização das coletas recomendados não sejam os mesmos, o parâmetro utilizado para determinar a recomendação foi o mesmo, a produção, reforçando a indicação anteriormente feita.

Entre os cultivares as diferenças só foram constatadas no "verão", com Tifton 85 superando Coastcross e Florona e não se diferenciando dos outros dois cultivares. $\mathrm{O}$ acúmulo apresentado por Tifton 85 foi $22 \%$ maior do que Coastcross e Florona no intervalo de 4 semanas e $10 \%$ maior do que estes mesmos cultivares no intervalo de 6 semanas. Este maior acúmulo de "verão", entretanto, não se refletiu em uma maior produção quando se considerou a "estação completa" de crescimento, sendo as diferenças produtivas diluídas no "inverno", apesar da não constatação de diferenças de acúmulo nessa "estação".

A não diferenciação dos cultivares no "inverno" se deveu provavelmente a uma interação entre os decréscimos de temperatura e intensidade luminosa, e fotoperíodos mais curtos, que restringem o desenvolvimento das plantas e resultam em menor acúmulo de matéria seca, mesmo em situações em que a umidade é suficiente (Evans \& Peaden, 1984), caso do presente estudo. No verão, em função da abundância de fatores de crescimento, especialmente temperatura e luz, as plantas conseguiram expressar plenamente seu potencial de crescimento, maximizando o desempenho o que 
evidenciou as diferenças genéticas entre os cultivares. De acordo com Cooper (1983), as diferenças entre cultivares refletem a história evolutiva da população, sejam estas adquiridas naturalmente ou através de programas de melhoramento e seleção.

Em trabalhos como os de Burton et al. (1993), Hill et al. (1993), Hill et al. (1996) e Mislevy \& Pate (1996) Tifton 85 é descrito como o mais produtivo quando comparado a outros cultivares de Cynodon como Coastal, Tifton 68, Florico ou Tifton 78 , e se esperaria um resultado semelhante no presente estudo. No entanto, os trabalhos estrangeiros de uma maneira geral, são gerados em condições de ambiente sub-tropical, com uma "estação" favorável ao crescimento das plantas em que os diferentes potenciais produtivos são expressados, e uma outra época do ano onde as restrições climáticas ao desenvolvimento vegetal são grandes, e o crescimento das plantas é pequeno ou praticamente nulo, pouco contribuindo para a produção total, o que faz com que as diferenças de acúmulo sejam aquelas estabelecidas no época favorável ao crescimento (Belesky et al., 1991), nos meses de Abril a Outubro (Hill et al., 1996). Nas condições em que este trabalho foi realizado, ocorreu uma mesma estação favorável ao crescimento em que as diferenças produtivas foram estabelecidas, mas na época desfavorável, as restrições ao crescimento foram menores, o que possibilitou que o crescimento das plantas, apesar de restrito e não diferenciável estatisticamente, fosse proporcionalmente maior a ponto de "anular" as diferenças geradas no "verão".

Os valores de acúmulo de forragem existentes na literatura, como os $25 \mathrm{Mg} \mathrm{MS}$ $\mathrm{ha}^{-1}$ ano $^{-1}$ obtidos por Villela \& Alvim (1996) para Coastcross, os 20,5 Mg MS ha ${ }^{-1}$ ano $^{-}$ 1 para o mesmo cultivar relatados por Alvim et al. (1996), 18,6 $5 \mathrm{Mg} \mathrm{MS} \mathrm{ha}^{-1} \mathrm{ano}^{-1}$ descritos para Tifton 85 por Hill et al. (1993) ou as produções de 19,9 e 20,4 Mg MS ha ${ }^{1}$ ano $^{-1}$ indicadas por Mislevy et al. $(1982$; 1989) contestam a aparente "igualdade" observada entre os diferentes cultivares em relação ao AF da "estação completa" no presente estudo, o que é reforçado pelas diferenças observadas no AF de "verão". Entretanto, em nosso meio, nenhuma avaliação agronômica comparativa foi realizada com tantos cultivares de um mesmo gênero, sob uma mesma condição ambiental, com tão poucos fatores restritivos ao crescimento das plantas e por um período tão longo, o 
que ratifica a relevância dos resultados, indicando que as diferenças entre os cultivares existe, mas é provavelmente menor do que a literatura sugere.

\subsection{Taxa média diária de acúmulo de forragem (TMDAF)}

Houve efeito apenas do intervalo entre cortes na TMDAF para a "estação completa" e para o "inverno", ambas com $\mathrm{P}=0,0001$, onde o intervalo entre cortes de seis semanas apresentou maiores taxas médias de acúmulo do que o intervalo de quatro semanas (Tabela 5). Para a TMDAF de "verão" observou-se a existência do efeito tanto de intervalo entre cortes $(\mathrm{P}=0,0001)$ como de cultivar $(\mathrm{P}=0,0041)$, com o intervalo de 6 semanas novamente apresentando maiores TMDAF do que o de 4 semanas, e Tifton 85 apresentando-se superior a Coastcross e Florona e igual aos demais (Tabela 5).

Tabela 5. Taxas médias de acúmulo de forragem de gramíneas Cynodon spp

\begin{tabular}{|c|c|c|c|c|c|c|}
\hline \multirow{2}{*}{ Cultivar } & \multicolumn{2}{|c|}{ “estação completa" } & \multicolumn{2}{|c|}{ “verão” } & \multicolumn{2}{|c|}{ "inverno" } \\
\hline & 4 sem. & 6 sem. & 4 sem. & 6 sem. & 4 sem. & 6 sem. \\
\hline & \multicolumn{6}{|c|}{ 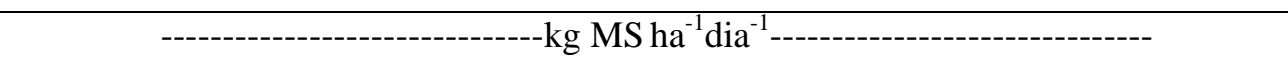 } \\
\hline Coastcross & $59,7^{\mathrm{a}} \pm 3,6$ & $77,1^{\mathrm{a}} \pm 3,1$ & $78,8^{\mathrm{b}} \pm 6,4$ & $100,9^{\mathrm{b}} \pm 2,6$ & $37,4^{\mathrm{a}} \pm 3,5$ & $47,4^{\mathrm{a}} \pm 3,7$ \\
\hline Estrela & $62,9^{\mathrm{a}} \pm 4,8$ & $74,2^{\mathrm{a}} \pm 7,2$ & $87,3^{\mathrm{ab}} \pm 9,4$ & $98,4^{\mathrm{ab}} \pm 10,8$ & $34,5^{\mathrm{a}} \pm 1,1$ & $43,8^{\mathrm{a}} \pm 3,6$ \\
\hline Florico & $63,6^{\mathrm{a}} \pm 8,3$ & $77,8^{\mathrm{a}} \pm 4,4$ & $85,4^{\mathrm{ab}} \pm 11,6$ & $99,4^{\mathrm{ab}} \pm 7,6$ & $38,2^{a} \pm 9,6$ & $50,6^{\mathrm{a}} \pm 1,1$ \\
\hline Florona & $58,2^{\mathrm{a}} \pm 3,3$ & $77,4^{\mathrm{a}} \pm 9,8$ & $77,4^{\mathrm{b}} \pm 5,4$ & $99,1^{\mathrm{b}} \pm 13,8$ & $35,8^{\mathrm{a}} \pm 1,7$ & $50,3^{\mathrm{a}} \pm 7,8$ \\
\hline Tifton 85 & $67,6^{\mathrm{a}} \pm 10,2$ & $80,5^{\mathrm{a}} \pm 1,9$ & $95,0^{\mathrm{a}} \pm 12,3$ & $111,1^{\mathrm{a}} \pm 4,9$ & $35,8^{\mathrm{a}} \pm 8,3$ & $42,2^{\mathrm{a}} \pm 1,8$ \\
\hline Média & $62,4^{\mathrm{B}}$ & $77,4^{\mathrm{A}}$ & $84,8^{\text {B }}$ & $101,8^{A}$ & $36,3^{B}$ & $46,9^{A}$ \\
\hline
\end{tabular}

Médias nas colunas seguidas de mesma letra minúscula, e na última linha dentro de estação, seguidas de mesma letra maiúscula não diferem entre si (P>0,05). 
As TMDAF refletem o ocorrido com os AF, mostrando mais uma vez que os cultivares só se diferenciam no "verão", onde as TMDAF foram $22 \%$ maiores entre o cultivar mais e o menos produtivo no intervalo de 4 semanas e $11 \%$ maiores entre esses mesmos cultivares com 6 semanas. Isto demonstra que os diferenciais produtivos foram gradativamente reduzidos com um maior tempo de rebrota, o que possivelmente ocorreu em função de reduções na taxa de acúmulo de Tifton 85 (o cultivar mais produtivo no "verão"), decorrentes da diminuição na eficiência fotossintética causada por um progressivo sombreamento das folhas inferiores do dossel (Gomide, 1994), haja visto que autores como Gomide (1996) e Fagundes (1999) descrevem este cultivar como sendo o de maior IAF quando comparado com outras plantas do gênero Cynodon a uma mesma idade, e Burton et al. (1993) afirmou que este cultivar apresenta porte mais alto com hastes grandes e folhas mais largas e compridas que os demais híbridos. As diferenças entre e dentro de espécies são devidas a características como tamanho de folhas e ângulo de inserção entre a folha e caule, que afetam a estrutura da pastagem e por conseqüência, o IAF, a IL refletindo em alterações na taxa de acúmulo de forragem (Cooper, 1983).

A princípio era de se esperar que os maiores AF apresentados pelo intervalo de corte de 6 semanas em relação ao de 4 semanas (Tabela 4) decorressem da diferença entre os intervalo de tempo para a rebrota, assim como o relatado por Parsons \& Penning (1988) que ao avaliarem azevém perene (Lolium perenne L.) sob diferentes intervalos de pastejo, observaram que quando se mudou de intervalos curtos (12 - 13 dias) para intervalos médios (19 - 23 dias) e longos (30 - 34 dias), a quantidade de massa seca acumulada aumentou, mas as taxas médias de acúmulo não foram aumentadas. No entanto, os valores das TMDAF dos intervalos entre corte (Tabela 5) evidenciam que os maiores AF para o intervalo de 6 semanas (Tabela 4) foram devidos não apenas ao maior intervalo de tempo para a rebrota das plantas, mas à associação desse fator com uma maior TMDAF. Esse fator seria um indicativo de que mesmo após 42 dias de crescimento, as plantas ainda estariam na fase linear da curva da curva sigmóide de crescimento (Rodrigues \& Rodrigues, 1987) e acumulando massa mais rapidamente do que as plantas cortadas a cada 4 semanas. Uma possível justificativa 
para este padrão de crescimento estaria na maior dose de $\mathrm{N}$ aplicada por corte no intervalo de 6 semanas em relação ao intervalo de 4 semanas para a obtenção de uma mesma dose de $\mathrm{N}$ total ao final do ano de produção. A alta responsividade das gramíneas tropicais à adição de $\mathrm{N}$ ao sistema (Corsi \& Nussio, 1993), a maior eficiência de conversão de $\mathrm{N}$ aplicado apresentada por maiores intervalos de desfolha (VicenteChandler et al., 1959) associadas ao incremento em massa e comprimento dos colmos promovido pelo N (Nascimento et al., 1980; Wilman \& Wringht, 1983) possibilitariam a ocorrência de maiores taxas de acúmulo.

A amplitude de valores de TMDAF (Tabela 5) é semelhante ao relatado na literatura para os capins do gênero por Carnevalli \& Da Silva (1999) que pastejando Coastcross a cada 3 - 4 semanas obtiveram 60,1; 79,5 e 40,7 kg MS ha ${ }^{-1}$ dia $^{-1}$ para o ano todo, o "verão" e o "inverno" respectivamente, ou por Hill et al. (1996) que em um ensaio de três anos de duração com Tifton 85 adubado com $200 \mathrm{~kg} \mathrm{~N} \mathrm{ha}^{-1}$ ano $^{-1}$ obteve acúmulos diários de 51,0 $\mathrm{kg} \mathrm{MS} \mathrm{ha}^{-1} \mathrm{dia}^{-1}$, o que demonstra a coerência dos dados.

\subsection{Distribuição estacional}

A distribuição estacional do acúmulo de forragem apresentou o mesmo padrão em ambos os intervalos entre cortes, com aproximadamente $73 \%$ da produção se concentrando no "verão", e $27 \%$ no "inverno". O único efeito constatado foi o de cultivar dentro da estação, com $\mathrm{P}=0,0049$ no "verão" e $\mathrm{P}=0,0041$ no "inverno", (Figura $6)$.

Dentre os cultivares, Tifton 85 apresentou o AF mais estacional, concentrando sua produção no "verão", com Estrela demonstrando um padrão intermediário e Coastcross, Florico e Florona apresentando-se menos estacionais. Este resultado se assemelha ao relatado por Carvalho (2000) e Pinto (2000) que reportaram que Tifton 85 apresentou estacionalidade de produção mais acentuada do que Coastcross e Florakirk. 
(a)

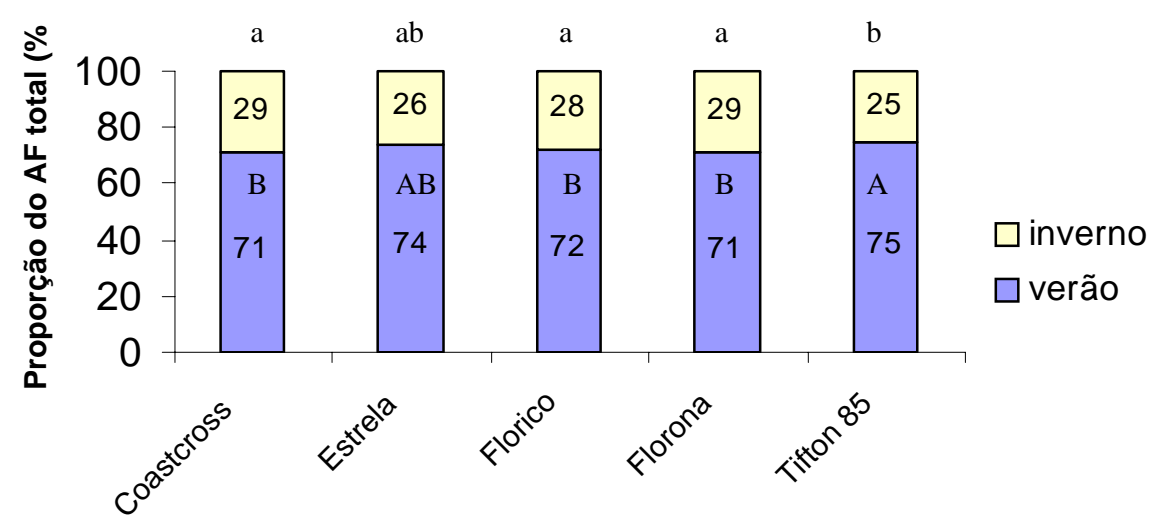

Cultivar

(b)

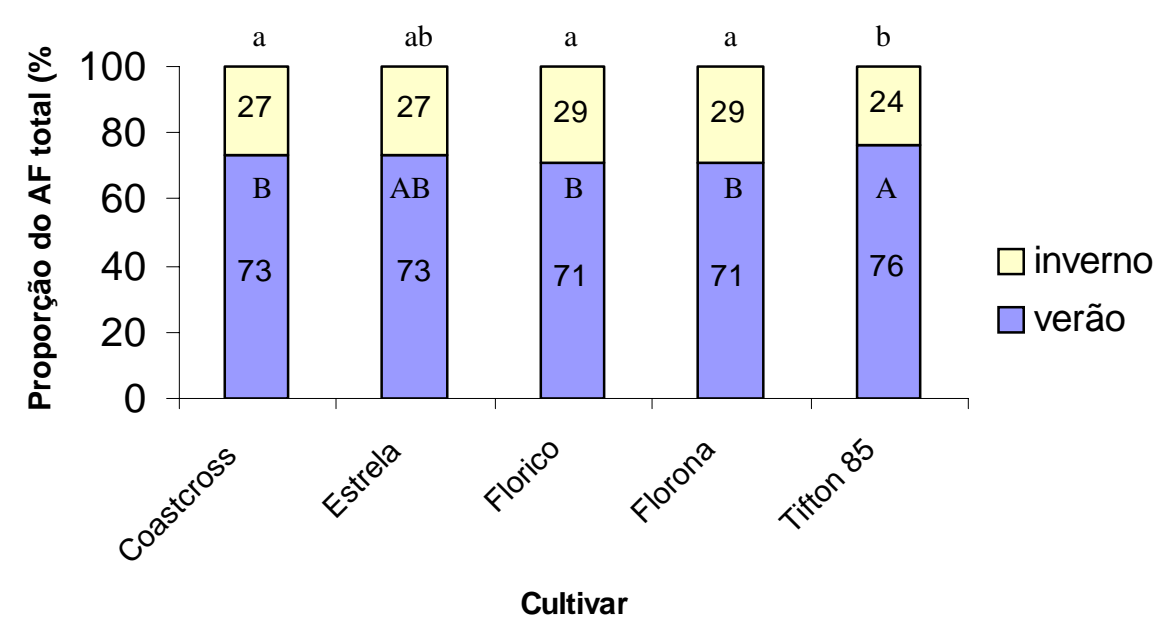

Figura 6 - Distribuição estacional de Cynodon spp. sob um intervalo de cortes de (a) 4 semanas e (b) 6 semanas

A maior estacionalidade apresentada por Tifton 85 se deve provavelmente a uma maior responsividade deste cultivar às variações estacionais nos fatores climáticos que condicionam o crescimento das plantas, marcadamente a temperatura e o fotoperíodo, características fisiológicas geneticamente determinadas (Rodrigues \& 
Rodrigues, 1987). Um indicativo dessa condição fisiológica diferenciada, seria a dormência apresentada por Tifton 85 nas condições de inverno americanas (Hill et al., 1996), e que não ocorre na maioria dos outros cultivares de Cynodon. Desta forma, a "estação" de crescimento para Tifton 85 seria menor, pois ele responderia mais cedo à chegada do "inverno" e demoraria mais tempo para retomar o crescimento no início do “verão". Os dados de Evers et al. (1996; citados por Corsi \& Martha Jr., 1998) reforçam esta idéia, pois Tifton 85 produziu na primavera (início da estação de crescimento) apenas 6,3\% da produção anual total, ao passo que os demais cultivares de Cynodon apresentaram mais de $12,5 \%$ de sua produção nessa mesma época.

As diferenças de "interpretação" dos parâmetros climáticos pelo cultivares também é evidenciada no estudo conduzido por Mislevy et al. (2001) em que Tifton 85, Florona e outros capins sub-tropicais foram submetidos a dois regimes de fotoperíodo, um, no qual o número de horas de luz variava naturalmente e era restritivo ao crescimento (sempre inferior a 15h/dia) e outro estendido artificialmente para $15 \mathrm{~h}$ diárias de luz, Tifton 85 apresentou produção $46 \%$ maior sob fotoperíodo estendido do que sob fotoperíodo natural, enquanto Florico apesar de também ter se mostrado sensível apresentou uma produção somente $22 \%$ maior.

'tMannetje e Pritchard (1974) estudando os efeitos do fotoperíodo e da oscilação da temperatura diurna/noturna sobre a produtividade de gramíneas tropicais verificaram que gramíneas crescendo sob um fotoperíodo maior (14h) apresentaram maior produtividade do que as que cresciam em fotoperíodos menores $(11 \mathrm{~h})$, mas o efeito da temperatura foi mais significativo, levando os autores a concluir que a associação de baixas temperaturas com fotoperíodo curtos seriam os causadores da redução de crescimento. 
(a)

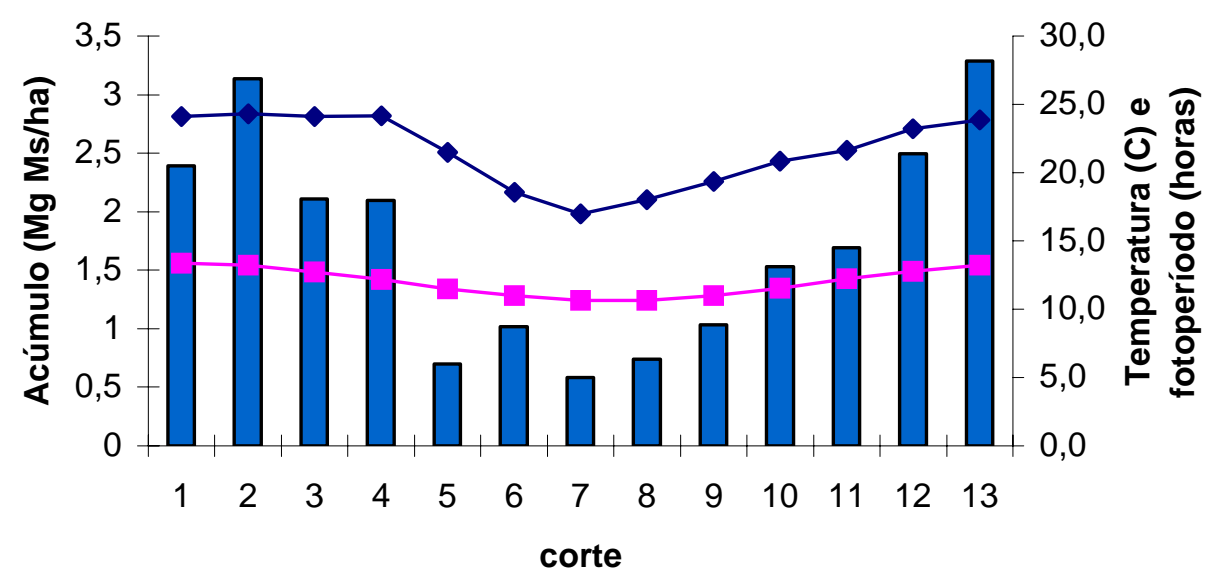

$\square$ acúmulo de forragem (média dos cinco cultivares)
$\rightarrow$ - temperatura
$\rightarrow$ fotoperíodo

(b)

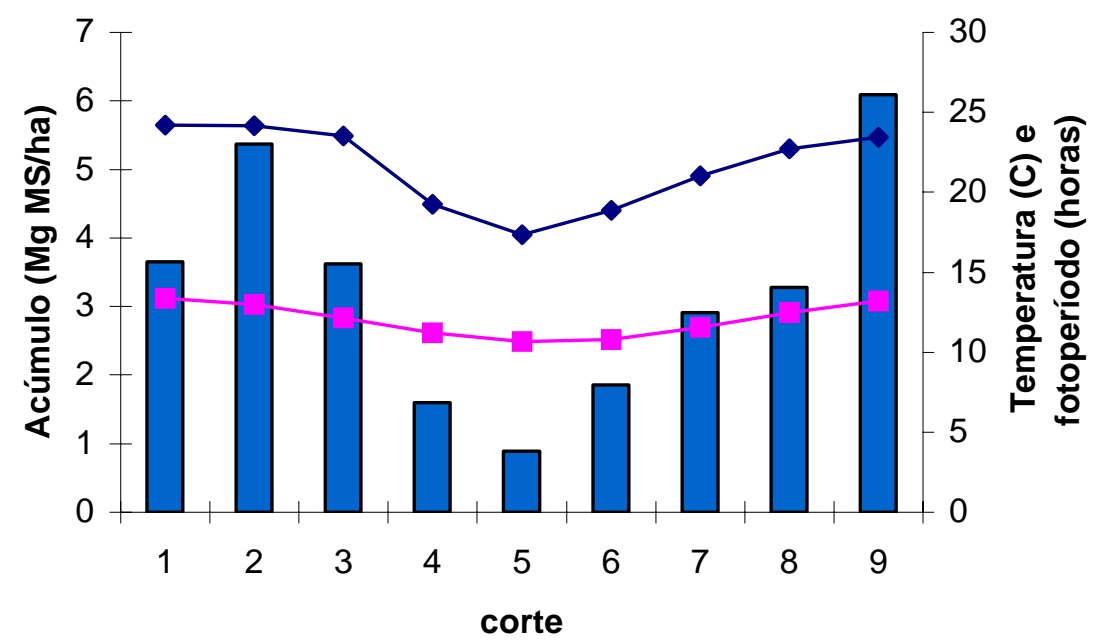

$\square$ acúmulo de forragem (média dos cinco cultivares)
$\rightarrow$ temperatura
$\rightarrow$ fotoperíodo

Figura 7 - Variação estacional no acúmulo de forragem, temperatura e fotoperíodo no decorrer do período experimental para plantas do gênero Cynodon spp. sob um intervalo de cortes de (a) 4 semanas e (b) 6 semanas 
A grande maioria dos capins tropicais concentra a sua produção em alguns meses do ano, o que pode ser facilmente observado em trabalhos como o de Ghelfi Filho (1972) com capim Napier (Pennisetum purpureum Schum.) que mesmo sob

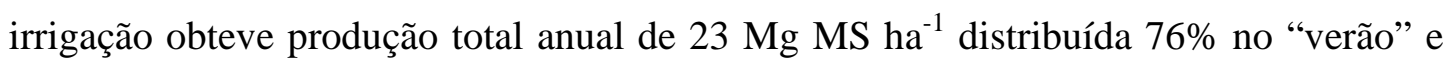
$24 \%$ no "inverno", ou no trabalho de Pedreira (1972) que avaliando o crescimento estacional dos capins Colonião (Panicum maximum Jacq.), Gordura (Melinis minutiflora Pal de Beauv.), Jaraguá (Hyparrhenia rufa [Ness] Stapf.) e Pangola de Taiwan A-24 (Digitaria pentzii Stent.), obteve 91, 84, 94 e 92\% das respectivas produções totais de matéria seca no "verão", este fato faz com que a produção animal seja limitada (Corsi, 1990) e se configura em um dos maiores empecilhos ao desenvolvimento da agropecuária brasileira (Rolim, 1980). Entretanto, a distribuição estacional das plantas do gênero Cynodon avaliadas no presente estudo (Figura 6) apresentaram uma menos concentradas ao longo do ano, assim como o relatado por Pedreira \& Mattos (1981) e por Evers et al. (1996) citados por Corsi \& Martha Jr. (1998), o que é um fator extremamente positivo, pois gera menores déficits entre as diferentes estações e possibilita a obtenção de maiores produções.

\subsection{Temperatura base inferior (TBi)}

A existência de temperaturas que limitam o crescimento das forrageiras já é um conceito bastante antigo, citado por diversos autores como Cooper \& Tainton (1968), Mc William (1978), Pedro Jr. et al. (1990) e Rocha (1991). Para plantas tropicais, o limite superior, temperatura base superior (TBs) é de pouca importância, já que o valor de temperatura que limitaria o crescimento seria bastante alto e por tanto, dificilmente factível em ambientes naturais de pastagens cultivadas. Já a temperatura base inferior (TBi) assume grande importância, pois temperaturas limitantes podem ocorrer em determinadas épocas do ano. 
Os valores exatos da TBi no entanto, têm gerado controvérsias, existindo citações "generalistas" indicando faixas como 10 a $15^{\circ} \mathrm{C}$ (Cooper \& Tainton, 1968), ou valores pontuais como $10^{\circ} \mathrm{C}$ (Rio Grande do Sul, 1975), $15^{\circ} \mathrm{C}$ (Mc William, 1978) ou $17^{\circ} \mathrm{C}$ (Costa, 1984) para forrageiras tropicais, e citações "específicas" como $10^{\circ} \mathrm{C}$ para capim elefante (Pennisetum purpureum Schum.) (Jacques, 1994) ou $10^{\circ} \mathrm{C}$ para Panicum virgatum (L.) (Sanderson \& Wolf, 1995). Tais valores, são as vezes gerados empiricamente, sem um método de determinação explícito. Há em outros casos, referências com $10^{\circ} \mathrm{C}$ para forrageiras tropicais (Pedro Jr. et al., 1990) e $13^{\circ} \mathrm{C}$ para capim elefante (Pennisetum purpureum Schum.) (Medeiros et al., 2002) que se basearam em diferentes métodos para determinar esses valores, mas fazem inferência apenas às espécies em questão, restringindo a utilidade da temperatura gerada em si, mas validando o método empregado. Em função disso, e da inexistência de TBi específicas para o gênero ou as espécies em questão na literatura, estes valores foram gerados (Figura 8).

As TBi obtidas (Figura 8) estiveram dentro da faixa proposta por Cooper \& Tainton (1968) mas se diferenciaram de qualquer valor pontual anteriormente relacionado na literatura, e principalmente apresentaram diferenças de até $13 \%$ entre os cultivares estudados demonstrando a grande individualidade dessa característica dentro de uma mesma espécie, e a possibilidade de erro em que se incorre quando se adotam valores arbitrários. Este fato também é um indicativo da grande variabilidade entre as diferentes espécies, já que cada espécie ou cultivar dentro de espécie, em função da interação existente entre genótipo e ambiente (clima) da região da qual ele se origina apresenta um diferente valor de TBi (Alcântara et al., 1993; Rodrigues et al., 1993). 
Tifton 85

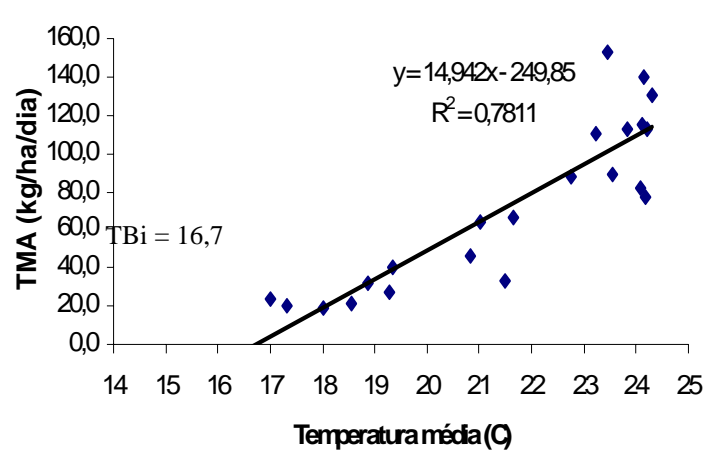

Estrela

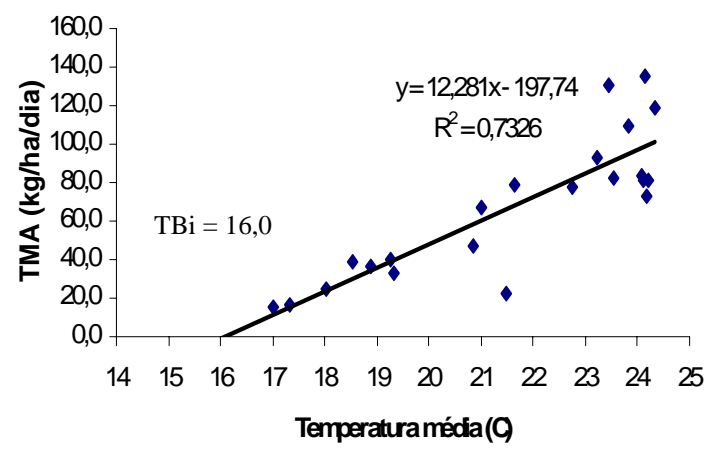

Coastcross

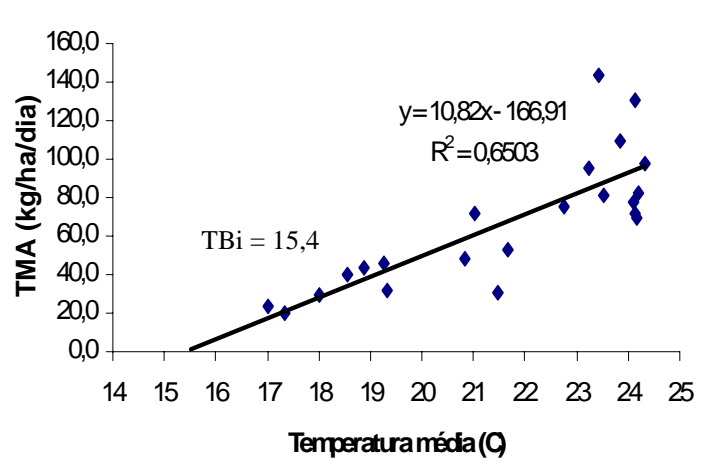

Porico

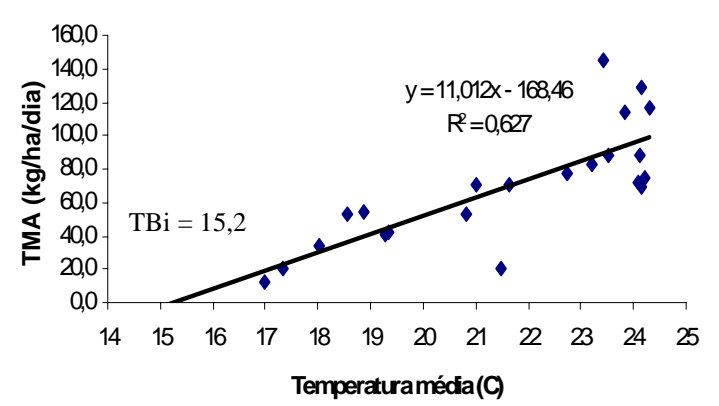

Porona

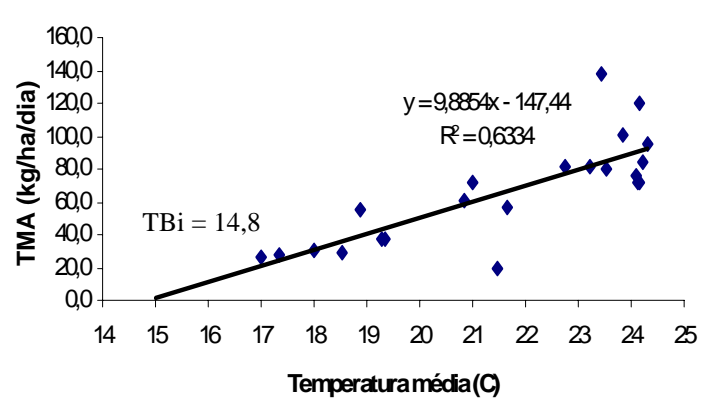

Figura 8 - Temperatura base inferior, e a correlação entre TMADF a temperatura média do ar em cada uma das rebrotas para os cinco cultivares de Cynodon spp 


\subsection{Graus-dia (GD) e unidade fototérmica (UF)}

Tabela 6. Graus-dia para os cinco cultivares de Cynodon spp a cada período de rebrota

\begin{tabular}{|c|c|c|c|c|c|}
\hline Data & Tifton 85 & Estrela & Coastcross & Florico & Florona \\
\hline & \multicolumn{5}{|c|}{ GD } \\
\hline & \multicolumn{5}{|c|}{4 semanas } \\
\hline 18/01/01 & 206,46 & 225,78 & 244,26 & 249,30 & 261,62 \\
\hline $15 / 02 / 01$ & 211,94 & 231,26 & 249,74 & 254,78 & 267,10 \\
\hline $14 / 03 / 01$ & 198,29 & 216,92 & 234,74 & 239,60 & 251,48 \\
\hline $12 / 04 / 01$ & 215,06 & 235,07 & 254,21 & 259,43 & 272,19 \\
\hline $10 / 05 / 01$ & 148,05 & 165,40 & 182,89 & 187,82 & 187,61 \\
\hline 07/06/01 & 80,78 & 94,86 & 109,39 & 113,53 & 123,98 \\
\hline 06/07/01 & 65,04 & 76,96 & 89,29 & 92,82 & 101,72 \\
\hline 02/08/01 & 73,30 & 85,25 & 97,52 & 101,00 & 109,79 \\
\hline $30 / 08 / 01$ & 101,67 & 115,60 & 129,76 & 133,77 & 143,81 \\
\hline $29 / 09 / 01$ & 139,78 & 157,83 & 176,12 & 181,28 & 194,22 \\
\hline $25 / 10 / 01$ & 142,62 & 145,33 & 162,49 & 167,17 & 178,61 \\
\hline $21 / 11 / 01$ & 174,72 & 193,35 & 211,17 & 216,03 & 227,91 \\
\hline \multirow[t]{2}{*}{$21 / 12 / 01$} & 212,66 & 233,36 & 253,16 & 258,56 & 271,76 \\
\hline & \multicolumn{5}{|c|}{6 semanas } \\
\hline $01 / 02 / 01$ & 313,36 & 342,34 & 370,06 & 377,62 & 396,10 \\
\hline $14 / 03 / 01$ & 303,33 & 331,62 & 358,68 & 366,06 & 384,10 \\
\hline $26 / 04 / 01$ & 291,86 & 321,53 & 349,91 & 357,65 & 376,57 \\
\hline $07 / 06 / 01$ & 145,12 & 167,28 & 189,94 & 196,37 & 212,55 \\
\hline 19/07/01 & 102,90 & 120,55 & 138,74 & 143,92 & 156,98 \\
\hline $30 / 08 / 01$ & 136,61 & 156,86 & 177,53 & 183,39 & 198,12 \\
\hline $11 / 10 / 01$ & 200,07 & 226,13 & 252,56 & 260,02 & 261,68 \\
\hline $21 / 11 / 01$ & 245,64 & 273,93 & 300,99 & 308,37 & 326,41 \\
\hline 03/01/02 & 287,49 & 317,16 & 345,54 & 353,28 & 372,20 \\
\hline
\end{tabular}


Tabela 7. Unidades fototérmicas (UF) para os cinco cultivares de Cynodon spp. a cada período de rebrota

\begin{tabular}{|c|c|c|c|c|c|}
\hline Data & Tifton 85 & Estrela & Coastcross & Florico & Florona \\
\hline & \multicolumn{5}{|c|}{$\mathbf{U F}$} \\
\hline & \multicolumn{5}{|c|}{4 semanas } \\
\hline $18 / 01 / 01$ & 5023,94 & 6000,55 & 7015,18 & 7305,54 & 8039,92 \\
\hline $15 / 02 / 01$ & 4848,21 & 5754,65 & 6692,92 & 6960,87 & 7637,60 \\
\hline $14 / 03 / 01$ & 4080,95 & 4863,92 & 5675,48 & 5907,42 & 6493,45 \\
\hline $12 / 04 / 01$ & 4633,69 & 5510,00 & 6417,11 & 6676,15 & 7330,33 \\
\hline $10 / 05 / 01$ & 2292,38 & 2846,29 & 3463,86 & 3648,33 & 3640,49 \\
\hline 07/06/01 & 741,91 & 1018,31 & 1348,44 & 1450,90 & 1725,76 \\
\hline 06/07/01 & 531,28 & 743,97 & 1001,81 & 1082,49 & 1300,21 \\
\hline 02/08/01 & 740,09 & 1005,70 & 1321,58 & 1419,41 & 1681,52 \\
\hline $30 / 08 / 01$ & 1533,20 & 1994,89 & 2528,14 & 2690,65 & 3121,16 \\
\hline 29/09/01 & 3035,33 & 3897,25 & 4883,89 & 5183,08 & 5972,85 \\
\hline $25 / 10 / 01$ & 3015,65 & 3134,12 & 3937,78 & 4173,23 & 4778,24 \\
\hline $21 / 11 / 01$ & 4379,74 & 5382,41 & 6439,93 & 6745,08 & 7521,28 \\
\hline \multirow[t]{2}{*}{$21 / 12 / 01$} & 5992,96 & 7225,84 & 8513,75 & 8883,45 & 9820,49 \\
\hline & \multicolumn{5}{|c|}{6 semanas } \\
\hline $01 / 02 / 01$ & 10722,11 & 12763,42 & 14879,60 & 15484,46 & 17012,93 \\
\hline $14 / 03 / 01$ & 8598,41 & 10218,17 & 11893,53 & 12371,74 & 13579,02 \\
\hline $26 / 04 / 01$ & 7553,93 & 9099,97 & 10707,57 & 11167,74 & 12331,68 \\
\hline 07/06/01 & 2167,47 & 2858,82 & 3661,96 & 3907,43 & 4558,87 \\
\hline $19 / 07 / 01$ & 1387,00 & 1907,61 & 2531,41 & 2725,38 & 3246,53 \\
\hline $30 / 08 / 01$ & 3027,10 & 4029,51 & 5206,50 & 5568,53 & 6533,86 \\
\hline $11 / 10 / 01$ & 6976,05 & 9000,39 & 11327,05 & 12034,25 & 12195,15 \\
\hline $21 / 11 / 01$ & 9715,59 & 12159,79 & 14762,17 & 15516,98 & 17443,66 \\
\hline 03/01/02 & 10826,54 & 13190,09 & 15670,31 & 16383,99 & 18195,82 \\
\hline
\end{tabular}




\subsection{Ajuste dos modelos de estimativa de acúmulo de matéria seca}

Com base nos dados de acúmulo de forragem por corte e nos valores de GD e UF calculados para cada rebrota foram parametrizados modelos para todos os níveis de agregação (combinações possíveis entre as duas variáveis climáticas, os cinco cultivares e os dois intervalos entre cortes). Assim sendo, ajustaram-se modelos de GD e UF para cada cultivar em cada uma das freqüências, para cada cultivar independentemente da frequiência, para cada freqüência independentemente do cultivar e modelos genéricos, para a média dos cultivares e das freqüências (Tabela 8, 9,10 e 11).

Tabela 8. Modelos de GD e UF para a média de todos os cultivares e intervalos

\begin{tabular}{rcccccc}
\hline Modelo & intercepto & $\begin{array}{c}\text { Coeficiente } \\
\text { angular }\end{array}$ & uf ufsq & $\mathbf{R}^{2}$ & RMSE & $\mathbf{C V}$ \\
\hline GD TOTAL & $\mathbf{M g ~ h \mathbf { ~ } ^ { - 1 }}$ & & & $\mathbf{\%}$ & $\mathbf{M g ~ h a}^{-\mathbf{1}}$ & $\mathbf{\%}$ \\
UF TOTAL & 0,62398 & 0,00482 & - & 0,6969 & 0,26971 & 18,5 \\
\hline
\end{tabular}


Tabela 9. Modelos de GD e UF para a média de todos os cultivares em cada um dos intervalos

\begin{tabular}{lcccccc}
\hline Modelo & intercepto & $\begin{array}{c}\text { Coeficiente } \\
\text { angular }\end{array}$ & uf ufsq & $\mathbf{R}^{\mathbf{2}}$ & RMSE & CV \\
\hline \multirow{2}{*}{ GD 4 sem } & $\mathbf{M g ~ h a}^{\mathbf{- 1}}$ & & & $\mathbf{\%}$ & $\mathbf{M g ~ h a}^{\mathbf{- 1}}$ & $\mathbf{\%}$ \\
GD 6 sem & 0,42932 & 0,004700 & - & 0,5572 & 0,2572 & 20,3 \\
UF 4 sem & 0,50288 & 0,00462 & - & 0,664 & 0,28577 & 16,5 \\
UF 6 sem & 0,62104 & 0,00019822 & $-8,56 \mathrm{E}-09$ & 0,6045 & 0,24356 & 19,2 \\
\hline
\end{tabular}

Tabela 10. Modelos de GD e UF para cada um dos cultivares na média do intervalos

\begin{tabular}{lcccccc}
\hline \multicolumn{1}{c}{ Modelo } & intercepto & $\begin{array}{c}\text { Coeficiente } \\
\text { angular }\end{array}$ & uf ufsq & $\mathbf{R}^{2}$ & RMSE & CV \\
\hline \multirow{2}{*}{ GD Florico } & $\mathbf{M g ~ h a} \mathbf{~}^{-1}$ & & & $\mathbf{\%}$ & $\mathbf{M g ~ h a}^{-1}$ & $\mathbf{\%}$ \\
GD Florona & 0,38217 & 0,00477 & - & 0,6851 & 0,27802 & 18,9 \\
GD Estrela & 0,347923 & 0,00444 & - & 0,7441 & 0,23134 & 15,9 \\
GD Coastcross & 0,36631 & 0,00543 & - & 0,7747 & 0,23455 & 16,3 \\
GD Tifton & 0,26828 & 0,00671 & - & 0,8264 & 0,22959 & 15,4 \\
UF Florico & 0,60369 & 0,00017126 & $-4,96 \mathrm{E}-09$ & 0,7064 & 0,27001 & 18,4 \\
UF Florona & 0,63447 & 0,00013718 & $-3,09 \mathrm{E}-09$ & 0,7923 & 0,20964 & 14,5 \\
UF Estrela & 0,57159 & 0,00022012 & $-8,08 \mathrm{E}-09$ & 0,7824 & 0,2319 & 16,1 \\
UF Coastcross & 0,65807 & 0,00015332 & $-3,82 \mathrm{E}-09$ & 0,7898 & 0,21567 & 14,9 \\
UF Tifton & 0,57157 & 0,00026548 & $-9,96 \mathrm{E}-09$ & 0,8372 & 0,22364 & 15,0 \\
\hline
\end{tabular}


Tabela 11. Modelos de GD e UF para cada um dos cultivares em cada um dos intervalos

\begin{tabular}{|c|c|c|c|c|c|c|}
\hline Modelo & intercepto & $\begin{array}{c}\text { Coeficiente } \\
\text { angular }\end{array}$ & uf ufsq & $\mathbf{R}^{2}$ & RMSE & $\mathbf{C V}$ \\
\hline & Mg ha $^{-1}$ & & & $\%$ & Mg ha $^{-1}$ & $\%$ \\
\hline \multicolumn{7}{|c|}{ GD } \\
\hline Florico 4 sem & 0,36935 & 0,00479 & - & 0,5230 & 0,2817 & 22,1 \\
\hline Florona 4sem & 0,38143 & 0,0043 & - & 0,6427 & 0,20154 & 16,3 \\
\hline Estrela 4sem & 0,31936 & 0,00566 & - & 0,6569 & 0,23978 & 18,9 \\
\hline Coastcross $4 \mathrm{sem}$ & 0,40491 & 0,00458 & - & 0,6680 & 0,19669 & 15,8 \\
\hline Tifton 4 sem & 0,24495 & 0,00701 & - & 0,7432 & 0,22873 & 17,5 \\
\hline Florico 6 sem & 0,44605 & 0,00459 & - & 0,6707 & 0,27978 & 16,0 \\
\hline Florona 6 sem & 0,56128 & 0,00399 & - & 0,6431 & 0,2656 & 15,2 \\
\hline Estrela 6sem & 0,32992 & 0,00544 & - & 0,7898 & 0,23231 & 13,7 \\
\hline Coastcross 6 sem & 0,42333 & 0,00477 & - & 0,7333 & 0,24791 & 14,2 \\
\hline Tifton 6sem & 0,19458 & 0,00690 & - & 0,8448 & 0,23223 & 13,3 \\
\hline \multicolumn{7}{|c|}{ UF } \\
\hline Florico 4 sem & 0,7673 & 0,00006703 & $6,47 \mathrm{E}-09$ & 0,6176 & 0,25477 & 19,9 \\
\hline Florona 4sem & 0,74029 & 0,00007069 & $3,45 \mathrm{E}-09$ & 0,7511 & 0,16991 & 13,7 \\
\hline Estrela 4sem & 0,65541 & 0,00015389 & $1,42 \mathrm{E}-09$ & 0,7289 & 0,21529 & 16,9 \\
\hline Coastcross 4 sem & 0,81122 & 0,00004441 & $8,86 \mathrm{E}-09$ & 0,7781 & 0,16241 & 13,0 \\
\hline Tifton 4 sem & 0,6063 & 0,00021939 & $9,17 \mathrm{E}-10$ & 0,8128 & 0,19724 & 15,0 \\
\hline Florico 6sem & 0,55827 & 0,00019029 & $-6,06 \mathrm{E}-09$ & 0,6514 & 0,29218 & 16,7 \\
\hline Florona 6 sem & 0,7075 & 0,00013497 & $-3,23 \mathrm{E}-09$ & 0,6761 & 0,25682 & 14,7 \\
\hline Estrela 6sem & 0,54137 & 0,00022011 & $-7,91 \mathrm{E}-09$ & 0,7459 & 0,25923 & 15,3 \\
\hline Coastcross 6sem & 0,66935 & 0,00016163 & $-4,49 \mathrm{E}-09$ & 0,6883 & 0,27204 & 15,6 \\
\hline Tifton 6sem & 0,66959 & 0,00017979 & $-2,42 \mathrm{E}-09$ & 0,8334 & 0,24422 & 13,9 \\
\hline
\end{tabular}


De uma maneira geral, todos os modelos tanto para UF quanto para GD apresentaram relações altamente significativas com o acúmulo de matéria seca das planta, e com coeficientes de determinação altos. Os modelos de UF de maneira geral apresentaram coeficientes de determinação superiores aos seu equivalentes (mesmo nível de agregação) com GD, o que indica que a inclusão de fotoperíodo no modelo aumenta a sua capacidade preditória. Resultados semelhantes foram apresentados por Burton et al. (1988) que comparando modelos baseados em GD ou em GD mais o efeito que ele denominou comprimento do dia, na capacidade de prever acúmulo de massa de Coastal (Cynodon dactylon L.), obteve os maiores coeficientes de determinação quando o comprimento do dia (fotoperíodo) foi incluído no modelo.

A análise comparativa segundo a método de Seber (1977), entre modelos conceitualmente semelhantes (modelos de GD comparados entre si, e modelos de UF comparados entre si, não realizando comparações entre modelos das duas unidades climáticas) demonstrou que os modelos gerados não são coincidentes para um grau de significância de 5\%, ou seja, diferenciam-se uns dos outros (a exceção dos modelos para a média dos cultivares em cada um dos intervalos de corte que mostraram-se coincidentes, indicando que a utilização de um modelo específico para um determinado cultivar em um determinado intervalo de tempo de crescimento forneceria melhores estimativas do que a utilização de modelos genéricos para os cultivares ou intervalos de crescimento. Isto no entanto, não significa que os modelos genéricos estejam errados, e não possam ser empregados, mas apenas que estes geram uma estimativa menos exatas da resposta que se está sendo modelada quando comparada com os modelos específicos.

Por outro lado, o grande número de observações utilizadas na parametrização dos modelos e o grande número de graus de liberdade do resíduo, tornou o teste aplicado extremamente sensível, o que possibilitou a detecção de diferenças sutis e a conseqüente diferenciação de modelos de grande semelhança no caso dos modelos de UF para os diferentes cultivares em cada um dos intervalos de corte. Este rigor pode ser desvantajoso, fazendo com que ferramentas valiosas como modelos mais genéricos, de aplicação mais ampla sejam descartados em troca de modelos mais específicos, mas de aplicação mais restrita, o que é prejudicial quando se atenta o aspecto prático dessa 
ferramenta. Portanto, em função da não diferenciação dos modelos de GD entre intervalos de corte, e vislumbrando vantagens de aplicação prática para estes mesmos modelos baseados em UF, foram gerados modelos para grupos de cultivares (Tabela 12).

Tabela 12. Modelos de GD e UF para grupo de cultivares

\begin{tabular}{lcccccc}
\hline \multicolumn{1}{c}{ Modelo } & intercepto & gd/uf & uf ufsq & $\mathbf{R}^{2}$ & RMSE & CV \\
\hline & Mg ha $^{-1}$ & & & \% & Mg ha $^{-1}$ & $\%$ \\
sem Tifton & 0,03973 & 0,00473 & - & 0,7243 & 0,24934 & 17,17982 \\
sem Tifton, Estrela & 0,38613 & 0,00465 & - & 0,7272 & 0,24557 & 16,88248 \\
Coastcross, Florona & 0,38666 & 0,0046 & - & 0,7535 & 0,22831 & 15,76309 \\
Coastcross, Florico & 0,37466 & 0,00482 & - & 0,731 & 0,24845 & 17,03931 \\
Florico, Florona & 0,3899 & 0,00457 & - & 0,7048 & 0,25757 & 17,67422 \\
Estrela, Tifton & 0,33698 & 0,00588 & - & 0,7696 & 0,24999 & 17,06945 \\
& & UF & & & & \\
sem Tifton & 0,62814 & 0,00016635 & $-4,70 \mathrm{E}-09$ & 0,744 & 0,24061 & 16,57792 \\
sem Tifton, Estrela & 0,63448 & 0,00015353 & $-3,95 \mathrm{E}-09$ & 0,7523 & 0,23444 & 16,11731 \\
Coastcross, Florona & 0,64628 & 0,0001461 & $-3,54 \mathrm{E}-09$ & 0,7817 & 0,21545 & 14,87542 \\
Coastcross, Florico & 0,62949 & 0,00016309 & $-4,46 \mathrm{E}-09$ & 0,7451 & 0,24253 & 16,6339 \\
Florico, Florona & 0,62493 & 0,00015214 & $-3,89 \mathrm{E}-09$ & 0,7377 & 0,24352 & 16,70973 \\
Estrela, Tifton & 0,55354 & 0,00025549 & $-1,04 \mathrm{E}-08$ & 0,7851 & 0,24217 & 16,53553 \\
\hline
\end{tabular}

A comparação entre os modelos para os grupos de cultivares indicou que para GD, Coastcross, Florico e Florona foram coincidentes $(\mathrm{P}=0,7290)$, podendo-se empregar um único modelo na realização de estimativas de produção dos três cultivares. Tifton 85 e Estrela apresentaram modelos diferentes dos demais e entre si, indicando a 
existência de um modelo melhor descritor do que o genérico. Para os modelos para UF as comparações apresentaram coincidência apenas para Coastcross e Florico $(\mathrm{P}=0,5120)$ que por tanto possibilitariam o emprego de um modelo comum, sendo os demais não coincidentes.

\subsection{Proteína Bruta (PB)}

Sobre os teores de $\mathrm{PB}$ houve efeito de cultivar $(\mathrm{P}=0,0001)$ e intervalo entre cortes $(\mathrm{P}=0,0001)$ tanto na "estação completa" como no "verão", com Coastcross apresentando menores teores de proteína do que os demais cultivares e o intervalo de 4 semanas gerando teores superiores àqueles no intervalo de 6 semanas. Para o "inverno" detectou-se efeito apenas do intervalo entre cortes $(\mathrm{P}=0,0001)$ com um padrão de respostas similar aos demais (Tabela 13).

Tabela 13. Teores médios de proteína bruta de forragem de Cynodon spp. em três estações

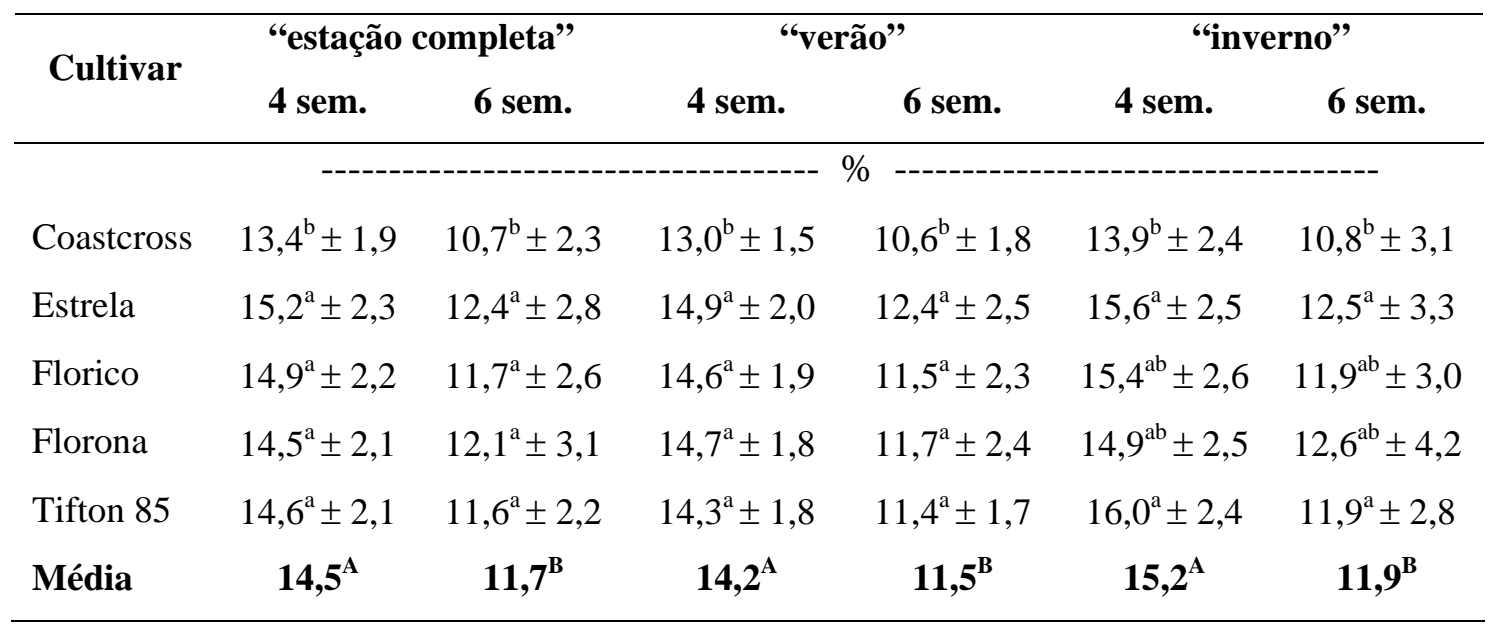

Médias nas colunas seguidas de mesma letra minúscula, e na última linha dentro de estação, seguidas de mesma letra maiúscula não diferem entre si ( $\mathrm{P}>0,05)$.

Nas três estações, os valores de PB obtidos foram superiores aos 6 a 7\% indicados por Minson, (1990) como o teor médio de plantas de ciclo fotossintético $\mathrm{C}_{4}$, e 
ao 7\% citados por Gomide \& Queiroz (1994) como o teor crítico abaixo do qual a atividade dos microrganismos ruminais é deprimida, causando diminuição nas taxas de digestão e passagem do alimento e conseqüentemente no consumo voluntário de forragem (Euclides, 1995).

De maneira geral, os teores constatados superaram ou ao menos se aproximaram dos $12 \%$ indicados por Reis, et al. (2003) como suficientes para o atendimento das exigências da maior parte das categorias de bovinas, e se posicionaram dentro da faixa de 11 a $14 \%$ de PB apresentados pelo $\operatorname{NRC}(1989,1996)$ como necessários à engorda de novilhos e produção de $17 \mathrm{~kg}$ diários de leite (com 4\% de gordura).

A análise comparativa entre os teores médios de PB nas estações ("estação completa", "verão" e "inverno") revelou diferenças $(\mathrm{P}=0,0030)$ entre as mesmas, com maiores teores de PB no "inverno" (13,5\%) do que no "verão" (12,8\%), e um valor intermediário (não diferenciável nem do "verão" nem do "inverno") quando se considera a "estação completa" (13,1\%). Esta diferença entre estações é considerada normal, sendo atribuída à diluição da quantidade de PB na forragem em função das maiores taxas de acúmulo de forragem no verão (Minson, 1990), marcadamente do componente haste (Santos, 1997), que são acompanhadas elevação nos teores de compostos estruturais (celulose, hemicelulose e lignina) e da diminuição no teor do conteúdo celular (Reis et al., 2003), porção onde se encontra a maior parte da proteína da forragem. Soria (2002) em um experimento com Tanzânia (Panicum maximum (Jacq.) cv. Tanzânia 1) adubado com nitrogênio e submetido a diferentes lâminas de irrigação também relata ter havido uma diluição da PB em função da maior produção de massa no "verão", e uma concentração da PB no "inverno" em função da diminuição nas taxas de crescimento.

Em relação aos intervalos entre cortes, o menor intervalo (4 semanas) gerou consistentemente maiores teores de PB do que o maior intervalo (6 semanas). A idade, independentemente do cultivar, foi o principal fator a influenciar a queda nos teores protéicos, assim como o relatado por Gomide (1996) para cinco cultivares de Cynodon (Tifton 85, Tifton 68, Florico, Florona e Florakirk) cortados em cinco diferentes idades $(14,28,42,56$ e 70 dias de crescimento). Este padrão pode ser considerado normal, já 
que a maior parte das espécies forrageiras apresenta um declínio em suas variáveis qualitativas com o aumento da idade (Nussio et al.,1998) que segundo Gomide (1976) pode ser atribuído à diluição destes componentes em uma maior massa de forragem acumulada com o tempo, associada à diminuição na atividade metabólica da planta que leva à menor síntese de compostos nitrogenados em comparação com idades mais jovens (Fisher et al.,1995). A maior dose de nitrogênio por corte aplicada no intervalo de 6 semanas apesar de influenciar na TMDAF não deve ter modificado os resultados de $\mathrm{PB}$, pois apesar de o $\mathrm{N}$ promover um crescimento mais rápido da planta (Corsi \& Nussio, 1994) e o incremento no diâmetro e comprimento do internódios (Wilman \& Wringht, 1983) (fatores que acelerariam o acúmulo de componentes estruturais e reduziriam os teores de $\mathrm{PB}$ ) a aplicação de maiores quantidades de $\mathrm{N}$ também promoveria maior acúmulo de folhas (componente estrutural mais rico em PB; Euclides, 1995) e conseqüentemente aumentos nos teores de PB (Gomide \& Queiroz, 1994).

Os valores medidos nos diversos tratamentos são coerentes com os apresentados na literatura, sendo semelhantes aos valores citados por Pedreira (1995) para Florakirk $(13,2 \%)$ e para Tifton 85 (12,2\%), por Castro et al. (1999) para Florico cortado aos 30 dias $(15,6 \%)$ e ao 40 dias $(15,03 \%)$ e por Alvim et al. (1996) que com Coastcross adubado com $250 \mathrm{~kg} \mathrm{~N} \mathrm{ha}^{-1}$ e cortado a 4 e 6 semanas obteve respectivamente 13,6 e 10,9\% PB nas "águas" e 13,1 e 14,9\% nas "secas".

\subsection{Fibra em Detergente Neutro (FDN)}

Houve efeito de cultivar na "estação completa" ( $\mathrm{P}=0,0001)$, "verão" $(\mathrm{P}=0,0001)$, e "inverno" ( $\mathrm{P}=0,0004)$. Também houve efeito de intervalo entre cortes $(\mathrm{P}=0,0001)$ nas três estações de crescimento, sem diferença entre elas $(\mathrm{P}=0,8430)$ (Tabela 14). 
Tabela 14. Teores médios de FDN em Cynodon spp. em três estações

\begin{tabular}{|c|c|c|c|c|c|c|}
\hline \multirow{2}{*}{ Cultivar } & \multicolumn{2}{|c|}{ “estação completa” } & \multicolumn{2}{|c|}{ “verão” } & \multicolumn{2}{|c|}{ “inverno" } \\
\hline & 4 sem. & 6 sem. & 4 sem. & 6 sem. & 4 sem. & 6 sem. \\
\hline & \multicolumn{6}{|c|}{ 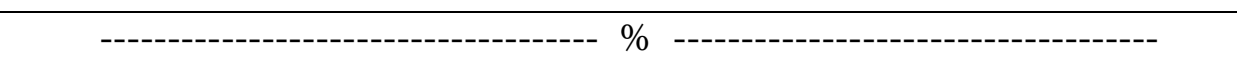 } \\
\hline Coastcross & $65,2^{\mathrm{a}} \pm 2,0$ & $67,8^{\mathrm{a}} \pm 2,0$ & $65,4^{\mathrm{a}} \pm 1,2$ & $67,8^{\mathrm{a}} \pm 2,0$ & $64,9^{\mathrm{a}} \pm 3,0$ & $67,7^{\mathrm{a}} \pm 2,0$ \\
\hline Estrela & $63,5^{\mathrm{b}} \pm 1,4$ & $65,8^{\mathrm{b}} \pm 2,4$ & $63,5^{\mathrm{c}} \pm 1,1$ & $65,5^{\mathrm{c}} \pm 2,2$ & $63,4^{\mathrm{bc}} \pm 2,1$ & $66,2^{\mathrm{bc}} \pm 3,0$ \\
\hline Florico & $62,8^{\mathrm{b}} \pm 1,7$ & $65,4^{\mathrm{b}} \pm 2,2$ & $62,8^{\mathrm{c}} \pm 1,1$ & $65,2^{\mathrm{c}} \pm 2,3$ & $62,7^{\mathrm{c}} \pm 2,9$ & $65,7^{\mathrm{c}} \pm 2,1$ \\
\hline Florona & $63,4^{\mathrm{b}} \pm 1,5$ & $65,8^{\mathrm{b}} \pm 2,5$ & $63,7^{\mathrm{bc}} \pm 1,0$ & $65,9^{\mathrm{bc}} \pm 2,0$ & $63,1^{\mathrm{bc}} \pm 2,5$ & $65,5^{\mathrm{bc}} \pm 3,3$ \\
\hline Tifton 85 & $64,9^{\mathrm{a}} \pm 2,2$ & $67,4^{\mathrm{a}} \pm 2,3$ & $64,8^{\mathrm{ab}} \pm 1,6$ & $67,3^{\mathrm{ab}} \pm 2,0$ & $63,9^{\mathrm{ab}} \pm 2,9$ & $67,5^{\mathrm{ab}} \pm 2,8$ \\
\hline Média & $63,9^{\mathrm{B}}$ & $66,4^{\mathrm{A}}$ & $64,0^{B}$ & $66,4^{\mathrm{A}}$ & $63,6^{\mathrm{B}}$ & $66,5^{\mathrm{A}}$ \\
\hline
\end{tabular}

Médias nas colunas seguidas de mesma letra minúscula, e na última linha dentro de estação, seguidas de mesma letra maiúscula não diferem entre si $(\mathrm{P}>0,05)$.

O teor de FDN da forragem é uma estimativa dos constituintes estruturais (parede celular) que a compõem (Mertens, 1994), podendo atingir níveis entre 30 e $80 \%$ em gramíneas tropicais (Fisher et al., 1995), intervalo no qual se situam os dados coletados nesse experimento.

As plantas do gênero Cynodon são caracterizadas por terem altas proporções de FDN, eventualmente menores que 75\% (Pedreira \& Mello, 2000), o que ocorreu no presente trabalho. Os teores de FDN estiveram um pouco abaixo dos comumente citados na literatura, onde autores como Castro et al. (1999) reportam teores de 65; 73 e $76 \%$ de FDN em forragem de Florico colhida com 20, 40 e 60 dias respectivamente, e Alvim et al. (1996) de 63 a 70,0 nas "águas" e de 65 a 67\% nas "secas" para Coastcross colhido com a intervalos de 4 e 6 semanas de crescimento.

Apesar das pequenas discrepâncias em valores absolutos, os intervalos entre cortes e cultivares tiveram efeito semelhante ao já relatado, com uma clara influência de intervalo nas respostas, ocorrendo um aumento dos teores de FDN com o avanço da idade em função da diminuição na relação folha/haste e do acúmulo de mais componentes estruturais, além de crescente lignificação da parede celular com o passar do tempo (Nussio et al.,1998). Este efeito também foi relatado por Gomide (1996) que 
na média de cinco cultivares de Cynodon registrou teores de 68,3; 74,8;75,8; 81,2 e 80,5\% de FDN nas idades de 14, 28, 42, 56 e 70 dias respectivamente. Quando se observam os dados referentes ao teores de PB (Tabela 13) e FDN (Tabela 14) percebese que o aumento do FDN esta associado ao decréscimo nos teores de PB, estando ambos relacionados à idade da planta, assim como o obtido por Pedreira (1995).

Entre os cultivares Coastcross e Tifton 85 apresentaram os maiores teores de FDN nas três estações de crescimento, e Estrela e Florico os menores teores nas mesmas estações. Florona foi igual a Tifton 85 no "verão" e no "inverno", e igual a Florico e Estrela na "estação completa". As diferenças entre cultivares foram pequenas em todas as estações, e provavelmente decorrentes de atributos genéticos das plantas.

\subsection{Digestibilidade in vitro da matéria orgânica (DIVMO)}

Houve efeito de intervalo entre cortes para a "estação completa", "verão" e “inverno" $(\mathrm{P}=0,0001)$, e de cultivar apenas para a "estação completa" $(\mathrm{P}=0,0234)$ (Tabela 15). A digestibilidade não diferiu entre as estações de crescimento ( $\mathrm{P}=0,4468)$.

Tabela 15. Valores médios de DIVMO em Cynodon spp. em três estações

\begin{tabular}{|c|c|c|c|c|c|c|}
\hline \multirow{2}{*}{ Cultivar } & \multicolumn{2}{|c|}{ “estação completa” } & \multicolumn{2}{|c|}{ “verão” } & \multicolumn{2}{|c|}{ “inverno" } \\
\hline & 4 sem. & 6 sem. & 4 sem. & 6 sem. & 4 sem. & 6 sem. \\
\hline & \multicolumn{3}{|c|}{ 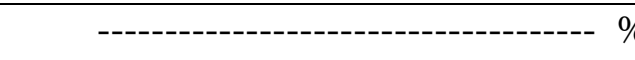 } & & & \\
\hline Coastcross & $63,9^{\mathrm{b}} \pm 2,1$ & $60,5^{\mathrm{b}} \pm 2,4$ & $63,9^{\mathrm{a}} \pm 1,2$ & $60,0^{\mathrm{a}} \pm 2,2$ & $64,0^{\mathrm{a}} \pm 3,3$ & $61,0^{\mathrm{a}} \pm 2,8$ \\
\hline Estrela & $63,5^{\mathrm{ab}} \pm 1,1$ & $61,5^{\mathrm{ab}} \pm 2,0$ & $63,5^{\mathrm{a}} \pm 0,4$ & $61,4^{\mathrm{a}} \pm 1,4$ & $63,5^{\mathrm{a}} \pm 2,0$ & $61,5^{\mathrm{a}} \pm 2,8$ \\
\hline Florico & $64,3^{\mathrm{ab}} \pm 1,3$ & $62,3^{\mathrm{ab}} \pm 2,4$ & $64,3^{\mathrm{a}} \pm 1,3$ & $61,9^{\mathrm{a}} \pm 2,1$ & $64,2^{\mathrm{a}} \pm 2,3$ & $62,8^{\mathrm{a}} \pm 2,9$ \\
\hline Florona & $65,3^{\mathrm{a}} \pm 1,3$ & $63,1^{\mathrm{a}} \pm 2,6$ & $64,9^{\mathrm{a}} \pm 1,1$ & $62,5^{\mathrm{a}} \pm 2,0$ & $65,8^{\mathrm{a}} \pm 2,3$ & $63,8^{\mathrm{a}} \pm 4,1$ \\
\hline Tifton 85 & $64,0^{\mathrm{ab}} \pm 1,0$ & $62,5^{\mathrm{ab}} \pm 3,0$ & $64,2^{\mathrm{a}} \pm 0,9$ & $62,4^{a} \pm 2,5$ & $64,2^{\mathrm{a}} \pm 1,5$ & $62,5^{\mathrm{a}} \pm 3,6$ \\
\hline Média & $64,2^{A}$ & $61,9^{\mathrm{B}}$ & $64,2^{A}$ & $61,6^{B}$ & $64,3^{A}$ & $62,3^{B}$ \\
\hline
\end{tabular}

Médias nas colunas seguidas de mesma letra minúscula, e na última linha dentro de estação, seguidas de mesma letra maiúscula não diferem entre si $(\mathrm{P}>0,05)$. 
A DIVMO dos cultivares sob o mesmo intervalo de corte foi a mesma no "verão" e no "inverno", havendo apenas uma pequena diferença entre Florona e Coastcross quando considerado todo o ano de crescimento ("estação completa"), com maior digestibilidade de Florona. Esta diferença pode ser atribuída em parte aos menores teores de FDN e maiores níveis de PB, indicativos de menor participação de parede celular e maior de conteúdo celular na massa acumulada por Florona em comparação a Coastcross, e ao provável menor teor de FDA apresentado normalmente por esse cultivar quando comparado aos demais cultivares do gênero, conforme o relatado por Gomide (1996). Isso seria um indicativo de uma maior digestibilidade da porção fibra, refletindo na digestibilidade da planta como um todo.

De maneira geral, a DIVMO foi alterada pelo intervalo entre cortes em todas as estações de crescimento onde o intervalo de 4 semanas apresentou consistentemente maiores valores do que 6 semanas, com diferenças de 2,3; 2,6 e 2,0 pontos percentuais entre os intervalos para a "estação completa", o "verão" e o "inverno". As diferenças registradas entre os intervalos decorrem possivelmente em função do aumento na participação de constituintes de parede celular em detrimento de conteúdo celular com o avançar da idade (Reis et al., 2003), o que pode ser observado ao se relacionar os dados de PB (Tabela 13), FDN (Tabela 14) e DIVMO (Tabela 15) em que se nota que com o avançar da idade, ocorreu aumento no FDN associado ao decréscimo na PB e na DIVMO. Alterações na relação haste/folha decorrentes do aumento da idade também podem contribuir para esta diminuição (Van Soest, 1994).

Em função da espécie da planta ou do estádio de maturidade desta, os constituintes da parede celular perfazem de 25 a $85 \%$ de seu peso seco, e a lignina, um polímero fenólico indigestível pode representar de 2 a 20\% desse peso, possuindo uma relação inversa com a digestibilidade (Dove, 1996).

Os valores de DIVMO (Tabela 15) obtidos em todos os tratamentos são bastante superiores aos 55\% indicados como média para gramíneas tropicais (Minson, 1990; Van Soest, 1994) e semelhantes aos 60,0\% apontados para Florico com 4 semanas de crescimento por Mislevy \& Pate (1996) e aos 63,2 e 65,8\% apresentados por Mislevy 
(1989a) para Coastcross e Florico respectivamente, estando superiores aos 56,9\% (Florico) e 52,7\% (Florona) registrados por Larbi et al. (1990) na média de dois anos de coleta.

Era de se esperar que as estações de crescimento apresentassem forragem com diferentes valores de digestibilidade. A taxa de declínio na digestibilidade da MS da forragem com a idade é mais lenta durante os meses frios do que durante os meses quentes (Wilson, 1982b) em função das alterações na temperatura e na luz provocarem diferenças na morfologia ou no tipo de tecido das folhas e caules, gerando alterações na proporção de parede celular e modificando a digestibilidade tanto para a folha como para a haste (Buxton \& Fales, 1994), o que não foi observado nesse estudo. Este fato combinado à não diferenciação dos teores de FDN entre as estações é um indício de que a adoção de diferentes intervalos entre cortes nas diferentes épocas seria desnecessária, o que só é refutado pelo maior teor de proteína apresentados no "inverno".

\subsection{Ajuste dos modelos de estimativa de PB, FDN e DIVMO}

A partir dos valores de PB FDN e DIVMO obtidos em cada rebrota foram parametrizados modelos para todas as combinações possíveis entre as duas variáveis climáticas, os cinco cultivares e os dois intervalos entre cortes (Tabela 16 a 27).

Tabela 16. Modelos de PB com base em GD e UF para média de todos os cultivares e intervalos

\begin{tabular}{lccccccc}
\hline Modelo & intercepto & $\begin{array}{c}\text { Coeficiente } \\
\text { angular }\end{array}$ & uf ufsq & $\mathbf{R}^{\mathbf{2}}$ & Pr $>$ F & RMSE & CV \\
\hline GD Total & 2,8313 & $-0,00088$ & - & 0,1187 & 0,0001 & 0,20219 & 7,6 \\
UF Total & 2,7648 & $-0,00002$ & $2,11 E-10$ & 0,1293 & 0,0001 & 0,20120 & 7,6 \\
\hline
\end{tabular}


Tabela 17. Modelos de FDN com base em GD e UF para média de todos os cultivares e intervalos

\begin{tabular}{lccccccc}
\hline Modelo & intercepto & $\begin{array}{c}\text { Coeficiente } \\
\text { angular }\end{array}$ & uf ufsq & $\mathbf{R}^{2}$ & Pr $>$ F & RMSE & CV \\
\hline & \% FDN & & & & & \% FDN & $\%$ \\
GD Total & 63,3232 & 0,00764 & - & 0,0534 & 0,0001 & 2,72734 & 4,2 \\
UF Total & 64,0051 & 0,00016 & $-1,25 E-09$ & 0,0050 & 0,0001 & 2,73612 & 4,2 \\
\hline
\end{tabular}

Tabela 18. Modelos de DVMO com base em GD e UF para média de todos os cultivares e intervalos

\begin{tabular}{cccccccc}
\hline Modelo & intercepto & $\begin{array}{c}\text { Coeficiente } \\
\text { angular }\end{array}$ & uf ufsq & $\mathbf{R}^{2}$ & Pr $>$ F & RMSE & CV \\
\hline & \% DIVMO & & & & & \% DIVMO & $\%$ \\
GD Total & 8,0753 & $-0,0006$ & - & 0,0638 & 0,0001 & 0,18464 & 2,3 \\
UF Total & 8,0271 & $-1 \mathrm{E}-05$ & $9,16 \mathrm{E}-11$ & 0,0638 & 0,0001 & 0,18485 & 2,3 \\
\hline
\end{tabular}

Tabela 19. Modelos de PB com base em GD e UF para a média de todos os cultivares em cada um dos intervalos

\begin{tabular}{lccccccc}
\hline Modelo & intercepto & $\begin{array}{c}\text { Coeficiente } \\
\text { angular }\end{array}$ & uf ufsq & $\mathbf{R}^{2}$ & Pr $>$ F & RMSE & CV \\
\hline & \% PB & & & & & \% PB & $\%$ \\
GD 4 sem & 2,8115 & $-0,00045$ & - & 0,0307 & 0,005 & 0,15544 & 5,7 \\
GD 6 sem & 2,5776 & $-0,00023$ & - & 0,0077 & 0,242 & 0,00210 & 8,9 \\
UF 4 sem & 2,7695 & $-0,00001$ & $-5,85 \mathrm{E}-10$ & 0,0281 & 0,126 & 0,15595 & 5,7 \\
UF 6 sem & 2,5977 & $-0,00002$ & $7,16 \mathrm{E}-10$ & 0,0116 & 0,356 & 0,22432 & 8,9 \\
\hline
\end{tabular}


Tabela 20. Modelos de FDN com base em GD e UF para a média de todos os cultivares em cada um dos intervalos

\begin{tabular}{lccccccc}
\hline Modelo & intercepto & $\begin{array}{c}\text { Coeficiente } \\
\text { angular }\end{array}$ & uf ufsq & $\mathbf{R}^{2}$ & Pr $>$ F & RMSE & CV \\
\hline & \% FDN & & & & & \% FDN & $\%$ \\
GD 4 sem & 63,7336 & 0,00116 & - & 0,0008 & 0,017 & 2,47024 & 3,9 \\
GD 6 sem & 66,5437 & $-0,00040$ & - & 0,0002 & 0,035 & 2,59965 & 3,9 \\
UF 4 sem & 63,7931 & 0,00008 & $-7,44 \mathrm{E}-09$ & 0,0004 & 0,951 & 2,47559 & 3,9 \\
UF 6 sem & 66,1537 & 0,00016 & $-1,08 \mathrm{E}-08$ & 0,0138 & 0,292 & 2,58914 & 3,9 \\
\hline
\end{tabular}

Tabela 21. Modelos de DIVMO com base em GD e UF para a média de todos os cultivares em cada um dos intervalos

\begin{tabular}{|c|c|c|c|c|c|c|c|}
\hline Modelo & intercepto & $\begin{array}{c}\text { Coeficiente } \\
\text { angular }\end{array}$ & uf ufsq & $\mathbf{R}^{2}$ & $\operatorname{Pr}>F$ & RMSE & $\mathrm{CV}$ \\
\hline & \% DIVMO & & & & & \% DIVMO & $\%$ \\
\hline GD 4 sem & 8,0536 & $-0,00023$ & - & 0,0081 & 0,148 & 0,00810 & 2,0 \\
\hline GD 6 sem & 7,9123 & $-0,00016$ & - & 0,0050 & 0,347 & 0,20024 & 2,5 \\
\hline UF 4 sem & 8,0335 & $-0,00001$ & $5,37 \mathrm{E}-10$ & 0,0029 & 0,690 & 0,16010 & 2,0 \\
\hline UF 6 sem & 7,9406 & $-0,00002$ & $7,93 \mathrm{E}-10$ & 0,0105 & 0,392 & 0,20024 & 2,5 \\
\hline
\end{tabular}


Tabela 22. Modelos de PB com base em GD e UF para cada um dos cultivares na média do intervalos

\begin{tabular}{lccccccc}
\hline \multirow{1}{*}{ Modelo } & intercepto & $\begin{array}{c}\text { Coeficiente } \\
\text { angular }\end{array}$ & uf ufsq & $\mathbf{R}^{2}$ & Pr $>$ F & RMSE & CV \\
& \% PB & & & & & \% PB & \% \\
GD Florico & 2,8898 & $-0,00100$ & - & 0,1580 & 0,000 & 0,19928 & 7,5 \\
GD Florona & 2,8526 & $-0,00083$ & - & 0,1091 & 0,002 & 0,21185 & 8,0 \\
GD Estrela & 2,8591 & $-0,00083$ & - & 0,0981 & 0,003 & 0,20077 & 7,5 \\
GD Coastcross & 2,7599 & $-0,00087$ & - & 0,1194 & 0,001 & 0,20132 & 7,8 \\
GD Tifton & 2,8288 & $-0,00101$ & - & 0,1456 & 0,000 & 0,18241 & 6,9 \\
UF Florico & 2,7837 & $-0,00001$ & $-2,88 \mathrm{E}-10$ & 0,1727 & 0,000 & 0,19870 & 7,5 \\
UF Florona & 2,7860 & $-0,00002$ & $1,88 \mathrm{E}-10$ & 0,1239 & 0,004 & 0,21132 & 8,0 \\
UF Estrela & 2,7926 & $-0,00002$ & $-9,58 \mathrm{E}-12$ & 0,1042 & 0,009 & 0,20127 & 7,5 \\
UF Coastcross & 2,6784 & $-0,00002$ & $-1,51 \mathrm{E}-10$ & 0,1364 & 0,002 & 0,20054 & 7,8 \\
UF Tifton & 2,7358 & $-0,00001$ & $-1,30 \mathrm{E}-09$ & 0,1699 & 0,000 & 0,18085 & 6,8 \\
\hline
\end{tabular}


Tabela 23. Modelos de FDN com base em GD e UF para cada um dos cultivares na média do intervalos

\begin{tabular}{lccccccc}
\hline \multicolumn{1}{c}{ Modelo } & intercepto & $\begin{array}{c}\text { Coeficiente } \\
\text { angular }\end{array}$ & uf ufsq & $\mathbf{R}^{2}$ & Pr $>$ F & RMSE & CV \\
& \% FDN & & & & & \% FDN & \% \\
GD Florico & 61,8639 & 0,00868 & - & 0,0778 & 0,009 & 2,56742 & 4,0 \\
GD Florona & 61,8455 & 0,01056 & - & 0,1219 & 0,001 & 2,51784 & 3,9 \\
GD Estrela & 62,6904 & 0,00869 & - & 0,0705 & 0,012 & 2,53028 & 3,9 \\
GD Coastcross & 63,9785 & 0,01022 & - & 0,1052 & 0,002 & 2,52605 & 3,8 \\
GD Tifton & 64,3311 & 0,00867 & - & 0,0588 & 0,023 & 2,58885 & 3,9 \\
UF Florico & 62,9317 & 0,00009 & $3,78 \mathrm{E}-09$ & 0,0736 & 0,039 & 2,58831 & 4,1 \\
UF Florona & 62,7892 & 0,00023 & $-2,92 \mathrm{E}-09$ & 0,1155 & 0,005 & 2,54185 & 3,9 \\
UF Estrela & 63,4719 & 0,00018 & $-4,89 \mathrm{E}-10$ & 0,0614 & 0,068 & 2,55758 & 4,0 \\
UF Coastcross & 65,0007 & 0,00017 & $1,01 \mathrm{E}-09$ & 0,1027 & 0,010 & 2,54435 & 3,8 \\
UF Tifton & 65,4119 & 0,00007 & $2,56 \mathrm{E}-08$ & 0,0764 & 0,034 & 2,57927 & 3,9 \\
\hline
\end{tabular}


Tabela 24. Modelos de DIVMO com base em GD e UF para cada um dos cultivares na média do intervalos

\begin{tabular}{lccccccc}
\hline \multicolumn{1}{c}{ Modelo } & intercepto & $\begin{array}{c}\text { Coeficiente } \\
\text { angular }\end{array}$ & uf ufsq & $\mathbf{R}^{2}$ & Pr $>$ F & RMSE & CV \\
& \% DIVMO & & & & & \% DIVMO & \% \\
GD Florico & 8,0854 & $-0,00053$ & - & 0,0701 & 0,013 & 0,16633 & 2,1 \\
GD Florona & 8,2087 & $-0,00078$ & - & 0,1166 & 0,001 & 0,19089 & 2,4 \\
GD Estrela & 8,0321 & $-0,00058$ & - & 0,0623 & 0,019 & 0,17954 & 2,3 \\
GD Coastcross & 8,1123 & $-0,00094$ & - & 0,1409 & 0,000 & 0,19563 & 2,5 \\
GD Tifton & 8,0296 & $-0,00038$ & - & 0,0306 & 0,103 & 0,16112 & 2,0 \\
UF Florico & 7,9984 & 0,00000 & $-7,09 \mathrm{E}-10$ & 0,0774 & 0,033 & 0,16665 & 2,1 \\
UF Florona & 8,1696 & $-0,00003$ & $7,32 \mathrm{E}-10$ & 0,1131 & 0,006 & 0,19238 & 2,4 \\
UF Estrela & 7,9828 & $-0,00001$ & $-1,71 \mathrm{E}-10$ & 0,0706 & 0,045 & 0,17979 & 2,3 \\
UF Coastcross & 8,0205 & $-0,00002$ & $-1,08 \mathrm{E}-10$ & 0,1433 & 0,001 & 0,19651 & 2,5 \\
UF Tifton & 7,9691 & 0,00001 & $-1,76 \mathrm{E}-09$ & 0,0455 & 0,138 & 0,16081 & 2,0 \\
\hline
\end{tabular}


Tabela 25. Modelos de PB com base em GD e UF para cada um dos cultivares em cada um dos intervalos

\begin{tabular}{|c|c|c|c|c|c|c|c|}
\hline Modelo & Intercepto & $\begin{array}{c}\text { Coeficiente } \\
\text { angular }\end{array}$ & uf ufsq & $\mathbf{R}^{2}$ & $\operatorname{Pr}>\mathbf{F}$ & RMSE & $\mathbf{C V}$ \\
\hline & $\%$ PB & & & & & $\% \mathbf{P B}$ & $\%$ \\
\hline \multicolumn{8}{|c|}{ GD } \\
\hline Florico 4 sem & 2,8611 & $-0,00054$ & & 0,0455 & 0,129 & 0,15183 & 5,5 \\
\hline Florona 4sem & 2,8286 & $-0,00049$ & & 0,0375 & 0,169 & 0,15706 & 5,8 \\
\hline Estrela 4sem & 2,8377 & $-0,00037$ & & 0,0209 & 0,306 & 0,14989 & 5,4 \\
\hline Coastcross 4 sem & 2,7415 & $-0,00046$ & & 0,0306 & 0,215 & 0,15628 & 5,9 \\
\hline Tifton 4 sem & 2,7867 & $-0,00035$ & & 0,0171 & 0,356 & 0,14782 & 5,4 \\
\hline Florico 6sem & 2,5825 & $-0,00022$ & & 0,0077 & 0,611 & 0,21814 & 8,7 \\
\hline Florona 6 sem & 2,6137 & $-0,00025$ & & 0,0074 & 0,619 & 0,25788 & 10,2 \\
\hline Estrela 6 sem & 2,6109 & $-0,00015$ & & 0,0028 & 0,758 & 0,23177 & 9,0 \\
\hline Coastcross 6sem & 2,4529 & $-0,00007$ & & 0,0008 & 0,872 & 0,21881 & 9,0 \\
\hline Tifton 6 sem & 2,6185 & $-0,00044$ & & 0,0328 & 0,290 & 0,18905 & 7,5 \\
\hline \multicolumn{8}{|c|}{ UF } \\
\hline Florico 4 sem & 2,7987 & 0,00000 & $-1,16 \mathrm{E}-09$ & 0,0388 & 0,379 & 0,15390 & 5,6 \\
\hline Florona 4sem & 2,7737 & 0,00000 & $-6,26 \mathrm{E}-10$ & 0,0326 & 0,444 & 0,15906 & 5,8 \\
\hline Estrela 4sem & 2,7753 & 0,00002 & $-4,01 E-09$ & 0,0288 & 0,489 & 0,15080 & 5,4 \\
\hline Coastcross 4 sem & 2,7144 & $-0,00002$ & $5,18 \mathrm{E}-10$ & 0,0280 & 0,498 & 0,15808 & 5,9 \\
\hline Tifton 4 sem & 2,7590 & 0,00000 & $-1,19 \mathrm{E}-09$ & 0,0164 & 0,667 & 0,14937 & 5,5 \\
\hline Florico 6sem & 2,5931 & $-0,00001$ & $5,29 \mathrm{E}-10$ & 0,0088 & 0,864 & 0,22129 & 8,8 \\
\hline Florona 6sem & 2,6920 & $-0,00003$ & 1,09E-09 & 0,0191 & 0,728 & 0,26021 & 10,2 \\
\hline Estrela 6sem & 2,7071 & $-0,00005$ & $3,15 \mathrm{E}-09$ & 0,0252 & 0,656 & 0,23260 & 9,0 \\
\hline Coastcross 6sem & 2,4949 & $-0,00002$ & $7,87 \mathrm{E}-10$ & 0,0043 & 0,931 & 0,22171 & 9,1 \\
\hline Tifton 6sem & 2,6511 & $-0,00004$ & 2,96E-09 & 0,0426 & 0,487 & 0,19092 & 7,6 \\
\hline
\end{tabular}


Tabela 26. Modelos de FDN com base em GD e UF para cada um dos cultivares em cada um dos intervalos

\begin{tabular}{|c|c|c|c|c|c|c|c|}
\hline Modelo & Intercepto & $\begin{array}{c}\text { Coeficiente } \\
\text { angular }\end{array}$ & uf ufsq & $\mathbf{R}^{2}$ & $\operatorname{Pr}>\mathbf{F}$ & RMSE & $\mathbf{C V}$ \\
\hline & $\%$ FDN & & & & & $\%$ FDN & $\%$ \\
\hline \multicolumn{8}{|c|}{ GD } \\
\hline Florico 4sem & 62,4143 & 0,00177 & & 0,0020 & 0,752 & 2,41856 & 3,9 \\
\hline Florona 4 sem & 62,2436 & 0,00586 & & 0,0276 & 0,239 & 2,18910 & 3,5 \\
\hline Estrela 4sem & 62,8981 & 0,00358 & & 0,0102 & 0,476 & 2,06639 & 3,3 \\
\hline Coastcross 4 sem & 64,4652 & 0,00385 & & 0,0870 & 0,511 & 2,51132 & 3,9 \\
\hline Tifton 4 sem & 64,6744 & 0,00129 & & 0,0009 & 0,831 & 2,36324 & 3,6 \\
\hline Florico 6 sem & 65,5766 & $-0,00059$ & & 0,0005 & 0,894 & 2,24200 & 3,4 \\
\hline Florona 6sem & 64,6466 & 0,00378 & & 0,0152 & 0,473 & 2,72105 & 4,1 \\
\hline Estrela 6sem & 65,7098 & 0,00039 & & 0,0001 & 0,946 & 2,78121 & 4,2 \\
\hline Coastcross 6sem & 67,2564 & 0,00194 & & 0,0063 & 0,645 & 2,09122 & 3,1 \\
\hline Tifton 6 sem & 67,4122 & $-0,00005$ & & 0,0000 & 0,993 & 2,40315 & 3,6 \\
\hline \multicolumn{8}{|c|}{ UF } \\
\hline Florico 4sem & 62,8016 & $-0,00007$ & $1,04 \mathrm{E}-08$ & 0,0010 & 0,975 & 2,44431 & 3,9 \\
\hline Florona 4sem & 62,6345 & 0,00017 & $-3,34 \mathrm{E}-09$ & 0,0276 & 0,504 & 2,21137 & 3,5 \\
\hline Estrela 4sem & 64,1058 & $-0,00068$ & $1,06 \mathrm{E}-07$ & 0,0448 & 0,325 & 2,05056 & 3,2 \\
\hline Coastcross 4 sem & 64,2098 & 0,00050 & $-4,95 \mathrm{E}-08$ & 0,0127 & 0,731 & 2,53162 & 3,9 \\
\hline Tifton 4 sem & 64,8034 & 0,00004 & $-4,07 \mathrm{E}-09$ & 0,0001 & 0,997 & 2,38818 & 3,7 \\
\hline Florico 6sem & 64,7920 & 0,00028 & $-1,74 \mathrm{E}-08$ & 0,0295 & 0,611 & 2,24254 & 3,4 \\
\hline Florona 6 sem & 64,6817 & 0,00021 & $-8,54 \mathrm{E}-09$ & 0,0081 & 0,874 & 2,77193 & 4,2 \\
\hline Estrela 6sem & 64,7467 & 0,00053 & $-3,84 \mathrm{E}-08$ & 0,0318 & 0,587 & 2,77800 & 4,2 \\
\hline Coastcross 6sem & 66,4272 & 0,00040 & $-2,17 \mathrm{E}-08$ & 0,0266 & 0,641 & 2,10088 & 3,1 \\
\hline Tifton 6sem & 67,1903 & 0,00014 & $-1,26 \mathrm{E}-08$ & 0,0023 & 0,962 & 2,43644 & 3,6 \\
\hline
\end{tabular}


Tabela 27. Modelos de DIVMO com base em GD e UF para cada um dos cultivares em cada um dos intervalos

\begin{tabular}{|c|c|c|c|c|c|c|c|}
\hline Modelo & Intercepto & $\begin{array}{c}\text { Coeficiente } \\
\text { angular }\end{array}$ & uf ufsq & $\mathbf{R}^{2}$ & $\operatorname{Pr}>$ F & RMSE & $\mathbf{C V}$ \\
\hline & \% DIVMO & & & & & \% DIVMO & $\%$ \\
\hline \multicolumn{8}{|c|}{ GD } \\
\hline Florico 4sem & 8,0210 & $-0,00003$ & - & 0,0001 & 0,932 & 0,15007 & 1,9 \\
\hline Florona 4sem & 8,2446 & $-0,00083$ & - & 0,1040 & 0,020 & 0,15367 & 1,9 \\
\hline Estrela 4sem & 8,0275 & $-0,00035$ & - & 0,0140 & 0,404 & 0,17064 & 2,1 \\
\hline Coastcross 4 sem & 8,1027 & $-0,00059$ & - & 0,0388 & 0,162 & 0,17751 & 2,2 \\
\hline Tifton 4 sem & 7,9998 & 0,00000 & - & 0,0000 & 0,987 & 0,11820 & 1,5 \\
\hline Florico 6sem & 7,9828 & $-0,00032$ & - & 0,1780 & 0,363 & 2,25577 & 0,0 \\
\hline Florona 6sem & 8,0156 & $-0,00026$ & - & 0,0100 & 0,562 & 0,22973 & 2,9 \\
\hline Estrela 6sem & 7,8663 & $-0,00011$ & - & 0,0027 & 0,764 & 0,18058 & 2,3 \\
\hline Coastcross 6sem & 7,8187 & $-0,00016$ & - & 0,0054 & 0,671 & 0,18469 & 2,4 \\
\hline Tifton 6sem & 7,9331 & $-0,00014$ & - & 0,0030 & 0,753 & 0,20232 & 2,6 \\
\hline \multicolumn{8}{|c|}{ UF } \\
\hline Florico 4sem & 7,9764 & 0,00002 & $-2,26 \mathrm{E}-09$ & 0,0065 & 0,852 & 0,15111 & 1,9 \\
\hline Florona 4sem & 8,1969 & $-0,00003$ & $1,66 \mathrm{E}-09$ & 0,0788 & 0,134 & 0,15740 & 1,9 \\
\hline Estrela 4sem & 7,9489 & 0,00004 & $-6,41 \mathrm{E}-09$ & 0,0350 & 0,418 & 0,17052 & 2,1 \\
\hline Coastcross 4 sem & 8,0936 & $-0,00005$ & $4,25 \mathrm{E}-09$ & 0,0270 & 0,511 & 0,18040 & 2,3 \\
\hline Tifton 4sem & 7,9792 & 0,00001 & $-1,84 \mathrm{E}-09$ & 0,0041 & 0,904 & 0,11915 & 1,5 \\
\hline Florico 6sem & 7,9783 & $-0,00002$ & $6,82 \mathrm{E}-10$ & 0,0170 & 0,754 & 0,18137 & 2,3 \\
\hline Florona 6sem & 8,0541 & $-0,00002$ & $8,08 \mathrm{E}-10$ & 0,0142 & 0,790 & 0,23269 & 2,9 \\
\hline Estrela 6sem & 7,8937 & $-0,00002$ & $1,01 \mathrm{E}-09$ & 0,0063 & 0,901 & 0,18297 & 2,3 \\
\hline Coastcross 6sem & 7,8779 & $-0,00002$ & 1,19E-09 & 0,0176 & 0,746 & 0,18631 & 2,4 \\
\hline Tifton 6sem & 7,9301 & $-0,00001$ & $3,33 \mathrm{E}-10$ & 0,0030 & 0,951 & 0,20536 & 2,6 \\
\hline
\end{tabular}


Os modelos gerados para PB, FDN e DIVMO (Tabela 16 a 27), apresentaram relações altamente significativas entre esses parâmetros e as variáveis climáticas empregadas (GD e UF) até o nível de agregação da média dos cultivares entre os intervalos (eg., GD Florona), não apresentando essa resposta quando se considerou as médias dos cultivares nos intervalos entre cortes. No entanto, mesmo nos modelos em que as relações foram significativas, os coeficientes de determinação foram muito baixos, indicando que apesar da existência das relações funcionais entre as variáveis a capacidade preditória do modelo foi muito pequena.

Uma das possíveis justificativas para o baixo coeficiente de determinação apresentado pelos modelos no presente trabalho é concentração das medições dos parâmetros qualitativos em apenas dois períodos de crescimento (28 e 42 dias) com um intervalo temporal (diferença em dias de crescimento) muito pequeno entre eles, o que impossibilitou a geração de dados em uma amplitude de variação grande o suficiente para a diluição dos erros experimentais, fazendo com que as diferenças associadas a esses erros fossem maiores que as diferenças devidas aos tratamentos. Em relação aos modelos mais específicos (para cada cultivar em cada intervalo entre cortes), os menores conjuntos de dados empregados para estudar as relações dentro de cultivares e intervalos não possibilitou uma inferência conclusiva, possivelmente pela potencialização dos erros experimentais ao se trabalhar com um conjunto de dados mais restrito.

Para a aplicação do conceito de GD na predição do valor nutritivo de plantas do gênero Cynodon, as respostas aqui obtidas corroboram o relatado por Mitchell et al. (2001) que usando GD entre outras variáveis preditoras para estimar os teores de FDN, PB, DIVMS de Panicum virgatum L. e Andropogon gerardii Vitman obtiveram relações funcionais claras entre GD e os parâmetros qualitativos, sendo a única diferença em relação aos coeficientes de determinação apresentados, que no estudo de Mitchell et al. (2001) mostraram-se superiores a $80 \%$.

Em relação aos modelos de UF os resultados do presente estudo não podem ser avaliados de forma conclusiva, já que este é um estudo pioneiro na utilização desta 
variável como preditora de valor nutritivo, mas inicialmente pode-se validar a aplicação desse conceito como preditor de parâmetros qualitativos, conforme demonstra a significância das regressões geradas. 


\section{CONCLUSÕES}

Os dois intervalos entre cortes empregados podem ser utilizados no manejo das plantas do gênero Cynodon, com o maior intervalo entre cortes propiciando um maior acúmulo de forragem de valor nutritivo um pouco inferior, e o menor intervalo entre cortes obtendo menores acúmulos de forragem mas de melhor valor nutritivo, quando manejados sob cortes em condições produtivas com alta reposição de nutrientes e ausência de déficits hídricos, devendo-se optar por um intervalo ou outro em função da resposta que se deseja priorizar.

Os cultivares de Cynodon estudados apresentam potenciais de acúmulo de forragem e distribuição estacional da produção diferentes ao longo de um ano quando cultivados em condições hídricas e de fertilidade não limitantes ao seu crescimento, o que reflete diferentes respostas às variáveis climáticas. Estas características e suas implicações nos sistemas produtivos, como adequação de suprimento à demanda de alimentos ou épocas de comercialização devem ser consideradas quando da opção por um determinado cultivar.

A utilização do conceito de uma temperatura base inferior específica para cada cultivar mostrou-se verdadeiro, auxiliando na determinação dos momento de paralisação e início do crescimento das plantas.

O método empregado para a determinação das temperaturas base de cada cultivar mostrou-se válido, podendo ser empregado no cálculo dessa variável para outros cultivares ou espécies.

Ambos os fatores climáticos, fotoperíodo e temperatura média diária estão intimamente relacionados ao acúmulo de massa e as alterações do valor nutritivo nas 
forragens do gênero Cynodon, concorrendo na determinação da sua produtividade, distribuição estacional de produção e valor nutritivo quando estas são cultivadas em condições de fertilidade e hídricas não limitantes.

As duas variáveis climáticas estudadas, graus-dia e unidades fototérmicas demonstraram ser viáveis para a realização de estimativas da produção total de matéria seca e sua variação estacional, além dos teores de proteína bruta, fibra em detergente neutro e digestibilidade da matéria orgânica em condições irrigadas ou de ausência de déficit hídrico, o que possibilita o seu uso em sistemas de predição do acúmulo de massa e qualidade das plantas.

Os modelos desenvolvidos para estimar o acúmulo de massa, de forma geral mostraram boa capacidade preditória, com melhores resultados (aumento na capacidade explicativa) com a inserção de menores níveis de agregação, podendo ser empregados para a realização de estimativas produtivas das plantas do gênero Cynodon.

Os modelos desenvolvidos para estimar as variáveis qualitativas apesar de apresentarem boa relação com os parâmetros estudados demonstraram baixa capacidade preditória, possivelmente em decorrência da alta variabilidade encontrada entre amostras, indicando que a sua utilização para a realização de estimativas produtivas é viável desde que se possa controlar ou diminuir variação em função de erro experimental. 


\section{REFERÊNCIAS BIBLIOGRÁFICAS}

ACUNHA, J. B. V.; COELHO, R. W. Efeito da altura e intervalo de corte do capimelefante-anão. Pesquisa Agropecuária Brasileira, v.32, n.1, p.117-122, 1997.

ALCANTARA, P. B.; PEDRO, J. R.; DONZELLI, P.L. Zoneamento edafoclimático de plantas forrageiras. In: SIMPÓSIO SOBRE ECOSSISTEMAS DE PASTAGENS 2. Jaboticabal, 1989. Anais. Jaboticabal: FUNEP, 1989. p.1-16.

ALVIM, M.J., RESENDE, H., BOTREL, M.A. . Efeito da freqüência de corte e do nível de nitrogênio sobre a produção e qualidade da matéria seca do Coast-cross. In: WORKSHOP SOBRE O POTENCIAL FORRAGEIRO DO GÊNERO CYNODON, Juíz de Fora, 1996. Anais. Juiz de Fora : EMBRAPA,CNPGL, 1996.p.45-55.

BARIONI, L. G. Modelagem dinâmica e otimização metaheurística para apoio à tomada de decisões na recria e engorda de bovinos de corte. Piracicaba, 2002. 100p. Tese (Doutorado) - Escola Superior de Agricultura "Luiz de Queiroz", Universidade de São Paulo.

BARIONI, L. G.; POLI, C. H. E. C.; COUTINHO, H. Maximizando lucratividade através do planejamento, monitorização e controle do forrageamento. Pecuária de Corte, v. 8, n. 75, 1998. p. 78-82.

BELESKY, D. P.; PERRY, H. D.; WINDMAN, W. R.; MATHIAS, E. L.; FEDDERS, J. M. Productivity and quality of bermudagrass in a cool temperate environment. Agronomy Journal v.83, p.810-813, 1991.

BERNARDES, M. S. Fotossíntese no dossel das plantas cultivadas In: CASTRO, P. R. C.; FERREIRA, S. O.; YAMADA, T. (Ed.). Ecofisiologia da produção agrícola. Piracicaba: Associação Brasileira de Pesquisa de Potassa e do Fosfato. 1987, p.1348. 
BÜRGI, R.; PAGOTTO, D. S. Aspectos mercadológicos dos sistemas de produção animal em pastagens. In: SIMPÓSIO SOBRE MANEJO DA PASTAGEM, 19., Piracicaba, 2002. Anais. Piracicaba: FEALQ, 2002. p. 217-231.

BURTON, G. W. Registration of Coastcross-1 bermudagrass. Crop Science, v.12, p.125, 1972.

BURTON, G. W.; HANNA, W. W. Bermudagrass. In: BARNES, R. F.; MILLER, D. A.; NELSON, C. J. (Ed.). Forages, an introduction to grassland agriculture. Ames: Iowa State University Press, 1995. p.421-430.

BURTON, G. W.; GATES, R. N.; HILL, G. M. Registration of Tifton 85 bermudagrass. Crop Science, v.33, p.644-645, 1993.

BURTON, G. W.; HOOK, J. E.; BUTLER, J. L. HELLWING, R. E. Effect of temperature, daylength and solar radiation on production of Coastal bermudagrass. Agronomy Journal, v.80, p.557-560, 1988.

BUXTON, D.R.; FALES, S.L. Plant environment and quality. In: FAHEY, G.C. (Ed.) Forage quality, evaluation and utilization. Madison: American Society Agronomy, 1994. p.155-199.

BROWN, W. G.; MISLEVY, P. Feed value of stargrass. In: INTERNATIONAL CONFERENCE ON LIVESTOCK IN THE TROPICS. Gainesville, 1989. Proceedings. Belle Glade: University of Florida, 1989. p.12-18.

CAIXETA FILHO, J. V. Pesquisa operacional : técnicas de otimização aplicadas a sistemas agroindustriais. Piracicaba: o autor, 2000. 212p.

CARNEVAlLI, R. A.; Da SILVA, S. C. Validação de técnicas experimentais para avaliação de características agronômicas e ecológicas de pastagens de Cynodon dactylon cv. Coastcross - 1. Scientia Agricola, v.56, p.489-499, 1999.

CARVALHO, C. A. B. Padrões demográficos de perfilhamento e acúmulo de forragem em pastagens de Cynodon spp. Manejadas em quatro intensidades de pastejo. Piracicaba, 2000. 96 p. Dissertação (Mestrado) - Escola Superior de Agricultura "Luiz de Queiroz", Universidade de São Paulo.

COOPER, J. P. Physiological and morphological advances for forage improvement. In: INTERNATIONAL GRASSLAND CONGRESS, 14., Lexington, 1981. Proceedings. Boulder:Westview Press, 1983. 
COOPER, J.P.; TAINTON, N.M. Light and temperature requirements for the growth of tropical and temperate grasses. Review article. Herbage Abstracts, v.38, p.167176, 1968.

CORSI, M. Estudo da produtividade e do valor nutritivo do capim elefante (Pennisetum purpureum Schum.) variedade napier submetido a diferentes frequiências e alturas de corte. Piracicaba, 1972. 139p. Tese (Doutorado). Escola Superior de Agricultura “Luiz de Queiroz", Universidade de São Paulo.

CORSI, M. Espécies forrageiras para pastagens. In: SIMPÓSIO SOBRE MANEJO DA PASTAGEM, 3., Piracicaba, 1976. Anais. Piracicaba: FEALQ, 1976. p.5-36.

CORSI, M. Produção e qualidade de forragens tropicais. In: Sociedade Brasileira de Zootecnia. Pastagens. Piracicaba: FEALQ, 1990. p.69-86.

CORSI, M. Espécies forrageiras para pastagens. In: PEIXOTO, A. M.; MOURA, J. C.; FURLAN, R. S.; FARIA, V. P. de (Ed.). Pastagens: Fundamentos da exploração racional. Piracicaba: FEALQ, 1994, p.225-254

CORSI, M.; NUSSIO, L. G. Manejo do capim elefante: correção e adubação do solo. In: SIMPÓSIO SOBRE MANEJO DA PASTAGEM, 10., Piracicaba, 1994. Anais. Piracicaba: FEALQ, 1994. p.87-116.

CORSI, M.; MARTHA JUNIOR, G. B. Manejo de pastagens para a produção de carne e leite. In: SIMPÓSIO SOBRE MANEJO DA PASTAGEM, 15., Piracicaba, 1998. Anais. Piracicaba: FEALQ, 1998. p.55-84.

COSTA, N.M.S. Regionalização da produção de sementes de plantas forrageiras em Minas Gerais. Informe Agropecuário, v.11, p.18 - 23, 1984.

Da SILVA, S.C. Condições edafo-climáticas para a produção de Panicum sp. In: SIMPÓSIO SOBRE MANEJO DA PASTAGEM, 12., Piracicaba. 1995. Anais. Piracicaba: FEALQ, 1995, p.129-146.

Da SILVA, S.C.; SBRISSIA, A. F. A planta forrageira no sistema de produção. In: SIMPÓSIO SOBRE MANEJO DA PASTAGEM, 17., Piracicaba, 2000. Anais. Piracicaba: FEALQ, 2000. p. 03-20.

DEREGIBUS, V. A.; SANCHEZ, R. A.; CASAL, J. J. Effects of light quality on tiller production in Lolium spp. Plant Physiology, v. 72, p. 900 - 912, 1983. 
DOURADO NETO, D.; TERUEL, D. A.; REICHARDT, K.; NIELSEN, D. R.; FRIZZONE, J.A.; BACCHI, O. O. S. Principles of crop modeling and simulation: 1. Uses of mathematical models in model development. Scientia Agricola, Piracicaba, 55, número especial, p.46-50, ago. 1998.

DOVE, $\mathrm{H}$. The ruminant, the rumen and the pasture resource: nutrient interactions in the grazing animal. In: HODGSON, J.; ILLIUS, A. W. The ecology and management of grazing systems. New York: CAB International, 1996. cap. 8, p.219-246.

DOVRAT, A. Irrigated forage production. Amesterdam:Elsevier, 1993., (Development in Crop Science), 24)

EAGLES, C. F.; WILSON, D. Photosynthetic efficiency and plant productivity. In: RECHCIGL, Jr., M. (Ed.) Handbook of agricultural productivity. Boca Raton: CRC Press, v.1, 1982. v.1, p.213-247.

EMPRESA BRASILEIRA DE PESQUISA AGROPECUÁRIA. Sistema brasileiro de classificação de solos. Brasília: EMBRAPA Produção de Informação, 1999. 412p.

EUCLIDES, V. P. B. Valor alimentício de espécies forrageiras do gênero Panicum. In: SIMPÓSIO SOBRE MANEJO DA PASTAGEM, 12., Piracicaba 1995. Anais. Piracicaba: FEALQ, 1995. p.245-276.

EVANS, D.W., PEADEN, R.N. Seasonal forage growth rate and solar energy conversion of irrigated vernal alfalfa. Crop Science, v.24, n.5, p.981-984. 1984.

FAGUNDES, J. L. Efeito de intensidades de pastejo sobre o índice de área foliar, interceptação luminosa e acúmulo de forragem em pastagens de Cynodon spp. Piracicaba, 1999. 69 p. Dissertação (Mestrado) - Escola Superior de Agricultura "Luiz de Queiroz", Universidade de São Paulo.

FICK, G. W.; WILKENS, P.W.; CHERNEY, J.H. Modeling forage quality changes in the growing crop. In: FAHEY, G.C. JUNIOR; MOSER, L. E.; MERTWNS, D. R.; COLINS, M. (Ed.). Forage quality evaluation and utilization. Madison: American Society of Agronomy, 1994. cap.18, p.757-795.

FISHER, D. S.; BURNS, J. C.; MOORE, J. E. The nutritive evaluation of forage. In: BARNES, R. F.; MILLER, D. A.; NELSON, C. J. (Ed.). Forages, an introduction to grassland agriculture. Ames: Iowa State University Press, 1995. p.105 - 175. 
FONTES, P. C. R.; MARTINS, C. E.; CÓSER, A. C.; VILELA, D. Produção e níveis de nutrientes em alfafa (Medicago sativa L.) no primeiro ano de cultivo, na zona da mata de Minas Gerais. Revista da Sociedade Brasileira de Zootecnia, v. 22, n. 2 , p.205-211, 1993.

GHELFI FILHO, H. Efeito da irrigação sobre a produtividade do capim elefante (Pennisetum purpureum Schum.) variedade napier. Piracicaba, 1972. 77p. Tese (Doutorado). Escola Superior de Agricultura "Luiz de Queiroz", Universidade de São Paulo.

GOMIDE, J. A. Composição mineral de gramíneas e leguminossas forrageiras tropicais. In: SIMPÓSIO LATINO-AMERICANO SOBRE PESQUISA EM NUTRIÇÃO MINERAL DE RUMINTES EM PASTAGENS, 1., Belo Horizonte, 1976. Anais. Belo Horizonte: EPAMIG, 1976. p.20-33.

GOMIDE, J.A. Fisiologia do crescimento livre de plantas forrageiras. In: PEIXOTO, A. M.; MOURA, J. C.; FURLAN, R. S.; FARIA, V. P. de (Ed.). Pastagens: Fundamentos da exploração racional. Piracicaba: FEALQ, 1994. p.01-14.

GOMIDE, J.A.; QUEIROZ, D. S. Valor alimentício das Brachiarias. In: SIMPÓSIO SOBRE MANEJO DA PASTAGEM, 11., Piracicaba, 1994. Anais. Piracicaba: FEALQ, 1994. p.223-247.

GOMIDE, C. C. C. Algumas características fisiológicas e químicas de cinco cultivares de Cynodon. Jaboticabal, 1996. 100p. Dissertação (Mestrado) - Faculdade de Ciências Agrárias e Veterinárias, Universidade Estadual Paulista "Júlio de Mesquita Filho".

HAY, R. K. M.; WALKER, A. J. An introduction to the physiology of crop yield. Essex: Longman Scientific and Technical, 1989. 292p.

HARLAN, J. R.; WET, J. M. J. Sources of variation in Cynodon dactylon (L.) Pers. Crop Science v.9, p.774-778, 1969.

HARLAN, J. R. Cynodon species and their value for grazing and hay. Review Article. Herbage Abstract, v. 40, n. 3, p. 233 - 238, 1970.

HARLAN, J. R.; WET, J. M. J.; RAWAL, K. M. Geografical distribution of the species of Cynodon L. C. Rich (Graminae). East African Agriculture Journal, v.36, p.220-226, 1970.

HILL, G. M.; GATES, R.N.; BURTON, G. W. Forage quality and grazing steer performance from 'Tifton 85 ' and Tifton 78 bermudagrass pastures. Journal of Animal Science, v. 71, p.3219-3225, 1993. 
HILL, G. M., GATES, R. N., WEST, J. W., BURTON, G.W. Tifton 85 bermudagrasses utilization in beef, dairy, and hay production. In: WORKSHOP SOBRE O POTENCIAL FORRAGEIRO DO GENERO CYNODON, Juiz de Fora, 1996 Anais. Juiz de Fora: EMBRAPA, CNPGL, 1996. p.139-150.

HILL, G. M., GATES, R. N., WEST, J. W., MANDEBVU, P. Pesquisa com capim Bermuda cv. 'Tifton 85' em ensaios de pastejo e de digestibilidade de feno com bovinos. In: SIMPÓSIO SOBRE MANEJO DA PASTAGEM, 15., Piracicaba, 1998. Anais. Piracicaba: FEALQ, 1998. p.7-22.

JACQUES, A.V.A. Caracteres morfo-fisiológicos e suas implicações com o manejo. In: CARVALHO, M.M.; ALVIM, M.J.; XAVIER, D.F. et al. (Ed.). Capim - elefante: produção e utilização. Coronel Pacheco, 1994. p.31-47

JONES, R.R. Efecto del clima, el suelo, y el manejo del pastoreo en la producción y persistencia del germoplasma forrajero tropical. In: PALADINES, O.; LASCANO, C. (Ed.). Germoplasma forrajero bajo pastoreo en pequeñas parcelas Metodologia de evaluación. Cali: CIAT, 1982. p.11-31.

JOHNSON, I. R.; THORNLEY, J. H. M. Temperature dependence of plant and crop processes. Annals of Botany, v.55, p.1-24, 1985.

KAISER, H.; KAPPEN, L. In situ observations of stomatal movements in different light-dark regimes: the influence of endogenous rhythmicity and long-term adjustments. Journal of Experimental Botany, v.48, n.313, p.1583 - 1589, 1997.

KORTE, C. J.; CHU, A. C. P. E.; FIELD, T. R. O. Pasture Production. In: NICOL, A. M. (Ed.). Livestock fielding on pasture. Hamilton: New Zeland Society of Animal Production, cap.10, p.7-20. 1987. (Occasional Publication, 10)

LANGER, R. H. M. How grasses grow. London. Elsevier 1979. 60 p (Studies in Biology, 34).

LARBI, A.; MISLEVY, P.; ADJEI, M. B.; BROWN, W. F. Seasonal and animal production from three Cynodon species. Tropical Grasslands, v.24, p.305-310, 1998.

LARCHER, W. Physiological plant ecology. Berlin: Spring-Verlag, 1975. 252p.

LEMAIRE, G.; CHAPMAN, D. Tissue flows in grazed plant communities. In: HODGSON, J.; ILLIUS, A. W. (Ed.). The ecology and management of grazing systems. Guilford: CAB international, 1996. p. 71-79. 
LEME, P. R. Limitações nutricionais à produção animal em pastagens tropicais. In: CURSO DE MANEJO DE PASTAGENS, 1., Nova Odessa, 1985. Anais. Nova Odessa : Instituto de Zootecnia, 1985.

MANNETJE, L.; PRITCHARD, A. J. The effect of daylength and temperature on introduced legumes and grasses for tropics and subtropics of Coastal Australia. I. Dry matter production, tillering and leaf area. Australian Journal of Experimental Agricultural and animal Husbandry, v.14, p.173-181, 1974.

MARASCHIN, G. E. Manejo de plantas forrageiras dos gêneros Digitaria, Cynodon e Chloris. In: SIMPÓSIO SOBRE MANEJO DA PASTAGEM, 9., Piracicaba, 1988. Anais. Piracicaba: FEALQ, 1988. p.109-140.

MATTHEW, C.; ASSUERO, S. G.; BLACK, C. K.; SACVILLE HAMILTON, N. R. Tiller dynamics of grazed swards. In: SIMPÓSIO INTERNACIONAL "GRASSLAND ECOPHYSIOLOGY AND GRAZING ECOLOGY", Curitiba, 1999. Anais. Curitiba: UFPR, UFRGS, 1999. p.109 - 133.

McWILLIAM , J. R. Response of pastures plants to temperature. In: WILSON, J. R. (Ed.) Plant relation in pastures. East Melbourne: CSIRO, 1978. p.17-34.

MEDEIROS, H. R.; PEDREIRA, C. G. S.; VILLA NOVA, N. A. Temperatura base de gramíneas forrageiras estimada através do conceito de unidades fototérmicas. (compact disc). In: REUNIÃO ANUAL DA SOCIEDADE BRASILEIRA DE ZOOTECNIA, 39., Recife, 2002. Anais. Recife: SBZ, 2002.

MEDEIROS, H. R.; PEDREIRA, C. G. S.; VILLA NOVA, N. A.; BARIONI, L. G.; MELLO, A. C. L. Prediction of herbage accumulation of cynodon grasses by an empirical model based on temperature and day length. In: INTERNATIONAL GRASSLANDS CONGRESS, 19., Piracicaba, 2001. Proceedings. Piracicaba:FEALQ, 2001. p.263-265.

MERTENS, D. R. Regulation of forage intake. In: FAHEY, G. C.; COLLINS, M.; MERTENS, D. R.; MOSER, L. E. (Ed.). Forage quality, evaluation and utilization. Madison: ASA; CSSA; SSSA, 1994. cap.11, p.450-493.

MINSON, D. J. Forage in ruminant nutrition. San Diego: Academic Press, 1990. $483 p$.

MISLEVY, P.; EVERETT, P. H. Subtropical grass species response to different irrigation and harvest regimes. Agronomy Journal v.73, p.601-604, 1981. 
MISLEVY, P.; PATE, F. M. Establishment, management and utilization of Cynodon grasses in Florida. In: WORKSHOP SOBRE O POTENCIAL FORRAGEIRO DO GÊNERO CYNODON, Juíz de Fora, 1996. Anais. Juiz de Fora : EMBRAPA, CNPGL, 1996.p.127-138.

MISLEVY, P.; SINCLAIR, T. R.; RAY, J. D. Extended daylength to increase fall/winter yields of warm-season perennial grasses. In: INTERNATIONAL GRASSLAND CONGRESS, 19.São Pedro, 2001. Proceedings. São Pedro: s.ed., 2001. p. 256-257.

MISLEVY, P.; MOTT, G. O.; MARTIN, F. G. Effect of grazing frequency on forage quality and stolon characteristics of tropical perennial grasses. In: SOIL AND CROP SCIENCE SOCIETY OF FLORIDA, 41., Gainesville, 1982. Proceedings. Gainesville. 1988, p.78-83.

MISLEVY, P.; BROW, W. F.; CARO-COSTA, R.; VICENTE-CHANDLER, J.; DUNAVIN, L. S.; HALL, D. W.; KALAMBACHER, R. S.; OVERMAN, A. J.; RUELKE, O. C.; SONODA, R. M.; SOTOMAYOR-RIOS, A.; STANLEY, R. L.; WILLIAMS, M. J. Florico stargrass. Ona: University of Florida, 1989a. 15 p. (Circular, S-361).

MISLEVY, P.; BROW, W. F.; CARO-COSTA, R.; VICENTE-CHANDLER, J.; DUNAVIN, L. S.; HALL, D. W.; KALAMBACHER, R. S.; OVERMAN, A. J.; RUELKE, O. C.; SONODA, R. M.; SOTOMAYOR-RIOS, A.; STANLEY, R. L.; WILLIAMS, M. J. Florona stargrass. Ona: University of Florida, 1989b. 15 p. (Circular, S-362).

MISLEVY, P.; BROW, W. F.; CARO-COSTA, R.; VICENTE-CHANDLER, J.; DUNAVIN, L. S.; HALL, D. W.; KALAMBACHER, R. S.; OVERMAN, A. J.; RUELKE, O. C.; SONODA, R. M.; SOTOMAYOR-RIOS, A.; STANLEY, R. L.; WILLIAMS, M. J. Registration of Florico stargrass. Crop Science., v. 33, n.2, p. 358-359, 1993 a.

MISLEVY, P.; BROW, W. F.; CARO-COSTA, R.; VICENTE-CHANDLER, J.; DUNAVIN, L. S.; HALL, D. W.; KALAMBACHER, R. S.; OVERMAN, A. J.; RUELKE, O. C.; SONODA, R. M.; SOTOMAYOR-RIOS, A.; STANLEY, R. L.; WILLIAMS, M. J. Registration of Florona stargrass. Crop Science., v. 33, n.2, p. 358-359, 1993 b.

MITCHELL, R.; FRITZ, J.; MOORE, K.; MOSER, L.; VOGEL, K.; REDFEARN, D.; WESTERN, D. Predicting forage quality in switchgrass and big bluestem. Agronomy Journal., v.93, p.118-124, 2001. 
MONTEIRO, F.A. Cynodon: Exigências minerais e adubação. Ed.. In: WORKSHOP SOBRE O POTENCIAL FORRAGEIRO DO GÊNERO CYNODON, Juiz de Fora, 1996. Anais. Coronel Pacheco: CNPGL, EMBRAPA, 1996. p. 23-44.

MULLER, M. S. Desempenho de Panicum maximum (cv. Mombaça) em pastejo rotacionado, sob sistema de irrigação por pivô central, na região de cerrado. Piracicaba, 2000. Dissertação (Mestrado) - Escola Superior de Agricultura "Luiz de Queiroz”, Universidade de São Paulo.

NABINGER, C. Eficiência do uso de pastagens: disponibilidade e perdas de forragem. In: SIMPÓSIO SOBRE MANEJO DE PASTAGEM, 14., Piracicaba, 1997. Anais. Piracicaba: FEALQ, 1997. p.213-251.

NABINGER, C.; MEDEIROS, R.B. Produção de Sementes de Panicum maximum jacq. In: SIMPÓSIO SOBRE MANEJO DA PASTAGEM, 12., Piracicaba, 1995 Anais. Piracicaba: FEALQ, 1995. p.59-128.

NABINGER, C.; PONTES, L. S. Morfogênese de plantas forrageiras e estrutura do pasto. In: A produção animal na visão dos brasileiros. In: REUNIÃO ANUAL DA SBZ, 38., Piracicaba, 2001. Anais. Piracicaba: SBZ, 2001. p.755-767.

NASCIMENTO, M. P. S.; NASCIMENTO, H. T. S.; GOMIDE, J. A. Alguns aspectos morfológicos de três gramíneas de clima tropical. Revista da Sociedade Brasileira de Zootecnia. v.9, n.1, p.142-158, 1980.

National Research Council. Nutrient requirements of dairy cattle. 6. ed. Washington, 1989, 157p.

National Research Council. Nutrient requirements of beef cattle. 7. ed. Washington, 1996, 242p.

NELSON, C. J.; VOLENEC, J. J. Environmental and physiological aspects of forage management. In: BARNES, R. F.; MILLER, D. A.; NELSON, C. J. (Ed.). Forages, an introduction to grassland agriculture Ames: Iowa State University Press, 1995. p.55- 70 .

NUSSIO, L. G.; MANZANO, R. P.; PEDREIRA, C. G. S. Valor alimentício em plantas do gênero Cynodon. In: SIMPÓSIO SOBRE MANEJO DA PASTAGEM, 15., Piracicaba, 1998. Anais. Piracicaba: FEALQ, 1998. p. 203-242.

OMETTO, J. C. Bioclimatologia vegetal. Piracicaba:Ed. Ceres, SP, 1981. 440p.

OMETTO, J. C. Registros e estimativas dos parâmetros meteorológicos da região de Piracicaba. Piracicaba: FEALQ, 1989. 76p. 
ORTOLANI, A. A.; CAMARGO, M. B. P. Influência dos fatores climáticos na produção In: CASTRO, P. R. C.; FERREIRA, S. O.; YAMADA, T. (Ed.). Ecofisiologia da produção agrícola. Piracicaba: Associação Brasileira de Pesquisa de Potassa e do Fosfato, 1987. p.71 - 82.

PARKER, W. J. Feed planning on the farm. In: CENTRAL DISTRICTS SHEEP AND BEEF CATTLE CONFERENCE, 1993. Proceedings. v.2, p.75-84.

PARSONS, A. J.; PENNING, P. D. The effect of the duration of regrowth on photosynthesis, leaf death and the average rate of growth in a rotationally grazed sward. Grass and Forage Science, v.43, p.15-27, 1988.

PEDREIRA, J. V. S. Crescimento estacional dos capins colonião (Panicum maximum Jacq.), Gordura (Melinis minutiflora Pal de Beauv.), Jaraguá (Hyparrhenia rufa [Ness] Stapf.) e Pangola de Taiwan A-24 (Digitaria pentzii Stent.). Piracicaba, 1972. 117p. Tese (Doutorado)-Escola Superior de Agricultura "Luiz de Queiroz", Universidade de São Paulo.

PEDREIRA, J. V. S; MATTOS, H. B. Crescimento estacional de vinte e cinco espécies ou variedades de capins. Boletim de Indústria Animal, v.38 n.2, p. 117 - 143. 1981.

PEDREIRA, C. G. S. Plant and animal responses on grazed pastures of Florakirk and Tifton 85 bermudagrasses. Gainesville, 1995. 153p. Thesis (Doctor) University of Florida.

PEDREIRA, C. G. S.; MELlO, A. C. L. Cynodon spp. In: SIMPÓSIO SOBRE MANEJO DA PASTAGEM,17., Piracicaba, 2000. Anais. Piracicaba: FEALQ, 2000. p. 109-134.

PEDREIRA, C. G. S.; NUSSIO, L. G.; Da SILVA, S. C. Condições edafo-climáticas para produção de Cynodon spp. In: SIMPÓSIO SOBRE MANEJO DA PASTAGEM, 15., Piracicaba 1998. Anais. Piracicaba: FEALQ, 1998. p. 85-113.

PEDREIRA, C. G. S.; MELLO, A. C. L.; OTANI, L. O processo de produção de forragem em pastagens In: REUNIÃO ANUAL DA SBZ, 38., Piracicaba, 2001. A produção animal na visão dos brasileiros. Piracicaba: SBZ.,.2001. p.772-807.

PEDRO JUNIOR, M. J.; ALCÂNTARA, P.B.; ROCHA, G.L. et al. Aptidão climática para plantas forrageiras no Estado de São Paulo. Campinas:Instituto Agronômico, 1990. 13p., (Boletim Técnico, 139) 
PINHEIRO, V. D.; COELHO, R. D.; LOURENÇO, L.F. Viabilidade econômica da irrigação de pastagem de capim Tanzânia em diferentes regiões do Brasil. In: SIMPÓSIO SOBRE MANEJO DA PASTAGEM, 19., Piracicaba, 2002. Anais. Piracicaba: FEALQ, 2002. p. 159-188.

PINTO, L. F. M. Dinâmica do acúmulo de matéria seca em pastagens de Cynodon spp. Piracicaba, 2000. 124 p. Dissertação (Mestrado) - Escola Superior de Agricultura "Luiz de Queiroz", Universidade de São Paulo.

POLLOCK, C.J. The response of plants to temperature change. Journal of Agricultural Science, v.115, p.1- 5, 1990.

RAIJ, B.V.; CANTARElla, H.; QUAGGIO, J. A. et. al. Recomendações de adubação para o Estado de São Paulo. 2. ed. Campinas: Instituto Agronômico, Fundação IAC, 1997. 285p.

REICHARDT, K. Processos de transferência no sistema solo-planta-atmosfera. Campinas, Fundação Cargill, 1985. 445p.

REIS, R. A.; FREITAS, D.; FERNANDES, L. O.; FREGADOLLI, F. L. Suplementação como estratégia para otimizar a utilização das pastagens. In: SIMPÓSIO GOIANO SOBRE MANEJO E NUTRIÇÃO DE BOVINOS DE CORTE E LEITE, 5., Goiânia, 2003. Anais. Goiânia: CBNA, 2003. p.85-120.

RIO GRANDE DO SUL. Programa de Investimentos Integrados para o Setor Agropecuário. Zoneamento climático por cultura: forrageiras de clima tropical e subtropical. Zoneamento agrícola. Porto Alegre: Ed. Pallotti, 1975. v.2, cap.2, p.177-183. (Estudos Básicos, 2)

ROBSON, M. J.; RYLE, G. J. A.; WOLEDGE, J. The grass plant - its form and function. In: JONES, M. B.; LAZENBY, A. (Ed.). The grass crop: the physiological basis of production. London: Chapman and Hall, 1988. cap. 2, p.2583.

ROCHA, G.L. Ecossistemas de pastagens: aspectos dinâmicos.. Piracicaba: FEALQ, 1991. 391p.

RODRIGUES, L. R. A.; RODRIGUES, T. J. D. Ecofisiologia de plantas forrageiras. In: CASTRO, P. R. C.; FERREIRA, S. O.; YAMADA, T. (Ed.) Ecofisiologia da produção agrícola. Piracicaba: Associação Brasileira de Pesquisa de Potassa e do Fosfato, 1987. p.203-230. 
RODRIGUES, T. J. D.; RODRIGUES, L. R. A.; REIS, R. A. Adaptação de plantas forrageiras as condições adversas. In: SIMPÓSIO SOBRE ECOSSISTEMAS DE PASTAGENS, 2., Jaboticabal, 1989. Anais. Jaboticabal: FUNEP, 1989. p.17-61.

ROLIM, F. A. Estacionalidade de produção de forrageiras. In: SIMPÓSIO SOBRE MANEJO DA PASTAGEM, 6., Piracicaba, 1980. Anais. Piracicaba: FEALQ, 1980. p.39-81.

SANDERSON, M. A.; WOLF, D. D. Morphological development of switchgrass in diverse environments. Agronomy Journal, v.87, p.908-915, 1995.

SANDERSON, M. A.; MOORE, K. J. Switchgrass morphological development predicted from day of the year or degree day models. Agronomy Journal, v.91, p.732-734, 1999.

SANTOS, A. M. P. V.; BOECHAT, S. C. Cynodon (Poaceae, Chloridoideae) no Rio Grande Do Sul, Brasil. Iheringia, Ser. Bot., v.44, p.85-102, 1994.

SANTOS, P. M. Estudo de algumas características agronômicas de Panicum maximum (Jacq.) cvs. Tanzânia 1 e Mombaça para o estabelecer o seu manejo. Piracicaba, 1997. 62p Dissertação (Mestrado) - Escola Superior de Agricultura "Luiz de Queiroz”, Universidade de São Paulo.

SAS INSTITUTE. SAS user's guide: Release 6.03 ed. Cary, 1988. 1028 p

SEBER, G. A. F. Linear regression analysis. New York.: John Wiley 1977. 465p.

SILVA, J.H.S.; JOHNSON, W.L.; BURNS, J.C.; ANDERSON, C.E. Growth and environment effects on anatomy and quality of temperate and subtropical forage grasses. Crop Science, v.27, p. 1266 - 1273, 1987.

SILBURY, J. H. Leaf growth in pasture grasses. Tropical Grasslands, v. 4, p.17 - 36, 1970.

SINCLAIR, T. R.; JEFFERY, D. R.; MISLEVY, P.; PREMAZZI, M. Growth of subtropical forage grasses under extended photoperiod during short-daylength months. Crop Science, v. 43, n. 1, p.618 - 623, 2003.

SOLLENBERGER, L.; PEDREIRA, C. G. S.; MISLEVY, P.; ANDRADE, I. F. New Cynodon forages for the subtropics and tropics. In: INTERNATIONAL CONF. LIVESTOCK IN THE TROPICS, Gainesville, 1995. Proceedings Gainsville: University of Florida, 1995. p.22 - 26. 
SOTO, A. H. Um modelo simples de estimativa de produção de forragem para colonião (Panicum maximum Jacq.) e pangola (A-24 Digitaria pentzii Stent) usando parâmetros climáticos. Piracicaba, 1981. 58p. Dissertação (Mestrado) - Escola Superior de Agricultura “Luiz de Queiroz", Universidade de São Paulo.

SORIA, L. G. T. Produtividade do capim-tanzânia (Panicum maximum Jacq. cv. Tanzânia) em função da lâmina de irrigação e de adubação nitrogenada. Piracicaba, 2002. 170 p. Tese (Doutorado) - Escola Superior de Agricultura "Luiz de Queiroz", Universidade de São Paulo.

TATIZANA, S. A. Um modelo conceitual de simulação da produção de gado de corte. Piracicaba, 1995. 95p Dissertação (Mestrado) - Escola Superior de Agricultura "Luiz de Queiroz", Universidade de São Paulo.

THORNTHWAITE, C. W.; MATHER, J. R. The water balance. New Jersey: Drexe Institute of Technology, 1955. 104p. (Publications in Climatology)

TURBAN, E. Decision support systems: managerial perspectives. New York:Macmillan, 1988. 697p.

VAN SOEST, P. J. Nutritional ecology of the ruminant. Ithaca: Cornell UNiversity, 1994. 476p.

VICENTE-CHANDLER, J.; SILVA, S.; FIGARELLA, J. Effects of nitrogen fertilization and frequency of cutting on the yield and composition of Napier Grass in Puerto Rico. Journal of Agriculture of the University of Puerto Rico, v.8, n.4, p.215-239, 1959.

VILELA, D.; ALVIM, M. J. Manejo de pastagens do gênero Cynodon: introdução, caracterização e evolução do uso no Brasil In: SIMPÓSIO SOBRE MANEJO DA PASTAGEM, 15., Piracicaba, 1998. Anais. Piracicaba: FEALQ, 1998. p. 23-54.

VILLA NOVA, N. A.; CARRETEIRO, M. V.; SCARDUA, R. Um modelo para avaliação do crescimento de cana-de-açucar (Sacharum spp.) em termos da ação combinada do fotoperíodo e da temperatura média do ar. In: CONGRESSO BRASILEIRO DE AGROMETEOROLOGIA, 2., Campinas, 1983. Proceedings. Campinas:Sociedade Brasileira de Agrometeorologia; Instituto Agronômico de Campinas, 1983. p31-48.

VILlA NOVA, N. A. V.; BARIONI, L. G.; PEDREIRA, C. G. S.; PEREIRA, A. R. Modelo para a previsão da produtividade do capim elefante em função de temperatura do ar, fotoperíodo e freqüência de desfolha. Revista Brasileira de Agrometeorologia, v.1, n. 1, p. 75 - 79, 1999. 
VOLENEC, J. J.; NELSON, C. J.; SLEPER, D. A. Influence of temperature on leaf dark respiration of diverse tall fescue genotypes. Crop Science, v. 24, p. 907 - 912, 1984.

WANG, C. Y. A critique of the heat unit approach to plant responses studies. Ecology, v.41, n.4, p.785-790, 1960.

WERNER, J. C. Estudo de épocas de aplicação da adubação nitrogenada em capim colonião (Panicum maximum, Jacq). In: REUNIÃO ANUAL DA Sociedade Brasileira de Zootecnia, 7., Piracicaba, 1970. Anais. Piracicaba: SBZ, 1970. p.2122.

WILMAN, D.; WRINGHT, P. Some effects of applied nitrogen on the growth and chemical composition of temperate grasses. Herbage Abstracts, v.53, p.387-393, 1983.

WILSON, J. R. Environmental and nutritional factors affecting herbage quality. In: HACKER, J.B. (Ed.). Nutritional limits to animal production from pastures,.1982a. p.111-131.

WILSON, J. R. Effects of water stress on herbage quality. In: INTERNATIONAL GRASSLAND CONGRESS, 14, Lexington, 1982. Proceedings. Lexington: s.ed., $1982 \mathrm{~b}, \mathrm{p} .470-472$.

ZIMMER, A. H.; SILVA, M. P.; MAURO, R. Sustentabilidade e impactos ambientais da produção animal em pastagens. In: SIMPÓSIO SOBRE MANEJO DA PASTAGEM, 19., Piracicaba, 2002. Anais. Piracicaba: FEALQ, 2002. p. 31-58.

ZIMMER, A. H.; MACEDO, M. C. M.; BARCELlOS, A. O.; KICHEL, A. N. Estabelecimento e recuperação de pastagens de Brachiaria spp. In: SIMPÓSIO SOBRE MANEJO DA PASTAGEM, 11., Piracicaba, 1994. Anais. Piracicaba: FEALQ, 1994. p.153-208. 